\title{
Dietary patterns, exercise behaviors and osteoporosis knowledge of college women at West Virginia University
}

Jamie Sutton Deem

West Virginia University

Follow this and additional works at: https://researchrepository.wvu.edu/etd

\section{Recommended Citation}

Deem, Jamie Sutton, "Dietary patterns, exercise behaviors and osteoporosis knowledge of college women at West Virginia University" (2003). Graduate Theses, Dissertations, and Problem Reports. 1756.

https://researchrepository.wvu.edu/etd/1756

This Thesis is protected by copyright and/or related rights. It has been brought to you by the The Research Repository @ WVU with permission from the rights-holder(s). You are free to use this Thesis in any way that is permitted by the copyright and related rights legislation that applies to your use. For other uses you must obtain permission from the rights-holder(s) directly, unless additional rights are indicated by a Creative Commons license in the record and/ or on the work itself. This Thesis has been accepted for inclusion in WVU Graduate Theses, Dissertations, and Problem Reports collection by an authorized administrator of The Research Repository @ WVU. For more information, please contact researchrepository@mail.wvu.edu. 
Dietary Patterns, Exercise Behaviors and Osteoporosis Knowledge of College Women at West Virginia University

\author{
Jamie Sutton Deem
}

Thesis submitted to the Davis College of Agriculture, Forestry and Consumer Sciences

at West Virginia University

in partial fulfillment of the requirements for the degree of

\author{
Master of Science \\ in \\ Family and Consumer Sciences \\ with an emphasis in \\ Human Nutrition \\ Cindy Fitch, Ph.D., Chair \\ Randy W. Bryner, Ed.D. \\ Betty J. Forbes, M.A., R.D.
}

Department of Family and Consumer Sciences

Morgantown, West Virginia

2003

Keywords: Osteoporosis, Diet, Exercise, College Women 


\title{
ABSTRACT \\ Dietary Patterns, Exercise Behaviors and Osteoporosis Knowledge of College Women at West Virginia University
}

\begin{abstract}
Jamie Sutton Deem
This study was conducted to describe the dietary patterns, exercise behaviors and osteoporosis knowledge of college women at West Virginia University. One hundred forty-one women were recruited (ages 18-27). Mean intake of nutrients including calcium $(860 \pm 369 \mathrm{mg} /$ day) was reported. Calcium intake was significantly lower than the recommendation $(1000 \mathrm{mg} /$ day; $p<0.0001)$. Mean reported exercise time was 54.4 minutes/day. This was significantly greater than the recommendation of 30 minutes/day $(p<0.01)$. Osteoporosis knowledge was measured by questionnaire. The majority of participants were able to identify $7 / 14$ risk factors. A T-test indicated that individuals who answered osteoporosis risk factor questions correctly had higher intakes of calcium, but were still significantly below the recommendation $(p<0.001)$. Results indicated that exercise time was significantly higher in individuals who answered osteoporosis risk factor questions correctly $(p<0.001)$. These results suggest that college women do not have adequate intakes of calcium or knowledge of osteoporosis for prevention of the disease.
\end{abstract}




\title{
ACKNOWLEDGMENTS
}

I would like to thank the following individuals for all their time, assistance and support throughout this endeavor:

\section{Thesis Committee Members}

Cindy Fitch, Ph.D., R.D.

Randy Bryner, Ed.D

Betty J. Forbes, M.A., R.D.

\section{Division of Family and Consumer Sciences}

Janice Yeager, Division Director

Claudia Schopper, M.S., R.D.

Kathy Timperman, M.S.

Melinda Walls, J.D.

Shirley Robinson

Joy Patterson

Linda Kent

All other faculty and fellow dietetic interns for their support and friendship.

\author{
Statistical Support \\ George Seidel, Ph.D. \\ Huilan Li \\ My Family \\ Jim and Rochelle Sutton \\ Bill Sutton \\ Kane M. Deem
}




\section{TABLE OF CONTENTS}

Page No.

\section{ABSTRACT}

ACKNOWLEDGEMENTS

TABLE OF CONTENTS

LIST OF TABLES

CHAPTER 1: INTRODUCTION

Significance of the Problem

Purpose of Research

Hypotheses

CHAPTER 2: REVIEW OF LITERATURE

Diet and Osteoporosis 5

Dietary calcium intake and bone 6

$\begin{array}{ll}\text { Protein, sodium, caffeine and alcohol intake and bone } & 7\end{array}$

Calcium intake/ dietary patterns of young women 13

Physical Activity and Osteoporosis 14

Physical activity behaviors of young women 15

Osteoporosis Knowledge 17

Other Risk Factors 19

Estrogen and bone 19

Tobacco use 20

Summary 20

CHAPTER 3: METHODS AND PROCEDURES 21

Research Design 21

Subjects 21

Data Collection $\quad 21$

Instrumentation and Procedures 22

Assessment of osteoporosis knowledge 24

Assessment of exercise 24

Assessment of diet 25

Statistical analysis $\quad 26$

CHAPTER 4: RESULTS 28

Characteristics 28

Dietary Patterns 28 
Exercise Patterns 31

Other Results 32

Osteoporosis knowledge 32

Other health behaviors $\quad 34$

Body mass index $\quad 35$

CHAPTER 5: DISCUSSION 36

Dietary Patterns 36

Calcium intake 36

Energy intake 36

Dietary protein intake $\quad 37$

Sodium intake 38

Alcohol intake $\quad 39$

Caffeine intake $\quad 39$

Servings of dairy 40

Intake patterns of other nutrients 41

Exercise Patterns $\quad 41$

Osteoporosis Knowledge $\quad 44$

Body Mass Index 46

Limitations $\quad 48$

Applications/Conclusions $\quad 51$

REFERENCES $\quad 54$

APPENDIX A. $\quad 59$

Institutional Review Board Approval $\quad 60$

Letter to Participants 62

Consent and Information Form 63

APPENDIX B. $\quad 65$

Survey $\quad 66$

APPENDIX C. $\quad 77$

Dietary Intake Forms/Computer Analysis $\quad 78$

CURRICULUM VITAE 93 


\section{LIST OF TABLES AND FIGURES}

\section{Figure 3-1}

Page No.

Procedure of Data Collection

22

\section{Table 3-1}

Recommended Daily Intake

26

Figure 3-2

Selected Dietary Guidelines for Americans

Table 4-1

Study Sample Characteristics

28

Table 4-2

Mean Nutrient Intake

Table 4-3

Daily Intake of Alcohol and Caffeine

Table 4-4

Commonly Consumed Calcium Foods

Table 4-5

Osteoporosis Knowledge Scores

Table 4-6

Difference in Dietary Calcium Intake Between Risk Factor Identification Groups

Table 4-7

Difference in Exercise Time Between Risk Factor Identification Groups

Table 4-8

Pearson Correlation Between Calcium Intake and BMI

\section{Table 4-9}

Pearson Correlation Between Reported Energy Intake and BMI

Table 4-10

Pearson Correlation Between Total Exercise Time and BMI

Table 4-11

Pearson Correlation Between Total Exercise Time and BMI, Without Athletes 


\section{Chapter 1: Introduction}

\section{Overview}

Osteoporosis is a condition that is characterized by decreased bone density, increased bone fragility and increased risk of fractures. This disease affects almost all men and women after the age of 70 , due to a slow, steady rate of bone calcium loss over the lifetime.

It is known that peak bone density is achieved by the third decade of life (Recker, 1992). This fact is particularly important for women due to the increased rate of bone loss following menopause. Therefore, the best strategy for delaying the onset of osteoporosis is to be sure that maximum bone density is achieved during the years before menopause.

The formation of ideal bone density occurs by practicing good health habits, such as consuming a balanced diet that provides adequate nutrients, participation in osteoprotective (weight-bearing) exercise, as well as possessing good understanding of osteoporosis and its prevention. One especially crucial time in the formation of these health habits is the college years. During this time, young people are laying the foundation of lifestyle behaviors that may continue throughout adulthood. These behaviors may prevent or increase risks for chronic diseases like osteoporosis. 


\section{Significance of the Problem}

College students have a lifestyle that is a combination of asserting independence, gaining knowledge, taking care of themselves, and having fun. Many times, people of this age do not express a large concern for taking care of themselves and preserving their own health. It is something that they have always had, and they do not expect it to change or deteriorate. As a result, this age group is likely to participate in unhealthy activities like exercise avoidance, cigarette smoking and binge drinking, even though they are aware that these activities are not healthy. In addition, it has been found that college students commonly consume a diet that is high in total fat, saturated fat, sodium, and cholesterol, as well as low in dietary fiber, calcium, vitamin $\mathrm{A}$, vitamin $\mathrm{C}$, and iron (Brevard, 1996, Hertzler and Frary, 1992).

Consuming a diet that is consistently high or low in certain nutrients can put individuals at an increased risk of developing chronic diseases later in life. One chronic disease of such concern is osteoporosis. Osteoporosis is a disease that is characterized by low bone density, which leads to increased bone fragility and fracture risk. It is a condition more commonly seen in women, due to the accelerated rate of bone loss following menopause. One of the most important concepts pertaining to prevention of osteoporosis is peak bone mass. In women, peak bone mass is achieved between 25 to 35 years of age. Once maximum bone mass has been accomplished, a plateau period of about 15 years proceeds, in which bone formation and resorption are approximately equivalent. Following this period, bone mass does not increase further (Leslie et al., 1999). 
Over time, this results in net bone loss, causing a decrease in bone mineral density. In the years following menopause in women, this process becomes faster due to the absence of estrogen. It is this loss of bone density that causes osteoporosis (Leslie et al., 1999). The higher the peak bone density that is achieved during the bone-building years, the longer it will take for age and menopause-related bone losses to increase the risk of fracture. Peak bone density is achieved from several modulating factors: genetics, diet, exercise, estrogen availability, and other lifestyle behaviors.

\section{Purpose of Research}

The goals of this research are to characterize the dietary patterns, exercise behaviors and osteoporosis knowledge among selected college women at West Virginia University, and to examine any relationship between osteoporosis knowledge, dietary patterns, and lifestyle habits. The rationale for this study is that female college students with inadequate eating patterns, exercise behavior and osteoporosis knowledge will be at an increased risk for the development osteoporosis later in life. The detection of lifestyle factors associated with osteoporosis as well as knowledge about the disease in target populations will identify the need for nutrition education programs. Such information is important for the future prevention of the disease. 


\section{Null Hypotheses $\left(\mathrm{H}_{\mathrm{O}}\right)$}

1. There is no difference in dietary calcium intake of participants compared to the recommendation of greater than or equal to $1000 \mathrm{mg}$ of calcium/day.

2. There is no difference in the energy intake of participants compared to the recommendation of greater than or equal to 1800 kilocalories/day.

3. There is no difference in the sodium intake of participants compared to the recommendation of less than or equal to $2400 \mathrm{mg}$ of sodium/day.

4. Among participants consuming alcoholic beverages, there is no difference in alcohol intake compared to the recommendation of less than or equal to one alcoholic beverage/day.

5. There is no difference in exercise time of participants compared to the recommendation of greater than or equal to 30 minutes of physical activity/day.

6. There is no difference in dietary calcium intake between the participants answering osteoporosis risk factor questions correctly compared to the participants who answer risk factor questions incorrectly.

7. There is no difference in total exercise time between the participants answering osteoporosis risk factor questions correctly compared to the participants who answer risk factor questions incorrectly.

8. There is no relationship between body mass index (BMI) and dietary calcium intake.

9. There is no relationship between BMI and total energy intake.

10. There is no relationship between BMI and total exercise time. 


\section{CHAPTER 2: REVIEW OF LITERATURE}

Osteoporosis is a disease that robs the body of bone strength. It can result in an increased risk of fractures, loss of independence and a decreased quality of life. An estimated 8 million women aged 50 years and older have osteoporosis, and by the year 2010, this number is expected to increase to 9 million (National Osteoporosis Foundation, 2003). In addition, osteoporosis is responsible for 1.5 million fractures each year. While these figures seem shocking, it was found in 2001 that the healthcare costs from hospital and nursing home stays associated with osteoporosis are 17 billion dollars annually, or 47 million dollars per day. These statistics are particularly disturbing because osteoporosis can be prevented in the majority of women. Adequate dietary intake patterns and healthy lifestyle habits help build bone density in the early years of life, allowing for sufficient bone strength later in life, when the effects of osteoporosis are most commonly seen.

\section{Diet and Osteoporosis}

It is known that diet plays a large role in the development and prevention of osteoporosis (Anding et al., 2001). Adequate calcium, vitamin D, phosphorus, magnesium, and fluoride must be available in the body to achieve maximum bone density (Dietary Reference Intakes, 1997). While it is fairly easy to incorporate these nutrients into the diet, inadequate dietary calcium is often the largest barrier to building adequate bone density in women (National Osteoporosis Foundation, 2003). In addition, some evidence suggests that excessive consumption of some nutrients and food additives such as caffeine 
can interfere with calcium absorption in older women, making it more difficult to maintain bone density (Leslie et al, 1999). Since bone mineral density is achieved in the early years of adulthood, dietary patterns of college women are of interest to characterize the availability of nutrients that influence bone formation.

\section{Dietary Calcium Intake and Bone}

Chronic calcium deficiency resulting from inadequate intake or poor intestinal absorption is one of the known causes of reduced bone mass and osteoporosis. A diet that is consistently insufficient in calcium causes the body to increase production of parathyroid hormone $(\mathrm{PTH})$. This hormone has three actions that cause calcium to be preserved. PTH induces calcium reabsorption in the distal renal tubule in the kidney; increases the production of $1,25(\mathrm{OH})_{2}$ vitamin D, which encourages intestinal absorption; and induces bone resorption, releasing calcium into the blood, at the expense of skeletal bone (Dietary Reference Intakes, 1997).

It has been well-established that dietary intake of calcium is related to bone density. Norris et al (2001) demonstrated this with the use of an animal model in which two groups of rabbits received two different levels of dietary calcium. The group with the higher calcium intake had significantly greater bone density $(p<0.006)$. These findings were similar to those of a longitudinal prospective study conducted by Recker et al. (1992) intended to assess the effect of dietary calcium intake on bone density in 156 young white women, ages 19-26. Participants of this longitudinal prospective study were seen at a medical 
center at 6-month intervals for five years to determine if nutrient intake or physical activity influences bone mineral density. Total body bone mineral (TBBM) was measured at the beginning and end of the study. Bone mineral density of the spine and forearm was determined at each 6-month visit. Nutrient intake and physical activity were also measured at various times throughout the study period, and the mean calcium intake value was $820 \pm 331 \mathrm{mg} / \mathrm{day}$. The researchers found that bone gain was seen in this group of young women in the spine, forearm and total body. An average combined (spine and forearm) gain of 4.8\% per decade was observed. Total body bone mineral also increased, at a rate of $12.5 \%$ per decade $(p<0.0001)$. Regression analyses of the data were performed to test the hypothesis that modifiable factors such as nutrient intake influenced the gain in bone mass. Calcium intake, unadjusted for protein intake showed a nearly significant $(p<0.132)$ correlation with the rate of change in spinal BMD. Protein intake showed a very weak negative correlation $(r=-0.0135)$ with $\mathrm{BMD}$, and the calcium/protein ration showed the strongest effect of all $(r=0.1998$; $p<0.104)$, which was still a rather weak correlation. Even though all correlation was weak, Recker et al. concluded that the gain in BMD seen in this study was enhanced by modest increases in calcium intake and physical activity.

\section{Protein, Sodium, Caffeine, and Alcohol intake and Bone}

Nutrients, such as protein and sodium as well as caffeine and alcoholcontaining beverages can have a negative effect on bone formation and resorption. Although there are few studies that support these relationships in younger women, there is evidence that excessive intake in adulthood can have a 
negative impact on bone density. Since dietary patterns are established in the younger years of life, it is of interest to include a discussion about these food products and their relationship to bone health.

It is known that the average American diet is high in animal protein and low in fruits and vegetables. A diet of this nature generates a large amount of acid, mainly as sulfates and phosphates. Kidneys deal with dietary acid by net acid excretion. Bone responds to this dietary acid by a physiochemical reaction with the rapid release of carbonate, citrate and sodium from the hydration shell surrounding the bone. In situations of chronic acid stress such as are seen in diets high in animal proteins, cellular responses mobilize bone calcium as a buffer. This potentially leads to the active breakdown of bone and excretion of calcium in the urine (Barzel and Massey, 1998). Although high protein diets have been shown to increase urinary calcium excretion and induce negative calcium balance, it is unknown if these diets increase the risk for developing osteoporosis (Cooper et al, 1996). A study conducted by Kerstetter et al (1999) sought to determine the effect of dietary protein from an animal source on markers of bone turnover in sixteen, healthy, premenopausal women (ages 20-40). The study protocol included three cycles, each of which consisted of two weeks of an adjustment diet followed by four days of the experimental diet, and three days of an ad libitum diet. The experimental diet was controlled in calcium, sodium, and phosphorus and contained high, medium or low dietary protein levels. The diet cycle was completed until all participants received each of the three protein levels in random order. The low protein diet contained $0.7 \mathrm{~g} / \mathrm{kg}$, the medium 
protein diet contained $1 \mathrm{~g} / \mathrm{kg}$, and the high protein diet contained $2.1 \mathrm{~g} / \mathrm{kg}$.

Laboratory values of urinary calcium excretion and bone markers were taken throughout the study. Results of this study indicate that urinary calcium was significantly decreased during the low protein diet compared to that during the medium protein diet $(p<0.05)$ and was significantly increased during the high protein diet $(p<0.0005)$ when compared to the medium protein diet. In addition, it was found that the markers of bone breakdown (urinary $\mathrm{N}$-telopeptide excretion) were significantly increased on the high protein diet compared to the low protein diet $(p<0.05)$ without a compensatory increase in bone formation measured by bone-specific alkaline phosphatase (BSAP). Based on these findings, the authors suggest that high levels of dietary protein intake can have an adverse effect on bone by increasing markers of bone turnover (urinary calcium excretion) without increasing markers for bone formation (BSAP) (Kerstetter et al., 1999).

Dawson-Hughes (2003) made similar conclusions in a review article about dietary protein and bone, but added that additional research suggests increased dietary calcium and vitamin $D$ intakes can offset the detrimental effects of excess dietary protein on bone.

Just as the large quantities of acid produced by animal protein breakdown encourage urinary calcium excretion, sodium has been shown to have a similar effect. Sodium and calcium excretion are linked in the proximal renal tubule of the kidney nephron. High intakes of sodium chloride result in an increased absorption of dietary calcium. Similarly, increased urinary sodium excretion results in an increased loss of calcium in the urine (Dietary Reference Intakes, 
1997). Like dietary protein, it is unknown if high intakes of sodium increase the risk for developing osteoporosis. Ginty, et al (1998) conducted a study to investigate the effect of dietary sodium on markers of bone metabolism and urinary calcium excretion in twenty-nine young adult females aged 22-28. The study consisted of a randomized crossover trial of the effect of low ( $80 \mathrm{mmol} / \mathrm{day})$ or high (180 mmol/day) sodium intake for 14 days. During this time, participants completed 24-hour recalls for the 3 days prior to entering the study. Urinary samples were collected every day of the study, in addition to serum osteocalcin and bone-specific alkaline phosphatase (BSAP). Results indicated that 8 of the 29 participants experienced a significant increase in urinary excretion of calcium in response to increased sodium $(p<0.05)$, while the other 21 subjects did not. Results also showed that there was no significant difference in serum osteocalcin or BSAP between the high and low sodium diets in any of the individuals. These findings led the researchers to conclude that increasing dietary sodium significantly increases urinary calcium excretion in some individuals, but not others. The authors concluded that this fact has little effect on bone turnover and there is no significant relationship between sodium intake and osteoporosis in young women.

Like sodium, caffeine has also been suspected to have a possible negative impact on bone health. In some studies, caffeine intake has been associated with increased risk of hip fracture in elderly women (Keil et al. 1990). Caffeine ingestion induces a short-term increase in renal calcium excretion, and may also decrease intestinal calcium absorption (Barger-Lux and Heaney, 1995). 
Very little research has been done to measure the impact of caffeine ingestion on bone structure and health, especially in pre-menopausal women. However, Heaney and Rafferty (2001) conducted a study to assess the intake of caffeinecontaining carbonated sodas on urinary calcium excretion in 32 women ages 20 40. Women who habitually consumed at least two 12-ounce cans of soda were recruited for the study. All subjects were instructed to maintain normal calcium intakes, and to refrain from high-sodium foods two days before testing. Nutrient intake information was estimated using a food frequency questionnaire written by Block et al. Seven beverages were tested: 4 different sodas ( 2 with caffeine, 2 without), water (negative control), and 2 milks (positive control). A random design was set up so that five beverages were tested in each woman, (all sodas, water and one milk) one beverage per week. Subjects reported to the unit fasting, and were given one of the test beverages. They remained at the testing site for 5 hours, ingesting $567 \mathrm{~mL}$ of water and having urine collected as needed. Results of this study indicated that relative to water, urinary calcium rose significantly only with the milk beverages and the 2 caffeine-containing sodas $(p<0.001)$. Phosphoric acid (present in all of the soda beverages) did not produce or augment calciuria in any of the beverages. Based on these findings, the researchers were hesitant to conclude that caffeine-containing beverages have a deleterious effect on bone, even though caffeine is known to increase calciuria. They concluded that individuals who participated in their study were more likely to drink soda as opposed to a calcium source such as milk, and that is where the impact on bone health is made. 
Also interested in the effects of caffeine intake on bone, Cooper et al. (1992) conducted a study to determine the effect of caffeine on bone mineral density in 290 free-living and institutionalized women, ages 30-75. Participants were recruited from the Rochester Epidemiology Project. During the four years of the study, the participants completed an interview to obtain lifestyle data and a 7-day food record to estimate nutrient intake. Caffeine consumption data was characterized and dichotomized into three beverages: coffee, tea, and other caffeinated beverages. The women also had bone mineral density determined by dual photon absorptiometry at six skeletal sites. The results showed that after controlling for BMI, smoking status, age, and alcohol consumption, there was no significant association between caffeine intake and bone mineral density at 5 of the 6 skeletal sites. There were significant interactions between age, caffeine consumption and bone mineral density $(p<0.05)$, suggesting that every $100 \mathrm{mg}$ increase in caffeine resulted in $1.7 \%$ bone loss at the femoral shaft in the oldest women. The authors of this study concluded that moderate caffeine intake (100 $\mathrm{mg} / \mathrm{day}=6 \mathrm{fl} . \mathrm{oz}$. coffee) is not related to bone breakdown at any age. They also concluded that older women might be at greater risk for bone loss due to impaired calcium balance performance, especially if caffeine consumption is greater than a moderate amount.

Although it is questionable that alcohol has any effect on bone density of younger women, alcohol intakes have been shown to have a negative affect in older women (Korpelainen et al, 2003). Although the exact way that alcohol intake affects bone is unknown, excessive consumption ( $>1$ alcoholic drink/day) 
has been associated with decreased calcium and vitamin D intakes and with urinary loss of calcium (Schapira, 1990).

\section{Calcium Intake/ Dietary Patterns of Young Women}

The National Research Council suggests that a daily intake of $1000 \mathrm{mg}$ of calcium per day is an adequate intake (Al) for the majority of the population (Dietary Reference Intakes, 1997). Since calcium intake is strongly associated with bone density, many researchers have questioned the adequacy of calcium intake and overall dietary patterns in young women.

A study conducted by Portsmouth et al. (1994) sought to determine the calcium intake of 113, 18-year-old, female college students in Australia.

Subjects completed a four-day weighed food record that included one weekend day. The results of this study showed that $86 \%$ of the participants had average daily calcium consumption below $800 \mathrm{mg}$ (the Australian recommended Daily Intake) suggesting that the majority of this sample was not receiving sufficient calcium for formation of ideal bone density.

Rangan and Binns (1997) conducted a study to determine the dietary calcium intake of 162 college women in Australia. Intake was estimated using a 270-item quantitative food frequency questionnaire. They found that the mean calcium intake for this sample was $917 \pm 385 \mathrm{mg} /$ day. While the majority of participants met the $800 \mathrm{mg} /$ day Australian recommendation, $43 \%$ of participants consumed less than $800 \mathrm{mg} /$ day. The authors concluded that calcium intake was not sufficient in roughly half the sample and that nutrition education programs should focus on sources of dietary calcium. 
Kasper et al (1994) were interested in the dietary calcium content, exercise habits and osteoporosis knowledge of college women. One hundred fourteen participants (mean age 19.6 \pm 1.8 years) were recruited through an undergraduate health course. Subjects completed a survey written to assess osteoporosis knowledge and exercise habits as well as a food frequency questionnaire to estimate daily calcium consumption. Results indicated that the sample consumed a mean of $773 \pm 626 \mathrm{mg}$ calcium/day and that only $18 \%$ respondents met the $1200 \mathrm{mg}$ calcium recommendation. The authors concluded that this group of college women was not consuming adequate dietary calcium for accretion of bone density.

In addition to inadequate calcium intake, as is seen in the previously described studies, it is also not uncommon for college women to have intakes of sodium greater than $2400 \mathrm{mg} /$ day and alcohol consumption greater than 1 drink per day, (Anding et al., 2001, Haberman and Luffey, 1998). A diet of this nature continued throughout the life span is likely to have a negative effect on bone health as well as increase the likelihood for other chronic diseases.

\section{Physical Activity and Osteoporosis}

In addition to dietary factors, it is known that physical activity has some effect on bone. It is generally accepted that weight bearing physical activity determines the shape, strength, and mass of bone (Recker, 1992). To confirm this, Davee et al. (1990) conducted a cross-sectional study of the physical activity patterns of healthy, nonsmoking college women and its effect on vertebral bone 
mineral density (BMD). A group of 27 women participated in the study. The women were asked to complete a diet history and survey that measured the type, duration, and frequency of exercise participation. From this, the women were separated into three groups: sedentary (SED)-Exercised $<1 \mathrm{hr}$./week; aerobic (AER)-Exercised aerobically $>2.5 \mathrm{hr} . /$ week; Muscle builders (MB)- Exercised $>2.5 \mathrm{hr}$./week aerobically, plus one additional hour of muscle building activity. BMD was measured twice throughout the study. Results showed that exercising women (AER and MB groups) had greater lean body mass than the sedentary group. AER and MB had similar training hours, which were significantly greater than those of the SED group $(p<0.003)$. The MB group had the greatest BMD versus AER versus SED $(p<0.007)$. AER and SED subjects had similar BMD, while the MB group had a significantly higher BMD. The researchers concluded that aerobic exercise probably does contribute to lumbar BMD, even though BMD was not significantly different than the sedentary group. They also concluded that muscle-building activity has a significant additive effect on BMD (Davee et al., 1990).

\section{Physical Activity Behaviors of Young Women}

Since bone density is related to physical activity, it is important to discuss the exercise patterns of college women. Anding et al (2001) conducted a study to assess the dietary intake, exercise and alcohol intake patterns of college women. A convenience sample of 60 participants aged 17-42 (mean age 21.6), was recruited through a physical education class. Participants completed a three-day food and exercise record. Results indicated that only $33 \%$ of the population 
exercised regularly, defined as 30 minutes of moderate activity most days from the 2000 Dietary Guidelines for Americans. The authors concluded that the majority of participants were not getting adequate exercise for prevention of chronic diseases, especially if the patterns continued later in life.

In a study conducted by Haberman and Luffey (1998) the authors wanted to characterize the exercise habits, and nutritional health behaviors of 302 college students, 140 men, and 161 women. A survey was administered to a random sample of students that included questions about dietary practices, height, weight, and exercise habits. Results indicated that only $39 \%$ of the participants reported that they engaged in moderate exercise 3 times per week, the criteria set by the Centers for Disease Control (CDC) for Healthy People 2000. The authors concluded that a large portion of the participants was not getting adequate exercise for optimal health. They also suggested that since physical activity decreases with age, higher standards should be set for physical activity in younger people in order to establish lifelong exercise patterns.

In a study described previously by Kasper et al. (1994), researchers sought to describe dietary patterns, exercise behavior and osteoporosis knowledge of college women. The results of this study showed that the participants got a mean of 219 minutes of exercise in a two-week period. It was also found that $60 \%$ of participants did not get adequate exercise based on the criteria of 180 minutes of activity for a two-week period. The authors concluded that the vast majority of young women engage in exercise behaviors that are inadequate for building healthy bone. 
Like most of the population, many college women do not get enough exercise to maintain adequate fitness. If continued throughout the lifetime, exercise patterns described above will increase the likelihood of developing osteoporosis, obesity, cardiovascular disease and diabetes.

\section{Osteoporosis Knowledge}

In addition to practicing good health habits, adequate knowledge of osteoporosis and its risk factors are essential for the understanding and prevention of the disease. Young women are at a critical point in bone formation and it is important to characterize their knowledge and awareness of osteoporosis.

Taggart and Connor (1995) wanted to determine the relationship between osteoporosis knowledge, personal awareness of susceptibility and exercise habits in college women. One hundred thirteen college women ages 18-53 (mean age 25 years) were recruited through enrollment in a basic health course that was a core requirement for many fields of study. A survey that measured health beliefs, knowledge and risk factors was administered as well as a selfreported exercise record that listed the type and frequency of weekly exercise. The results showed that the study population was able to identify behaviors that prevent or cause osteoporosis. However, there was no significant correlation between both osteoporosis knowledge and susceptibility of the disease, and osteoporosis knowledge and exercise habits. There was a significant correlation between the age of the student and osteoporosis knowledge $(r=0.19 ; p<0.04)$. The authors concluded that even though study participants were able to identify 
risk factors for osteoporosis, the subjects were still at risk for the disease because of the lack of relationship between actual behavior, perceived risk and understanding of the disease.

Turner and Bass (2001) also wanted to characterize the relationship between osteoporosis knowledge and behavioral practices among 114 female college athletes (mean age 19.6 \pm 1.4 years). Participants were recruited through a collegiate athletic department. An osteoporosis knowledge questionnaire was administered to determine subjects' osteoporosis knowledge, attitudes and perceived risk, and dairy product intake. The results indicated that the majority of athletes could answer 7.1 out of 10 questions correctly. In addition, the participants consumed a mean of $2.4 \pm 1.6$ servings of dairy per day. It was also found that there was no correlation between osteoporosis knowledge and dairy intake ( $r=0.03)$, osteoporosis attitudes and dairy intake $(r=0.08)$, as well as dietary calcium knowledge and dairy intake $(r=0.05)$. Based on these findings, the authors concluded that even though most women participating in this study possessed adequate osteoporosis knowledge, the disease still posed a threat because of the demanding lifestyle of a female collegiate athlete.

In a study described previously, Kasper et al (1994) also wanted to correlate osteoporosis knowledge and attitudes with diet and exercise behavior in 114 college women. The results showed that there was no significant relationship between risk factor identification and exercise habits, calcium intake, or beliefs about osteoporosis. The authors concluded that increasing levels of osteoporosis knowledge and awareness is not related to health beliefs and 
behaviors. They also suggested that these findings warrant the implementation of an educational campaign that is effective at improving the osteoporosis awareness, knowledge and behaviors of young women.

\section{Other Risk Factors}

Although diet, physical activity, and knowledge are important in the development and prevention of osteoporosis, other factors such as estrogen availability and cigarette smoking have also been shown to affect bone density formation and preservation.

\section{Estrogen and Bone}

No other factor is more important in the formation of bone density than the availability of estrogen. Estrogen is the primary sex hormone present in women that mediates the response of osteoblasts and osteoclasts, the two types of cells that are responsible for the formation and breakdown of bone, respectively (Lorenzo, 2003). The lack of estrogen that is seen in menopause is the primary reason for the accelerated bone loss that is observed during this period. The osteoclasts begin a cycle of accelerated apoptosis, and the osteoblasts cannot adequately fill resorption sites quickly enough (Follin and Hansen, 2003).

The increased rate of bone loss in menopause has been well documented. Estrogen-related bone loss can also occur after oophorectomy in young women, or with amenorrhea due to malnutrition, a condition that is commonly associated with eating disorders (Zipfel et al, 2001). Rigotti et al (1991) measured the bone density of 27 young women (mean age: $26 \pm 5$ years) who had been amenorrheic for a mean of 5.8 years due to malnutrition and 
excessive exercise associated with anorexia nervosa. The results of the study found that the mean bone mineral density of the sample was 2 standard deviations below the age-adjusted standard at $0.63 \pm 0.7 \mathrm{~g} / \mathrm{cm}^{2}$. It was also found that bone density was inversely correlated with the duration of amenorrhea ( $r=-$ $0.49 ; p<0.01)$. The authors concluded that this low bone density was due to a failure to attain peak bone mass and premature loss of bone due to low levels of circulating estrogen in the body (Rigotti et al, 1992).

\section{Tobacco Use}

The use of tobacco has been shown to have a negative effect on bone density in women of all ages (Gerhem and Obrant, 2002, Baron et al, 2001, Mazess and Barden, 1991). It has been suggested that smokers have diminished intestinal absorption of calcium, either due to the decreased formation of parathyroid hormone, 25 -hydroxyvitamin $\mathrm{D}$, and 1,25 -dihydroxyvitamin $\mathrm{D}$ or from the nicotine found in tobacco products (Baron, et al 2001).

\section{Summary}

The prevention and development of osteoporosis depends on a variety of aspects including genetics, age, diet and exercise patterns, endocrine health and various lifestyle practices. Since osteoporosis is a disease that has its beginning in early adulthood when maximum bone density is achieved, it is important to characterize the knowledge and behavioral patterns of college women to understand the risks that this population has for the development of the disease. 


\section{CHAPTER 3: METHODS AND PROCEDURES}

\section{Research Design}

The research design of this study is a descriptive, cross-sectional model. The research will describe the dietary patterns, exercise behaviors and osteoporosis knowledge of a group of college women at West Virginia University. The independent variables of this research include osteoporosis knowledge scores, reported dietary intake and exercise time. The dependent variables include dietary patterns, exercise time, and body mass index (BMI).

\section{Subjects}

A convenience sample of college women was recruited from the Human Nutrition and Foods Introductory Nutrition courses taught during the spring semester 2003 at West Virginia University. The course is a requirement for various academic majors. Recruitment was made possible by the cooperation of the instructors teaching the classes. Participation was voluntary, anonymous, and in accordance with university and federal guidelines for human subjects.

\section{Data Collection}

After the West Virginia University Institutional Review Board (IRB) granted approval of the research proposal, the principle investigator visited the Introductory Nutrition classes to explain the purpose, procedures and pertinent details of the study to the class orally and in writing on the consent form (Appendix A, page 62-63). Female students willing to participate, along with the principal investigator signed the consent form. The completed consent forms 
were collected by the principal investigator and placed in an envelope. All subjects were provided a copy of the consent and information form, which included contact information of the researchers.

Upon completion of informed consent, each participant was assigned an identification number. The participants were reassured that the surveys and diet record would remain anonymous and confidential, and that they would be identified by the number at the top of the survey. The participants spent between 10-20 minutes completing the survey. The surveys and diet records were then collected by the principal investigator. The data collection process was completed over a three-day period to accommodate different class schedules.

\section{Figure 3-1: Procedure of Data Collection}

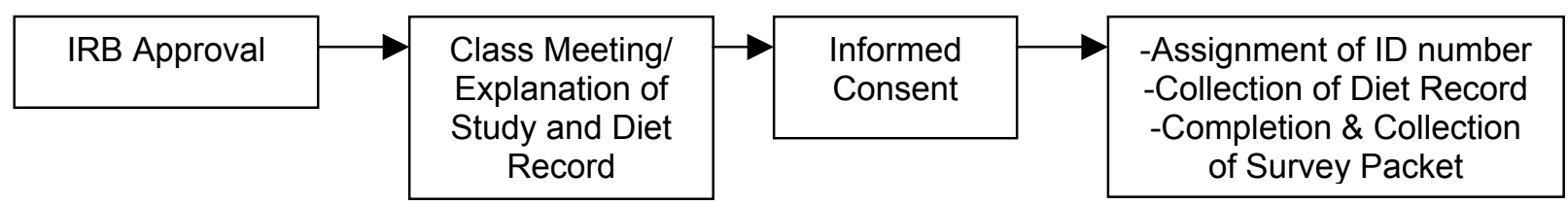

\section{$\underline{\text { Instrumentation and Procedures }}$}

The questionnaire administered to participants was a survey written by Kasper, et al (1994) intended to assess osteoporosis knowledge, attitudes and behaviors in college women (Appendix B, pages 66-76). The principle investigator contacted the authors of the survey for permission to use the instrument to collect osteoporosis knowledge and behavior data. For the current study, only three of the four survey sections was used: osteoporosis knowledge/attitudes section, a behavior section designed to assess exercise, smoking, and vitamin use, and a section to obtain demographic information. The 
osteoporosis knowledge section (Appendix B, page 69) asked participants to complete fourteen questions intended to assess knowledge of osteoporosis risk factors rated on a numerical scale $(2=$ definitely does not increase osteoporosis risk through $8=$ definitely increases the risk for osteoporosis). The exercise section of the survey (Appendix B, page 70) lists 13 types of exercise commonly performed by college women. Smoking and vitamin use are each defined by two questions that ask about vitamin/cigarette use and the frequency of use (Appendix B, pages 71 and 74). The demographic section of the survey includes questions about height, weight, academic rank/major, age, residence, and ethnic/racial background (Appendix B, page 76). In addition, participants completed a three-day diet record that included two weekdays and one weekend day as part of a class assignment that was used to assess diet in this study (Appendix C, pages 78-92). The students received instructions on how to complete the diet record from both the course instructor and the principle investigator so it was accurate and reflected usual intake. 


\section{Assessment of Osteoporosis Knowledge}

The survey used in this study was written and revised by a multidisciplinary team from various academic institutions in 1992 and then administered in a pilot study at Eastern Illinois University in 1993 to assess validity. Based on the results of the pilot study, the study conducted in 1994 and a follow-up completed in 2001, the survey has been shown to be valid and reliable measure for assessment of osteoporosis knowledge in college women. Comparable studies have used similar validated methods and questions to successfully test osteoporosis knowledge of college women (Turner and Bass, 2001).

\section{Assessment of Exercise}

The two-week exercise recall record used in this study is also part of the survey written by Kasper et al (Appendix B, page 70). This portion of the survey listed 13 types of exercise commonly performed by college women. Four additional spaces were provided at the bottom of the page for subjects to add any other activities that they had participated in the last two weeks. The participants completed this portion of the survey by indicating if they participated in the activity, how many times in the last two weeks, and for what duration. Each activity record was evaluated by taking the frequency of each activity multiplied by the minutes of participation, summing each activity score and then dividing by 14 to give the average exercise participation time/day. This value was then compared to the recommendation of 30 minutes/day, and was classified as adequate ( $\geq 30$ minutes/day) or inadequate ( $<30$ minutes/day). 


\section{Assessment of Diet}

The original survey by Kasper et al. used a modified version of the foodfrequency questionnaire (FFQ) written by Block et al (1986) to assess dietary calcium intake. This semiquantitative FFQ was an eleven-item list that included 6 dairy calcium foods, 2 non-dairy calcium sources, and soft drinks. It was intended to estimate usual daily calcium consumption. This FFQ was acceptable to assess usual calcium intake but it was not appropriate to assess overall dietary patterns due to its limited list of foods. Because overall dietary patterns and specific calcium sources of the participants were of interest, the three-day food record was chosen as the way to obtain nutrient intake data. It has been argued that food records tend to underestimate the actual intake of some nutrients such as energy (Serdula et al., 2001). Other accounts have shown no significant difference in nutrient composition between food records and weighed intake studies or food records (Schlund, 1988) and food frequency questionnaires (Bergman et al., 1990).

The students completed the three-day diet records as a requirement for a class assignment. It was thought that since the students were already keeping the 3-day records, this would increase participation in the study. The diet records were handwritten by the students and were analyzed using The Food Processor nutrient analysis software, version 7.7 (ESHA, 2001) to determine quantitative nutrient intake for energy, fat, carbohydrate, protein, calcium, dietary vitamin $D$, magnesium, phosphorus, sodium, as well as alcohol and caffeine (Appendix C, pages 78-92). The principle investigator of the study completed all computer 
nutrient analysis. If a food item was not available in the nutrient analysis program, a comparable item was substituted.

\section{$\underline{\text { Statistical Analysis }}$}

All statistical analyses were completed using SAS statistical analysis computer software version 8.0. Descriptive statistics were used to explain dietary patterns, including total energy, fat, carbohydrate, protein, calcium, vitamin $\mathrm{D}$, magnesium, phosphorus, sodium, caffeine, and alcohol intake. This information was used further in a one-tailed t-test to determine if the mean intake of any nutrient was significantly different from the standards listed in Table 3-1. Descriptive statistics were also used to explain the number of servings of dairy foods consumed per day, amount of alcohol and caffeine consumed per day, and the total amount of time spent exercising per day. Exercise time, servings of dairy per day and alcohol intake was then compared to a selected portion of The Dietary Guidelines for Americans in Figure 3-1.

Table 3-1 Recommended Daily Intake

\begin{tabular}{|l|l|l|}
\hline Nutrient & $\begin{array}{l}\text { Recommended } \\
\text { Intake }\end{array}$ & Inappropriate Intake \\
\hline Energy $(\mathrm{kcal})$ & $1800^{2}-2400^{1}$ & $<1800$ \\
\hline Calcium $(\mathrm{mg})$ & $1000^{1}$ & $<1000$ \\
\hline Vitamin D $(\mu \mathrm{g})$ & $5^{1, *}$ & $<5$ \\
\hline Magnesium $(\mathrm{mg})$ & $310^{1}$ & $<310$ \\
\hline Phosphorus $(\mathrm{mg})$ & $700^{1}$ & $<700$ \\
\hline Protein $(\mathrm{g})$ & $46^{1}$ & $<46$ \\
\hline Sodium $(\mathrm{mg})$ & $500^{2}-2400^{2}$ & $>2400 \mathrm{mg}$ (Excessive intake) \\
\hline
\end{tabular}

\footnotetext{
${ }^{1}$ Adequate Intakes (AI) (Institute of Medicine, 1997-2002)

${ }^{2}$ Recommended Daily Allowances (RDAs) (National Research Council, 1989)

${ }^{*}$ In the absence of sunlight
}

\section{Figure 3-2: Selected Dietary Guidelines for Americans}

- Aim for $\mathbf{3 0}$ minutes of moderate physical activity per day.

- Women should consume at least 3 servings of dairy products per day

- Alcohol in moderation: Women $=1$ drink/day $(\approx 13 \mathrm{~g}$ alcohol/day) 
Osteoporosis knowledge section was analyzed using descriptive statistics to score the number and percent of correct responses to the risk-factor questions.

A t-test was performed to establish the difference in exercise time between those individuals who answered risk factor questions correctly and those who did not. A similar t-test was performed to establish the difference between dietary calcium intake between those answering questions correctly and those who did not. Additional statistics included Pearson correlation coefficients to determine the relationship between $\mathrm{BMI}$ and dietary calcium intake, BMI and energy intake as well as BMI and total exercise time. All results were considered statistically significant for $p$-values less than or equal to 0.05 . 


\section{CHAPTER 4: RESULTS}

\section{Characteristics}

A total of 141 subjects, ages $18-27$ participated in the study. Of this number, 132 subjects completed both the entire survey and food record. The nutrition classes that were used to recruit subjects had a total of 205 female students, yielding a participation rate of $64-68 \%$. The subjects were from nine different academic disciplines within the university. The majority $(97 \%, n=129)$ of subjects reported white, non-Hispanic race/ethnicity, while 2 participants (1.5\%) reported African-American race and 2 reported Hispanic race (1.5\%). In addition, 7 collegiate athletes agreed to participate in the study, however, only 3 athletes completed the entire study. Group characteristics such as self-reported height, weight, and age, as well as BMI are shown on Table 4-1.

Table 4-1: Study Sample Characteristics

\begin{tabular}{lll} 
Variable & Mean & Range \\
\hline Age $(\mathrm{yrs})$ & $19.85 \pm 1.52$ & $18-27$ \\
Height (in) & $64.98 \pm 2.66$ & $59.5-70.5$ \\
Weight (lbs) & $139.21 \pm 25.36$ & $100-265$ \\
BMl & $23.00 \pm 3.92$ & $16-44^{*}$
\end{tabular}

${ }^{*}$ Average $\mathrm{BMI}=23$, before and after exclusion of outliers and collegiate athletes

\section{Dietary Patterns}

The diets of 139 participants were analyzed. Two diet records were excluded due to incompletion. Descriptive statistics revealed that the group had a mean energy intake of $1796 \pm 511$ kilocalories. The percent of calories from energy-yielding nutrients were approximately: $53 \%$ carbohydrate, $15 \%$ protein and $29 \%$ fat. Alcohol intake made up the additional $3 \%$ of calories. Mean 
intakes of all nutrients, as well as comparisons to dietary recommendations are in Table 4-2.

Table 4-2: Mean Nutrient Intake

\begin{tabular}{|l|c|c|c|c|c|c|}
\hline \multicolumn{1}{|c|}{ Nutrient } & Mean & SD & Minimum & Maximum & $\begin{array}{c}\text { Adequate/ } \\
\text { Recommended } \\
\text { Intake }\end{array}$ & $\begin{array}{c}\% \\
\text { Recommended } \\
\text { Intake }\end{array}$ \\
\hline Energy (g) & 1796 & 511 & 783 & 3395 & 1800 & 99.7 \\
\hline Carbohydrate $(\mathrm{g})$ & $243(53 \% \mathrm{kcal})$ & 82 & 74 & 494 & $50-55 \% \mathrm{kcals}$ & 100 \\
\hline Protein (g) & $71(15 \% \mathrm{kcal})$ & 34 & 24 & 363 & $15-20 \% \mathrm{kcals}$ & 154 \\
\hline Fat (g) & $59(29 \% \mathrm{kcal})$ & 24 & 11 & 155 & $25-30 \% \mathrm{kcal}$ & 100 \\
\hline Calcium (mg) & 860 & 369 & 205 & 2547 & 1000 & 86 \\
\hline Vitamin D (ug) & 3.4 & 2.9 & 0.1 & 15.4 & 5.0 & 68 \\
\hline Magnesium (mg) & 226 & 99 & 63 & 657 & 310 & 73 \\
\hline Phosphorus (mg) & 1065 & 432 & 325 & 3244 & 700 & 152.1 \\
\hline Sodium (mg) & 2947 & 1005 & 1145 & 6659 & 2400 & 122.7 \\
\hline
\end{tabular}

Fifty-three percent $(n=74)$ of the participants had inadequate energy intake, and $47 \%(n=65)$ had adequate energy intake. Calcium intake was found to be inadequate in $74 \%(n=103)$ of the sample, and adequate in only $26 \%$ $(n=36)$ of the sample. In addition, the mean calcium intake of participants was significantly lower than the recommendation $(p<0.0001)$. The mean number of servings of dairy consumed per day was $1.7 \pm 1.1$, which is lower than the recommendation of at least 3 servings per day. Only $9.3 \%(n=13)$ of participants met this recommendation.

Referring to Table 4-2, mean intake of protein was well above the recommendation at $71 \mathrm{~g} /$ day. In addition, $12.2 \%(\mathrm{n}=17)$ of participants reported average protein intakes of $24-46$ grams of protein, $78.4 \%(n=108)$ reported average intakes of $47-100 \mathrm{~g} /$ day, and the remaining $10.1 \%(n=14)$ consumed 
greater than $100 \mathrm{~g}$ protein/day. Mean protein intake was found to be significantly higher than the recommendation $(p<0.0001)$.

Mean reported intake of phosphorus was found to be significantly greater than the recommendation $(p<0.0001)$. Mean reported intakes of vitamin $D$ and magnesium were significantly less than the recommendation $(p<0.0001)$.

Additionally, the sample's mean intake of sodium was significantly higher than the recommendation $(\mathrm{p}<0.00001)$, with $69.1 \%(\mathrm{n}=96)$ of participants reporting average intakes greater than $2400 \mathrm{mg}$.

Mean alcohol and caffeine intake was $7 \pm 17 \mathrm{~g} /$ day and $56 \pm 71 \mathrm{mg} /$ day, respectively. Since not all participants consumed alcohol and caffeine, the nonconsumers were removed for analysis. The mean intake of alcohol and caffeine consumers is listed in Table 4-3 below.

Table 4-3: Daily Intake of Alcohol and Caffeine

\begin{tabular}{|l|c|c|c|c|c|}
\hline Variable & Subjects & Mean & SD & Minimum & Maximum \\
\hline Alcohol $(\mathrm{g})$ & $\mathrm{n}=37$ & 26 & 24 & 0.04 & 75.5 \\
\hline Caffeine $(\mathrm{mg})$ & $\mathrm{n}=124$ & 63 & 72 & 0.3 & 484 \\
\hline
\end{tabular}

Referring to Table 4-3, the mean intake of alcohol was $26 \mathrm{~g} /$ day, which is approximately equal to two alcoholic beverages. The participants who consumed alcohol had an intake significantly higher than the recommendation of 1 alcoholic beverage per day $(p<0.001)$. In addition, mean caffeine intake was $63 \mathrm{mg} / \mathrm{day}$, which is approximately equal to 12 fluid ounces (fl.oz) of caffeinated soda, $6 \mathrm{fl} \mathrm{oz}$ of black tea, or four $\mathrm{fl} \mathrm{oz}$ of coffee. Since there is no maximum recommendation concerning caffeine intake supported by research, the intake of participants was reported using descriptive statistics. 
The primary food source of dietary calcium for each participant was also of interest. Frequencies of consumption for the food providing the majority of dietary calcium are listed in Table 4-4.

Table 4-4: Commonly Consumed Calcium Foods

\begin{tabular}{|l|c|c|}
\hline \multicolumn{1}{|c|}{ Food } & $\begin{array}{c}\text { Number getting majority } \\
\text { of calcium from listed } \\
\text { food }\end{array}$ & Percent \\
\hline Milk (All types) & 60 & $43 \%$ \\
\hline Cheese & 25 & $18 \%$ \\
\hline Pizza & 20 & $14 \%$ \\
\hline Yogurt & 10 & $7 \%$ \\
\hline Fortified OJ & 5 & $4 \%$ \\
\hline Slim Fast & 4 & $3 \%$ \\
\hline $\begin{array}{l}\text { Frozen } \\
\text { Yogurt/lce } \\
\text { Cream }\end{array}$ & & \\
\hline $\begin{array}{l}\text { Macaroni \& } \\
\text { Cheese }\end{array}$ & 4 & $3 \%$ \\
\hline Grapefruit juice & 3 & $2 \%$ \\
\hline Pudding & 2 & $1 \%$ \\
\hline Fortified Cereal & 2 & $1 \%$ \\
\hline Cream Soup & 1 & $0.7 \%$ \\
\hline Lasagna & 1 & $0.7 \%$ \\
\hline Biscuit & 1 & $0.7 \%$ \\
\hline
\end{tabular}

Referring to Table 4-4, milk provided the majority of dietary calcium in $43 \%(n=60)$ participants. All types of milk were combined for this count, but the type of milk that was the most commonly consumed by this group was $2 \%$ low fat milk.

\section{Exercise Patterns}

Exercise information was available for 133 participants. Eight exercise records were excluded due to incomplete responses. Subjects were asked to recall any physical activity that they had participated in for the last 14 days, and 
to record duration and intensity of the activity. Descriptive statistics revealed that $35.3 \%(n=47)$ did not get adequate exercise, and that the majority of participants $(n=86,64.7 \%)$ got at least 30 minutes of activity per day. Mean exercise time was found to be 54.5 minutes per day, which was significantly higher than the recommendation $(p=0.01)$

\section{Other Results}

\section{Osteoporosis Knowledge}

One hundred thirty-three participants completed the osteoporosis knowledge section of the survey. Eight surveys had to be removed from analysis due to incomplete or inappropriate entries. Descriptive statistics were used to illustrate the sample's overall knowledge score for each question. These results can be seen in Table 4-5 below.

Table 4-5: Osteoporosis Knowledge Scores

\begin{tabular}{|l|c|c|c|}
\hline Risk Factor Question & $\begin{array}{c}\text { \# subjects } \\
\text { correct }\end{array}$ & $\begin{array}{c}\text { \# subjects } \\
\text { incorrect }\end{array}$ & $\begin{array}{c}\text { Correct } \\
\text { response, } \\
\%\end{array}$ \\
\hline Low Dairy Intake & 124 & 17 & $87.90 \%$ \\
\hline Family History & 122 & 19 & $86.50 \%$ \\
\hline Exercise & 108 & 33 & $76.60 \%$ \\
\hline Post-menopausal & 98 & 43 & $69.50 \%$ \\
\hline Scoliosis & 87 & 54 & $61.70 \%$ \\
\hline Oophorectomy & 74 & 67 & $52.40 \%$ \\
\hline Small/Thin & 72 & 69 & $51.10 \%$ \\
\hline Excess Caffeine & 68 & 73 & $48.20 \%$ \\
\hline Steroids & 65 & 76 & $46.10 \%$ \\
\hline Amenorrhea & 58 & 83 & $41.30 \%$ \\
\hline Cigarette & 54 & 87 & $38.30 \%$ \\
\hline Excess Alcohol & 42 & 99 & $29.80 \%$ \\
\hline Caucasian & 36 & 105 & $25.50 \%$ \\
\hline Asian & 16 & 125 & $11.40 \%$ \\
\hline
\end{tabular}


As can be seen in the table, the majority of participants could identify the risk factors of low calcium intake (87.9\%), family history of osteoporosis $(86.5 \%)$, and lack of physical exercise (76.6\%). However, only a small percentage of participants were able to identify the risk factors of excess alcohol (29.8\%), and Caucasian (25.5\%) or Asian (11.4\%) race.

T-tests were performed to determine if there was a significant difference in mean dietary calcium intake between the group who answered each risk factor question correctly and the group who did not. Dietary calcium intake was significantly higher in those individuals who correctly identified dietary calcium as a risk factor for osteoporosis $(p<0.02)$ than in those who did not. Dietary calcium intake was significantly higher in those individuals who correctly identified "family history of osteoporosis" as a risk factor than in those who did not $(p<0.004)$.

There was no significant difference in dietary calcium intake between groups for all other risk factor questions. These results can be seen in Table 4-6.

Table 4-6: Difference in Dietary Calcium Intake Between Risk Factor Identification Groups

\begin{tabular}{|l|c|c|c|}
\hline Answer/Question & $\begin{array}{l}\text { \# of subjects } \\
\text { answering }\end{array}$ & $\begin{array}{c}\text { Mean Calcium } \\
\text { intake }\end{array}$ & p-value \\
\hline Correct: Family History & 112 & 882.4 & \multirow{2}{*}{0.004} \\
\hline Incorrect: Family History & 19 & 674 & \\
\hline Correct: Diet Low in Dairy & 115 & 874.58 & \multirow{2}{*}{0.02} \\
\hline Incorrect: Diet Low in Dairy & 16 & 691.1 & \\
\hline
\end{tabular}

T-tests were also performed to determine if there was a significant difference in exercise time between the group that correctly identified risk factors and the group that did not. Exercise time was significantly higher in the group that correctly identified "lack of physical exercise" as a risk factor than in the 
group that did not $(p<0.001)$. There was no significant difference in exercise time between groups for any other risk factor. These results can be seen in Table 4-7.

Table 4-7: Difference in Exercise Time Between Risk Factor Identification Groups

\begin{tabular}{|l|c|c|c|}
\hline Answer/Question & \# of subjects & Exercise Time (min/day) & p-value \\
\hline Correct: Lack of Physical Exercise & 100 & 61.1 & \multirow{2}{*}{0.001} \\
\hline Incorrect: Lack of Physical Exercise & 32 & 36.7 & \\
\hline
\end{tabular}

\section{Other Health Behaviors}

Descriptive statistics were used to summarize the results of smoking, calcium supplement and vitamin use behaviors. There were 136 records included in this analysis, as five records were excluded due to incompletion. Eighteen percent $(n=24)$ of participants reported that they currently smoke cigarettes, while $31 \%(n=42)$ reported that they had smoked at least 100 cigarettes in their life. Fifty -four percent (74) of participants reported that they never take a vitamin supplement, while the remaining $24 \%(n=33)$ and $21 \%(n=29)$ reported that they take a vitamin supplement regularly and not regularly, respectively. In addition, $84 \%(n=114)$ reported that they never take a calcium supplement, $5 \%(n=7)$ reported that they take a supplement, but not regularly and the remaining $10 \%$ $(n=13)$ reported that they take a calcium supplement regularly. Of this group reporting regular intake, only 10 out of 13 participants took the supplement once a day, and of these 10 subjects, only 5 could identify the dosage of the supplement.

In the menstrual health/oral contraceptive section, $71 \%(n=96)$ of the participants reported current birth control pill use. In addition, only one individual 
reported amenorrhea for 6 months or greater. All other participants reported regular menstruation.

\section{Body Mass Index}

Pearson correlation coefficients were calculated for BMI and calcium, BMI and total exercise time, as well as BMI and total energy intake. Again, 133 records were included in this analysis, 8 being excluded due to incompletion. The results can be seen in Tables 4-8, 4-9 and 4-10 below.

Table 4-8: Pearson Correlation Between Calcium Intake and BMI

\begin{tabular}{|c|c|c|}
\hline Variable & Correlation Coefficient & $\mathrm{P}$-value \\
\hline Calcium intake & 0.009 & $\mathrm{p}=0.91$ \\
\hline
\end{tabular}

Table 4-9:Pearson Correlation Between Reported Energy Intake and BMI

\begin{tabular}{|c|c|c|}
\hline Variable & Correlation Coefficient & $\mathrm{P}$-value \\
\hline Total Energy Intake & 0.055 & $\mathrm{p}=0.54$ \\
\hline
\end{tabular}

Table 4-10: Pearson Correlation Between Total Exercise Time and BMI

\begin{tabular}{|c|c|c|}
\hline Variable & Correlation Coefficient & $P$-value \\
\hline Total Exercise Time & -0.10 & $\mathrm{p}=0.25$ \\
\hline
\end{tabular}

Referring to the tables, no significant relationships were seen between any of the performed correlations. Since no correlation was seen between total exercise time and BMI for the study sample, an additional correlation was performed excluding the collegiate athletes $(n=3)$ who participated in the study. This is because BMI does not always accurately project body composition in athletes, and because athletes are usually required to exercise more frequently at a greater intensity than typical college students.

Table 4-11: Pearson Correlation Between Total Exercise Time and BMI, Without Athletes

\begin{tabular}{|c|c|c|}
\hline Variable & Correlation Coefficient & P-value \\
\hline Total Exercise Time & -0.097 & $\mathrm{p}=0.28$ \\
\hline
\end{tabular}




\section{CHAPTER 5: DISCUSSION}

\section{Calcium Intake}

\section{Dietary Patterns}

This study confirms findings from other studies with regard to dietary intake patterns of college women. The majority of women involved in the current study were not getting the adequate intake (Al) of $1000 \mathrm{mg}$ calcium/day, resulting in a significant difference between dietary calcium intake of participants and the recommendation. Therefore, the null hypothesis is rejected because the participants consumed significantly less dietary calcium. This result suggests that the majority of women involved in this study were not meeting their calcium needs. These findings are similar to those of Kasper et al. (1994) who also found that the majority of participants in their study were not meeting the recommendation of $1200 \mathrm{mg}$ calcium/day, an estimate made using a food frequency questionnaire. Portsmouth et al (1994) also made the same conclusion about their study population of Australian college women by the use of weighed food records. Although these results may not be completely comparable due to the differences in methodology, the study participants were similar, and these findings imply that many young women do not have adequate calcium intake for the formation of maximum bone density.

\section{Energy Intake}

Vitamin and mineral intake is usually related to total energy intake. If a diet is deficient in energy, it is likely that it will be low in other nutrients such as calcium and vitamin D (Nydhal et al., 2003). Mean energy intake was normal for participants in the current study (1796 kcal/day); however total energy intake was 
also low for the majority of subjects $(n=74,53 \%)$. There was no significant difference in the mean energy intake of participants compared to the recommendation. Therefore, the null hypothesis suggesting no difference was not rejected. These results are different than the findings of Rangan and Binns (1997) who discovered that energy intake was low in their Australian college women, assessed by a food frequency questionnaire. Again, although the participants were similar, differences in data collection methods and study location might not allow the results to be completely comparable.

\section{Dietary Protein Intake}

Mean dietary protein intake was found to be $71 \mathrm{~g} / \mathrm{day}$, which is significantly greater than the recommendation of $46 \mathrm{~g} /$ day $(p<0.0001)$. The majority of study participants $(78.4 \%)$ reported protein intakes of $47-100 \mathrm{~g} /$ day. Mean protein intake in grams/ kg body weight was found to be approximately $1.14 \mathrm{~g} / \mathrm{kg} /$ day. This amount is within the recommendation of $0.8-1.8 \mathrm{~g} / \mathrm{kg} / \mathrm{day}$ for this age group. According to Kerstetter et al., (1999) this intake would not increase the risk for osteoporosis in this age group. Barzel and Massey (2001) found that any effect of high protein diets on bone is likely to be offset by adequate calcium intake and vitamin D. Heaney (1998) has suggested that maintaining a calcium to protein ratio of $20 \mathrm{mg}$ calcium: $1 \mathrm{~g}$ protein is sufficient to prevent bone loss. The majority of participants $(96 \%, n=134)$ in the current study had a calcium to protein ratio less than $20 \mathrm{mg} \mathrm{Ca:} 1 \mathrm{~g}$ protein. This finding is of concern and reaffirms that these individuals are not consuming adequate dietary calcium for adequate bone density. 
Seventeen percent of participants $(n=23)$ consumed dietary protein amounts that were lower than the recommendation of $0.8 \mathrm{~g} / \mathrm{kg}-1.8 \mathrm{~g} / \mathrm{kg}$. This low intake can also have a detrimental affect on the formation of bone density. According to Kerstetter et al (1999), too little dietary protein can lead to secondary hyperparathyroidism, which results in decreased release of insulin-like growth factor-1 (IGF-1). Reduced plasma IGF-1 suppresses osteoblastmediated bone formation, leading to decreased bone density.

\section{Sodium Intake}

The majority of subjects $(n=96,69 \%)$ reported sodium intakes that exceed the recommendation of $2400 \mathrm{mg} / \mathrm{day}$. It was also found that there is a significant difference in the sodium intake of participants compared to the recommendation. Based on these results, the null hypothesis is rejected, because sodium intake was significantly higher in the participants of the current study compared to the recommendation. Anding et al (2001) found similar results from a study characterizing dietary patterns of college women. Like the current study, the researchers utilized a 3-day food record to collect nutrient intake information. In that study, mean sodium intake was also found to be significantly higher than the recommendation, and more than half the participants reported sodium intakes that exceeded the $2400 \mathrm{mg} /$ day recommendation. Although the relationship between sodium intake and bone density is debatable, demonstrated in the study by Ginty et al (1998), there are various other reasons to observe the sodium recommendation, such as hypertension and cardiovascular disease (Jurgens and Graudal, 2003). 


\section{Alcohol Intake}

The majority of participants in the current study abstained from alcohol use. This suggests that alcohol intake is not a major problem for this particular sample. However, the 37 individuals (26.6\%) classified as "alcohol consumers" had a mean alcohol intake of 26 grams/day. This is roughly equivalent to two drinks per day, which is higher than the recommendation. Since the amount consumed by the participants was significantly higher than the recommendation, the null hypothesis suggesting that there is no difference is rejected $(p<0.001)$. It was also found in the current study that the majority of participants $(78 \%, n=29)$ who consumed alcohol did so in the one weekend day, reported in the three-day intake. While this may not reflect "usual" intake patterns, it does suggest that there may be a pattern of binge drinking on the weekends. This finding is similar to that of Wechsler et al. (2002) who found that while undergraduate students drank alcohol infrequently, when they did drink, they were much more likely to drink excessively. This is noteworthy even if alcohol intake is not directly associated with bone density in the young adult years, because patterns of binge drinking can lead to subsequent alcohol abuse problems later in life (Collins et al., 2001) when alcohol intake is most likely to have a negative effect on bone mineral density.

\section{Caffeine Intake}

The intake patterns of the participants consuming caffeinated beverages and food reflect a mean daily intake of $63 \mathrm{mg} /$ day. This is roughly the same amount that is found in one serving of black tea (6 fluid ounces). This amount 
would not be described as excessive and is not a cause for worry as far as bone loss in concerned, as it is a much smaller amount than the $100 \mathrm{mg} /$ day that is suggested to be safe by Cooper et al (1992). Although additional research is needed to determine exactly what intake is considered safe with regard to bone health, moderate intake is unlikely to cause complications, especially in young women.

\section{Servings of Dairy}

It was found that a small percentage $(9.3 \%)$ of students fulfilled the recommendation for 3 or more servings of dairy per day. These results are in line with those of Turner and Bass (2001) who found that only $31 \%$ of participants consumed the recommended number of servings from the dairy group. Although the group in their study was female collegiate athletes and FFQ was used to determine dairy intake, the results still project that the majority of college women are not getting the recommended number of servings from the dairy group. This is of concern because dairy foods are rich in calcium, vitamin $D$ (if fortified), phosphorus and protein. In addition, many Americans get the majority of dietary calcium from dairy products. Unless there is extra effort to increase dietary calcium from other sources, a diet low in dairy usually means that the diet is also low in calcium. 


\section{Intake Patterns of Other Nutrients}

The mean reported intake of phosphorus was found to be adequate, while mean magnesium intake was inadequate. The adequate intake of phosphorus was expected, because phosphorus is abundant in a variety of foods such as meat products and cola-type sodas. Magnesium, on the other hand, was low in this group probably due to the overall diet quality of this study sample. Magnesium is found primarily in whole grains, nuts, and green leafy vegetables, foods that are not commonly consumed by college students (Tavelli and Beerman, 1998).

One particularly surprising finding was that vitamin $D$ intakes were significantly lower than the recommendation. This finding is of concern because it is very difficult to produce vitamin $D$ during the early spring months in the northeastern United States, due to the latitude and availability of sunlight. Because of this, it is essential that dietary sources provide the majority of vitamin D during this time of year (Calvo and Whiting, 2003).

\section{Exercise Patterns}

According to the analysis of exercise reports, the majority of the participants $(65 \%)$ got adequate exercise according to the Dietary Guidelines for Americans. In addition, the participants of the current study exercised significantly longer (54 minutes/day; $p<0.0001$ ) compared to the recommendation of at least 30 minutes a day. This finding leads to the rejection of the null hypothesis that suggests that there would be no difference in exercise time between study participants and the recommendation. This result was 
unexpected. It was hypothesized that the participants in the current study would have an average exercise time that was less than the recommendation of 30 minutes, based on findings of similar studies. Anding et al (2001) found that only $33 \%$ of participants in their study were getting adequate exercise according to the same recommendation in the 2000 Dietary Guidelines for Americans. The difference between the findings of the current study compared to that of Anding et al might be due to reporting methods, in that Anding et al used a 3-day activity record to measure exercise, whereas the current study used a 2-week exercise recall record. The current study utilized the same reporting method used by Kasper et al (1994). Unlike the current study, Kasper and colleagues' results also found that the majority of participants did not get adequate exercise. These differences might be attributable to over reporting of overall exercise time and intensity by participants in the current study. The definition of strenuous, moderate and light exercise might vary for each participant, based on her level of fitness. Errors in this estimation could explain the differences in results of the current study when compared to previous studies.

While the mean exercise time of $\sim 54$ minutes/day reported by participants was surprising, it would not be considered an excessive amount of activity. The Institute of Medicine issued a recommendation that individuals engage in 60 minutes of moderate exercise for weight maintenance (Dietary Reference Intakes, 2002). The Institute of Medicine recommendation focuses on organized exercise time, while the purpose of the Dietary Guidelines for Americans recommendation is to get Americans to replace sedentary activities such as 
driving a car with physical activities such as walking (Dietary Guidelines for Americans, 2000). This is a possible explanation in the large amount of participants $(65 \%)$ reporting adequate activity. West Virginia University has 3 different campuses situated throughout Morgantown, and although there is transportation provided between campuses, some students choose to walk to classes. Participants included walking to class when reporting total exercise time, as this is the only exercise that some students get. In addition, the University also has a new Student Recreation Center that is available for faculty and students. The facility features various exercise machines, swimming pool, aerobic classes, climbing wall, free weights, and areas to play organized games such as basketball. Since the fee for the facility is included in tuition, it is widely used by many students. Combining the time spent walking to class plus any other organized exercise time might help explain why the majority of students reported at least 30 minutes of activity per day.

Forty-seven participants (35\%) reported getting $<30$ minutes of activity per day. This group is not getting adequate exercise. Lack of physical activity is a known modifiable risk factor for diseases such as osteoporosis, heart disease, obesity, type 2 diabetes and cancer. It is important that these individuals increase exercise time if they are to decrease their risk for developing these chronic diseases.

It is also important to note that 14 participants (11\%) reported exercising for greater than two hours per day. All three athletes who participated in the study fell into this category. This group could possibly be at risk for exercise- 
induced amenorrhea. Since there was only one individual who reported amenorrhea occurring for six months or longer, this further supports that exercise time was probably over-estimated by most participants in this group. While it is important to note that all other participants of the study reported regular menstruation, this might be due to the use of oral contraceptives by study participants $(71 \%)$.

\section{Osteoporosis Knowledge}

The majority of participants were able to correctly identify 7 of the 14 risk factors for osteoporosis (50\%), two of which are arguably the most important to the prevention of osteoporosis: a diet low in dairy products and lack of physical exercise. These results suggest that while most participants can identify half of the risk factors listed, the sample probably does not possess adequate knowledge about osteoporosis prevention, similar to the findings of Kasper et al (1994). Conversely, the knowledge findings of the current study contradict those of Taggart and Connor (1995) and Turner and Bass (2001) who found that the majority of college students participating in their studies recognized and correctly identified the majority of risk factors for osteoporosis. The differences in findings could be attributed to the study samples. In Taggart and Connor's study, participants were older than the subjects of the current study, and in Turner and Bass' study, the participants were all female collegiate athletes. It is possible that these factors have allowed participants to gain more knowledge about osteoporosis and its risk factors. 
There was a significant difference in the dietary calcium intake patterns of individuals who could correctly identify dietary calcium and family history of osteoporosis as risk factors for the disease and those who could not. This finding leads to the rejection of the null hypothesis suggesting that there is no difference in calcium intake between the two groups. However, the mean calcium intake of the group correctly answering this question was still significantly lower $(837 \mathrm{mg} / \mathrm{day} ; \mathrm{p}<0.001)$ than the recommendation of $1000 \mathrm{mg} /$ day. There may be an association between increasing calcium intake in response to increasing osteoporosis knowledge, but since the knowledgeable group was still significantly below the recommendation, it can be concluded that knowledge probably does not encourage adequate calcium intake. More research should be done to clarify this finding. It should also be noted that there was no significant difference in calcium intake for the rest of the risk factors.

No significant relationship was seen between any osteoporosis knowledge question and exercise time, except for correctly identifying exercise as a risk factor and total time participants spent exercising. There was a significant difference in exercise times, which leads to rejection of the null hypothesis that states that no difference exists. This finding was unexpected, as it was hypothesized that there would be no significant difference in exercise time in participants who could identify exercise as a risk factor and those who could not. It is also important to note that even though there was a significant difference in exercise time between the two groups, both groups still had mean exercise times that were greater than the recommendation. This finding is unlike the results of 
the study conducted by Kasper et al (1994). Their results indicated that the majority of subjects did not exercise adequately, and that there was no relationship between risk factor identification and exercise time. Similarly, Taggart and Connor (1995) found that although participants demonstrated adequate knowledge about osteoporosis, there was no significant correlation between osteoporosis knowledge and exercise habits. Although the methods of statistical analysis differed between these studies and the current study, the results are still comparable. The findings of the current study may be due to the participants' age, (as younger people usually exercise more often), availability of an on-campus exercise facility, or overestimation by the subjects on the exercise record.

\section{Body Mass Index}

Body mass index (BMI) is a measure of body composition based on individuals' height and weight. It has been found that the mean BMI of Americans sampled by NHANES III, aged 20 years and older is $>25$, which indicates overweight. The mean BMI of the current study sample is 23 , which might suggest that this group is leaner than the general population. However, when the BMI of the current study group was compared to the age and sex stratified NHANES BMI data, their BMI was found to be very similar to a mean BMI of 23.8 for white, non-Hispanic women aged 20-29. This suggests that the current study's participants are not unique, in that their BMI is very close to the average BMI for young adult women (NHANES III). 
The correlations performed to determine the relationship between $\mathrm{BMI}$ and calcium and energy intakes as well as BMI and exercise time yielded no significant correlation. The results of these analyses leads to accepting the null hypotheses stating that there is no relationship between these pairs of data.

It has been suggested in recently conducted research that there is a meaningful relationship between calcium intake and BMI (Kamchycheva et al., 2003 and Heaney et al., 2002). These researchers have suggested that increased calcium intake is related to better weight control. Although this suggestion is controversial, the relationship may be due to overall diet quality, as people who have a healthy intake of fruits, vegetables, low-fat dairy and meats are more likely to have better weight control. The reason why the current study showed no significant relationship between calcium intake and BMI could be due to overall low calcium intake of the group or from underreporting on the three-day diet record.

The lack of a significant relationship between energy intake and BMI was unexpected. It is well established that energy intake effects body weight, and therefore, BMI. The lack of correlation seen in the current study might be due to the use of self-reported height, weight and dietary information. This information provided by the participants must be interpreted with caution, as it is common for women to underreport weight and dietary intake (Jacobson and DeBock, 2001).

The results that showed no significant relationship between BMI and exercise time was also unexpected. Like total energy intake, exercise is known to play a role in body composition and weight control. This finding might be 
attributable to reporting error in height, weight and exercise time. Participants may have over-estimated exercise time and intensity. In addition, all types of activity were included in the statistical analysis of this data, even light activity. This type of low-effort activity reported by many of the study participants is not likely to produce a large effect on overall energy expenditure or body composition, which might also explain the lack of meaningful relationship between these two variables.

It is also important to note that BMI is influenced by many complex factors including height, weight, physical activity, nutrient intake, and genetics. This may also help explain the lack of relationship between calcium and energy intakes and $\mathrm{BMI}$ as well as reported exercise time and BMI.

\section{Limitations}

Limitations of this study include the use of a convenience sample, and self-reported exercise record, height, weight, and dietary information.

The use of a convenience sample produces limitations because the results might be unique to the specific group studied. The information obtained from this type of sample might not be representative of other groups within West Virginia University or other populations. In addition, the group may not be representative of other groups due to enrollment in the nutrition course. These individuals may be more interested in health and well being, therefore, the results obtained from this specific study are only applicable to this specific group. Another limitation associated with the use of a nutrition course has to do with when osteoporosis was covered during the semester. This group may have 
already reviewed osteoporosis and its risk factors, which might explain their ability to identify $50 \%$ of the risk factors. This sample may be more aware of osteoporosis risk factors than the general West Virginia University student population, again, suggesting that these findings are only applicable to the specific group studied.

The limitations of the dietary pattern section of this study were related to the use of 3-day food records. Although food records have acceptable variation from weighed food records, the motivation of the participants is always a factor. Although the mean age of participants (19.9) in this study is fairly close to the mean age of all undergraduate students at West Virginia University (20.6 years), the motivation of these participants to correctly characterize dietary intake was probably not that high due to the time required to accurately report intake. In addition, participants tend to over or underreport food items with a food record which would significantly alter analysis of nutrient intakes. Over or underreporting might also help explain the lack of correlation between BMI and energy intake.

The exercise section of the survey had similar limitations. The use of a two-week, self-reported exercise chart such as the one used in this study only estimates exercise time, and participants may over-report activity time and intensity. This limitation helps explain the discrepancy between activity times found in the current study compared to previous studies, and might also help explain the lack of correlation between BMI and exercise. 
The questionnaire portion of the survey that identified risk factors also had some limitations. Some participants found the numerical scale describing risk factors confusing $(2=$ definitely does not increase risk for osteoporosis through 8=definitely increases risk for osteoporosis; Appendix B, page 69). The knowledge section would probably be better understood by eliminating the numerical scale and substituting yes or no responses.

Other limitations lie in the use of self-reported height and weight. It is well-documented that the reliability of self-reported height and weight is limited, especially in convenience samples (Jacobson and DeBock, 2001; Shapiro and Anderson, 2003). This also may help explain the lack of correlation between energy intake and BMI as well as exercise time and BMI.

The lack of reliability testing for survey responses is also a limitation. Due to time constraints in the semester, a test-retest reliability exercise was not performed. This would be useful to check the correlation of responses on the survey and with the 3-day food record. 


\section{Applications/Conclusions}

The results of this research provide information on the dietary patterns, exercise behaviors, and osteoporosis knowledge of a group of college women at West Virginia University. It has been demonstrated in other studies that this age group is at a high risk for low calcium consumption a lack of knowledge of osteoporosis risk factors (Kasper et al, 1994, Turner and Bass, 2001) and the current study confirms these findings. In addition, the results of this study also showed that young college women are at risk for low intake of vitamin D and magnesium, other nutrients essential for bone health.

Examination of other dietary patterns in this study showed that college women are not following the sodium intake recommendation, which has possible implications for bone health and definite implications in cardiovascular health. In addition, high sodium intake generally indicates consumption of processed foods, which can be high in saturated fat, trans-fatty acids and calories. While these foods can be part of a healthy diet, excessive consumption can contribute to the development of chronic diseases.

High protein intakes were also common in this group of college women. While this is not an issue taken alone, the calcium to protein ratio of participants was found to be unfavorable for bone health. While more research needs to be completed to elucidate the level of protein needed to preserve bone, this finding further supports the inadequate calcium intake of college women.

The alcohol and caffeine intakes can also be problematic in college women (Wechsler et al, 2002 and Heaney and Rafferty, 2001). While this was 
not observed in this specific sample, it is important that young women are aware that excessive consumption of food and beverages containing alcohol and caffeine can have a negative effect on bone health, especially if the pattern continues throughout the life span.

Previous studies have shown that college women lack knowledge about osteoporosis (Kasper et al, 1994) and that behavior and knowledge about osteoporosis are not related (Taggart and Connor, 1995, Kasper et al, 1994). While the majority of participants of the current study were aware of half the osteoporosis risk factors that were tested, they did not demonstrate adequate calcium intake, and this might suggest that knowledge about osteoporosis is not related to calcium intake behavior. However, the majority of participants did demonstrate a pattern of exercise that might aid in the prevention of chronic diseases like osteoporosis, if continued throughout adulthood.

Several recommendations can be issued based on the results of this study. It is important that this age group of females know that the formation of maximum bone density occurs during young adulthood. It is also important to stress the role of diet in the prevention of osteoporosis, specifically adequate intake of calcium and vitamin D providing foods and/or supplements. Young women should also be made aware of the other risk factors that are associated with osteoporosis, such as irregular menstruation, exercise, and cigarette smoking. If this information is not already covered in the Introductory Nutrition course at West Virginia University, it is recommended that this information as well as the results of this study be shared with students enrolled in this class in 
the future. The course offers a perfect opportunity to educate students about the risks of osteoporosis while they are still in the years of bone density formation.

Additional research should be conducted to examine the relationship between osteoporosis awareness and behaviors. Research that focuses on different exercise reporting methods might be interesting and more precise in describing the exercise patterns of college women, which might yield a more accurate account of exercise behavior. In addition, research about the specific needs of this young population should be conducted to determine what motivates them to practice preventive measures concerning osteoporosis. This will aid the development of osteoporosis education programs that are geared toward the promotion of healthy lifestyles and prevention of osteoporosis in this group of young women. 


\section{References}

Anding JD, Suminski RR, Boss L. Dietary intake, body mass index, exercise and alcohol: are college age women following the dietary guidelines for Americans? J Am Coll Health. 2001; 49(4): 167-71.

Barger-Lux MJ and Heaney RP. Caffeine and calcium economy revisited. Osteopor Int. 1995; 5: 97-102.

Baron JA, Farahmand BY, Wederpass E, Michaelsson K, Alberts A, Persson I, Ljunghall S. Cigarette smoking, alcohol consumption, and risk of hip fracture in women. Arch Intern Med. 2001; 161: 983-988.

Barzel US, Massey LK. Excess dietary protein can adversely affect bone. $J$ Nutr. 1998; 126: 1051-53.

Bergman EA, Boyungs JC, Erickson ML. Comparison of a food frequency questionnaire and a 3-day diet record. Journal of the American Dietetic Association. 1990;90:1431-1433.

Block G, Hartman A, Dresser C, Carroll M, Gannon J, Gardner L. A data-based approach to diet questionnaire design and testing. American Journal of Epidemiology. 1986; 124: 453-469.

Brevard PB, Ricketts CD. Residence of college students affects dietary intake, physical activity, and serum lipid levels. Journal of the American Dietetic Association. 1996; 96: 35-38.

Calvo MS and Whiting SJ. Prevalence of vitamin D insufficiency in Canada and the United States: importance to health status and efficacy of current food fortification and dietary supplement use. Nutrition Reviews. 2003; 61:108-113.

Collins RL, Koutsky JR, Morsheimer ET, MacLean MG. Binge drinking among underage college students: a test of a restraint-based conceptualization of risk for alcohol abuse. Psychology of Addictive Behaviors. 2001; 15: 333-340.

Cooper C, Atkinson EJ, Wahner HW, O'Fallon WV, Riggs BL, Judd HL, Melton LJ. Is caffeine consumption a risk factor for osteoporosis? J Bone Miner Res. 1992; 7: 465-471.

Cooper C, Atkinson EJ, Hensrud DD, Wahner HW, O'Fallon WM, Riggs BL, Melton LJ. Dietary protein intake and bone mass in women. Calcif Tissue Int. 1996; 58: 320-325. 
Davee AM, Rosen CJ, Adler RA. Exercise patterns and trabecular bone density in college women. J Bone Min Res. 1990; 5:245-50.

Dawson-Hughes B. Interaction of dietary calcium and protein in bone health in humans. Journal of Nutrition. 2003;133: 852S-854S.

Dietary Guidelines for Americans, $5^{\text {th }}$ ed. Washington, DC: US Department of Agriculture and Health and Human Services:

http://www.health.gov/dietaryguidelines/dga2000. (accessed 2003, July).

Dietary Reference Intakes for Calcium, Magnesium, Phosphorus, Vitamin D, and Flouride. Food and Nutrition Board, Institute of Medicine. Washington, DC:

National Academy Press, 1997.

Dietary Reference Intakes for Energy, Carbohydrates, Fiber, Fat, Protein, and Amino Acids (Macronutrients). Food and Nutrition Board, Institute of Medicine. http://www.nap.edu/openbook/0309085373/html. The National Academy of Sciences, 2002. (accessed 2003, July).

ESHA Research. Food processor for windows. Version 7.71, 2001.

Follin SL, Hansen LB. Current approaches to the prevention and treatment of postmenopausal osteoporosis. Am J Health-Syst Pharm. 2003; 60: 883-901.

Gerdhem P, Obrant KJ. Effects of cigarette-smoking on bone mass as assessed by dual-energy X-ray absorptiometry and ultrasound. Osteporosis Int. 2002;13: 932-936.

Ginty F, Flynn A, Cashman K. The effect of sodium intake on biochemical markers of bone metabolism in young women. Br J Nutr. 1998; 79: 343-50.

Haberman S, Luffey D. Weighing in college students' diet and exercise behaviors. J Am Coll Health. 1998; 46: 189-191.

Heaney RP. Excess dietary protein may not adversely affect bone. J Nutr. 1998;128: 1054-1057.

Heaney RP, Davies KM, Barger-Lux MJ. Calcium and weight: clinical studies. Journal of the American College of Nutrition. 2002; 21: 152S-155S.

Heaney RP and Rafferty K. Carbonated beverages and urinary calcium excretion. Am J Clin Nutr. 2001; 74: 343-47.

Hertzler AA, Frary R. Dietary status and eating out practices of college students. J Am Diet Assoc. 1992; 92: 867-869. 
Jacobson $\mathrm{BH}$ and DeBock $\mathrm{DH}$. Comparison of BMI by self reported versus measured height and weight. Perceptual and Motor Skills. 2001;96: 128-132.

Jurgens G, Graudal NA. Effeects of low sodium diet versus high sodium diet on blood pressure, rennin, aldosterone, catecholamines, cholesterols, and triglyceride.

Kamycheva E, Joakimsen RM, Jorde R. Intakes of calcium and vitamin d predict body mass index in the population of Northern Norway. J Nutr. 2003;133: 102106.

Kasper MJ, Peterson MG, Allegrante JP, Galsworthy TD, Gutin B. Knowledge, beliefs, and behaviors among college women concerning the prevention of osteoporosis. Arch Fam Med. 1994; 3: 696-702.

Kerstetter J, Mitnick J, Gundberg CM, Caseria DM, Ellison AF, Carpenter TO, Isogna $\mathrm{KL}$. Changes in bone turnover markers in young women consuming different levels of dietary protein. J Clin Endocrino Metab. 1999; 84:1052-56.

Kiel DP, Relson DT, Hannan MT, Anderson JJ, Wilson PW. Caffeine and the risk of hip fracture: The Framingham Study. Am J Epidemiol. 1990; 132: 675-684.

Korpelainen R, Korpelainen J, Heikkinen J, Vaananen K, Keinanen-Kiukaanniemi $\mathrm{S}$. Lifestyle factors are associated with osteoporosis in lean women but not in normal and overweight women: a population-based cohort study of 1222 women. Osteoporosis International. 2003;14:34-43.

Leslie M, St. Pierre RW. Osteoporosis: implications for risk reduction in the college setting. J Am Coll Health. 1999; 48: 67-72.

Lorenzo J. A new hypothesis for how sex steroid hormones regulate bone mass. J Clin Investigation. 2003; 111: 1641-1643.

Mazess RB, Barden HS. Bone density in premenopausal women: effects of age, dietary intake, physical activitiy, smoking, and birth control pills. Am J Clin Nutr. 1991;53: 132-142.

National Osteoporosis Foundation (NOF). Disease statistics. 2003. http://www.nof.org/osteoporosis/stats.htm (accessed 2003, July).

National Research Council. Recommended Dietary Allowances, $10^{\text {th }}$ Edition. Washington DC, 1989.

NHANES III. Body mass index statistics 1988-1994. www.cdc.gov/nchs/data/nhanes/t9.pdf. (accessed 2003, July). 
Norris SA, Pettifor JM, Gray DA, Buffenstein R. Calcium metabolism and bone mass in female rabbits during skeletal maturation: the effect of dietary calcium intake. Bone. 2001; 29: 62-69.

Nydhal M, Andersson J, Sidenvall B, Gustafsson K, Fjellstrom C. Food and nutrient intake in a group of self-managing elderly Swedish women. J. Nutr. Health Aging. 2003; 7:67-74.

Packard PT, Recker RR. Caffeine does not affect the rate of again in spine bone in young women. Osteoporos International. 1996; 6: 149-52.

Portsmouth K, Henderson K, Graham N, Price R, Cole J, Allen J. Dietary calcium intake in 18-year-old women: comparison with recommended daily intake and daily energy intake. J Adv Nurs. 1994: 20: 1073-1078.

Rangan AM, Binns CW. Dietary iron and calcium intakes of female university students. Australian Journal of Nutrition and Dietetics. 1997; 54: 110-117.

Recker RR, Davies KM, Hinders SM, Heaney RP, Stegman MR, Kimmel DB. Bone gain in young adult women. JAMA. 1992; 268: 2403-2408

Rigotti NA, Neer RM, Skates SJ, Herzog DB, Nussbaum SR. The clinical course of osteoporosis in anorexia nervosa. JAMA. 1991; 265: 1133-1138.

SAS Institute Inc., SAS. Version 8, 1999. Cary, NC.

Serdula MK, Alexander MP, Scanlon KS, Bowman BA. What are preschool children eating? A review of dietary assessment. Ann Rev Nutr. 2001; 21:475499.

Schapira D. Alcohol abuse and osteoporosis. Semin Arthritis Rheum. 1990; 19: 371-377.

Shapiro JR and Anderson DA. The effects of restraint, gender and body mass index on self-reported weight. International Journal of Eating Disorders. 2003; 34: 177-180.

Schlund DG. Accuracy and reliablitiy of nutrient intake estimates. Journal of Nutrition.1988; 118: 1432-1435.

Taggart HM, Connor SE. The relation of exercise habits to health beliefs and knowledge about osteoporosis. Journal of American College Health. 1995; 44: 127-131. 
Tavelli S, Beerman K. Source of error and nutritional adequacy of the food guide pyramid. Journal of American College Health. 1998; 47: 77-83.

Turner LW, Bass MA. Osteoporosis knowledge, attitudes and beliefs of female college athletes. International Journal of Sport Nutrition and Exercise Metabolism. 2001; 11: 482-489.

Wechsler H, Lee JE, Nelson TF, Kuo M. Underage college students' drinking behavior, access to alcohol, and the influence of deterrence policies. Journal of American College Health. 2002; 50: 223-237.

Zipfel S, Seibel MJ, Lowe B, Beaumont PJ, Kasperk C, Herzog W. Osteoporosis in eating disorders: a follow-up study of patients with anorexia and bulimia nervosa. J Clin Endocrinolgy and Metabolism. 2001; 86: 5227-5233. 
Appendix A 


\section{WestVirginiaUniversity \\ Office of Research Compliance}

DATE: January 24, 2003

This research will be monitored for re-approval annually. APPROVAL PERIOD: January 24, 2003 to January 23, 2004

NOTICE OF APPROVAL FOR PROTOCOL: HS \#15724

TO: Jamie Sutton

TITLE: Dietary Behaviors and Beliefs of Young Women Concerning Osteoporosis

AGENCY: N/A

The Institutional Review Board for the Protection of Human Research Subjects (IRB) has approved the project described above. Approval was based on the descriptive material and procedures you submitted for review. Should any changes in your protocol/consent form be necessary, prior approval must be obtained from the IRB.

According to the Code of Federal Regulations, Section 312.32, investigators are required to notify the FDA and the study sponsor of any adverse experience associated with the use of an investigational drug that is serious and unexpected. A serious adverse experience is considered any event that is fatal or life-threatening, is permanently disabling, requires inpatient hospitalization, or is a congenital anomaly, cancer, or overdose. An unexpected adverse experience is an event that is not identified in nature, severity, or frequency in the current investigator brochure. Any experience reportable to FDA and the sponsor must also be reported immediately to the IRB.

A consent form* $\mathrm{X}$ is__ is not required of each subject.

An assent form_ is $\mathrm{X}$ is not required of each subject.

A recruitment ad has__has not $\mathrm{X}$ been approved.

\section{Chestnut Ridge Research Building}


Date: January 24,2003

Page -2-

Sutton

HS \#15724

Only copies of the consent and/or assent form with the IRB's approval stamp may be used with human subject research. It is the responsibility of the investigator to submit a revised consent form for the IRB's approval should funding be obtained. This stamped consent form must then be used for subjects enrolled. A copy of each subject's signed Consent/Assent Form must be retained by the investigator and accessible to federal regulatory authorities for at least three years after the study is completed.

Charles R. Craig, Ph.D.
Director
for Research Compliance

$\mathrm{CRC} / \mathrm{baw}$ 


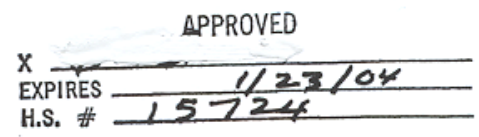

Dear Student,

You have been asked to participate in a research study at West Virginia University. This study has some very important possibilities and will allow researchers to understand more about your behaviors related to health issues. Your participation is appreciated.

The purpose of this study is to find out about your dietary and exercise habits, as well as your awareness of the bone disease osteoporosis. You will be asked to complete a threeday food record and a short survey that will allow the researchers to characterize your behaviors and knowledge of osteoporosis.

You will meet with the researcher twice. The first meeting will consist of the researcher explaining the procedures of the study to you. The second meeting will consist of all study participants completing a survey about college age women's opinions and behaviors related to health issues. The survey will take 10-15 minutes to complete. It will be confidential, and there are no right or wrong answers.

The diet record will be explained to you during the first meeting with the researcher. It is the portion of the study that you will complete on your own time. Diet record sheets will be provided for you. Once you return the record to the researchers, it will be analyzed for a variety of nutrients such as calcium and vitamin D using computer software. The information generated by the program will be made available to you, if interested.

I appreciate your time for considering participation in the study. If you have any additional questions or concerns, feel free to contact me at jsutton3@wvu.edu, or 5997739. Thank you for your time.

Sincerely,

Jamie Sutton 


\section{Dietary behaviors and beliefs of young women concerning osteoporosis}

\section{Consent and Information Form}

Introduction. I, , have been invited to participate in this research study which has been explained to me by Jamie Sutton. This research is being conducted to fulfill the requirements for a Master's thesis in Human Nutrition at West Virginia University.

Purposes of the study. The purpose of the study is to learn more about female college students' dietary and exercise practices as well as their understanding of the bone disease osteoporosis.

Descriptions of the Procedures. This study involves 2 sessions with the researcher. One of these sessions will be used to explain the study and the three-day food record, and to obtain my consent. The second session will be used to turn in my three-day food record and complete a survey. The first session will take about 30 minutes of my time, and the second session will take about 15 minutes of my time. It is my understanding that I will receive extra credit in Human Nutrition and Foods 171 for giving my consent to participate in the study.

Risks and Discomforts. There will be no known or expected risks from participating in this study, except for the use of my time.

Benefits. This study may help me understand and prevent the bone disease osteoporosis. I understand that I will earn extra credit for participating in this study. I also understand that other options are available for earning the same extra credit.

Financial Consideration. There are no costs associated with participation in this study.

Alternatives. I understand that nonparticipation in this research study is an option.

Contact Persons. For more information about this research, I can contact Jamie Sutton at 599-7739, or her advisor, Dr. Cindy Fitch, at 293-3402 X 1768. For information regarding my rights as a research subject, I may contact the Executive Secretary of the Institutional Review Board at 293-7073.

Confidentiality. I understand that any information about me obtained as a result of my participation in this research will be kept as confidential as legally possible. In any publications that result from this research, neither my name nor any information from which I might be identified will be published without my consent. Date 


\section{West VirginiaUniversity}

Davis College of Agriculture, Forestry and Consumer Sciences

Dietary behaviors and beliefs of young women concerning osteoporosis

Voluntary Participation. Participation in this study is voluntary. I understand that I am free to withdraw my consent to participate in this study at any time. Refusal to participate or withdrawal will involve no penalty or loss of benefits and will not affect my grades or class standing. I have been given the opportunity to read the survey and to ask questions about this research, and I have received answers concerning areas I did not understand.

Upon signing this form, I will receive a copy.

I willingly consent to participate in this research.

Signature of Subject or Subject's representative

$\overline{\text { Signature of Investigator or Investigator's Representative }}$ $\overline{\text { Date }} \overline{\text { Time }}$

$\overline{\text { Date }} \overline{\text { Time }}$

Page 2 of 2 01/16/2003 Initial __ Date 


\section{APPENDIX B}


1. How much information have you heard or read about the health condition OSTEOPOROSIS, sometimes-called brittle or weak bones?

\section{A lot}

Some

Nothing at all (skip to question 4)

2. Where have you seen information or heard about OSTEOPOROSIS? (Check all that apply).

Television

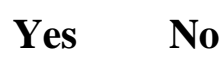

Radio

A newspaper

A magazine

A relative, friend or neighbor

Your work

A school or teacher

A clinic, doctor's office or health service

Billboards, buses or trains

Posters, handouts or brochures

A sorority or women's club

Somewhere else (please specify)

3. Thinking about your lifetime, do you think the number of people per 100 in West Virginia who will get Osteoporosis each year will ...

Increase greatly $\quad 0$

Increase somewhat $\quad 0$

Stay the same $\quad 0$

Decrease somewhat $\quad 0$

Decrease greatly $\quad$ o

In the next series of questions, please answer by circling a number from 1 to 5 . The list of illnesses is the same for each question. The first question is: 
4. At one time or another, most of us have been concerned of becoming ill. Using a number between 1 to 5 , where 1 means you are not at all concerned and 5 means you are extremely concerned, please tell me, how concerned are you of ...

\begin{tabular}{|c|c|c|c|c|c|}
\hline & $\begin{array}{l}\text { Not at all } \\
\text { Concerned }\end{array}$ & & & & $\begin{array}{l}\text { Extremely } \\
\text { Concerned }\end{array}$ \\
\hline a. getting heart disease? & 1 & 2 & 3 & 4 & 5 \\
\hline b. getting breast cancer? & 1 & 2 & 3 & 4 & 5 \\
\hline c. getting osteoporosis? & 1 & 2 & 3 & 4 & 5 \\
\hline d. getting HIV or AIDS? & 1 & 2 & 3 & 4 & 5 \\
\hline e. getting Alzheimer's disease? & 1 & 2 & 3 & 4 & 5 \\
\hline f. catching a common cold? & 1 & 2 & 3 & 4 & 5 \\
\hline
\end{tabular}

5. Now thinking about the future, indicate how likely you think it is that you will get the illness, where 1 means you are not at all likely to get the illness and 5 means you are extremely likely to get the illness. How likely are you to....

Not at all

Extremely

Concerned
a. get heart disease?
12
3
45
b. get breast cancer?

12
3
45
c. get osteoporosis?
d. get HIV or AIDS?

12
3
45
e. get Alzheimer's disease?

12
45
f. catch a common cold?

$\begin{array}{ll}1 & 2 \\ 1 & 2\end{array}$
4 
6. Please indicate how serious you think each illness is, where 1 means the illness is not at all serious and 5 means the illness is extremely serious. How serious is ...

Not at all
serious
a. heart disease?
b. breast cancer?
c. osteoporosis?
d. HIV or AIDS?
e. Alzheimer's disease?
f. a common cold?

$\begin{array}{lllll}1 & 2 & 3 & 4 & 5 \\ 1 & 2 & 3 & 4 & 5 \\ 1 & 2 & 3 & 4 & 5 \\ 1 & 2 & 3 & 4 & 5 \\ 1 & 2 & 3 & 4 & 5 \\ 1 & 2 & 3 & 4 & 5\end{array}$ 5 5 5

Extremely serious 5

7. Now please indicate how personally responsible you think a person is for having each illness, where 1 means a person is not at all responsible and 5 means a person is completely responsible. In general, how responsible do you think a person is for having ...

Not at all
responsible
a. heart disease?
b. breast cancer?
c. osteoporosis?
d. HIV or AIDS?
e. Alzheimer's disease?
f. a common cold?

$\begin{array}{lllll}1 & 2 & 3 & 4 & 5 \\ 1 & 2 & 3 & 4 & 5 \\ 1 & 2 & 3 & 4 & 5 \\ 1 & 2 & 3 & 4 & 5 \\ 1 & 2 & 3 & 4 & 5 \\ 1 & 2 & 3 & 4 & 5\end{array}$

Completely responsible 
8. There are many factors that may or may not increase your risk of developing OSTEOPOROSIS. For each factor listed below circle if you think it definitely increases (8), probably increases (4), probably not (2) or definitely not increases (1) the chances of developing OSTEOPOROSIS.

DOES NOT

Increase
Definitely

Increases
a. Drinking alcohol in excess

12
b. Being Caucasian
12
3
4
8
c. Infrequent of skipped menstrual periods
d. Drinking caffeine in excess

12
3
4
8
e. A family history of osteoporosis 1
f. Eating a diet high in animal fat 1
g. Lack of physical exercise

12
h. Being African-American

12
i. A diet low in dairy products or other sources of calcium

12
j. Taking steroid of thyroid medication for asthma, arthritis, or cancer
k. Having a small, thin frame
1. Worry or anxiety
m. Being Asian
n. Being post menopausal
o. Having high blood cholesterol

12
3
4
8

3

$4 \quad 8$
4

4

8

3

3

3

4
4 8
p. A early or surgically induced menopause
q. Getting sunburn
r. Smoking cigarettes
s. Scoliosis or curved spine

12

3

$4 \quad 8$

\section{(1)}




\section{Exercise}

This section is about your usual exercise habits. Thinking back over the past 14 days, have you done any of the following exercises, sports, or physically active hobbies?

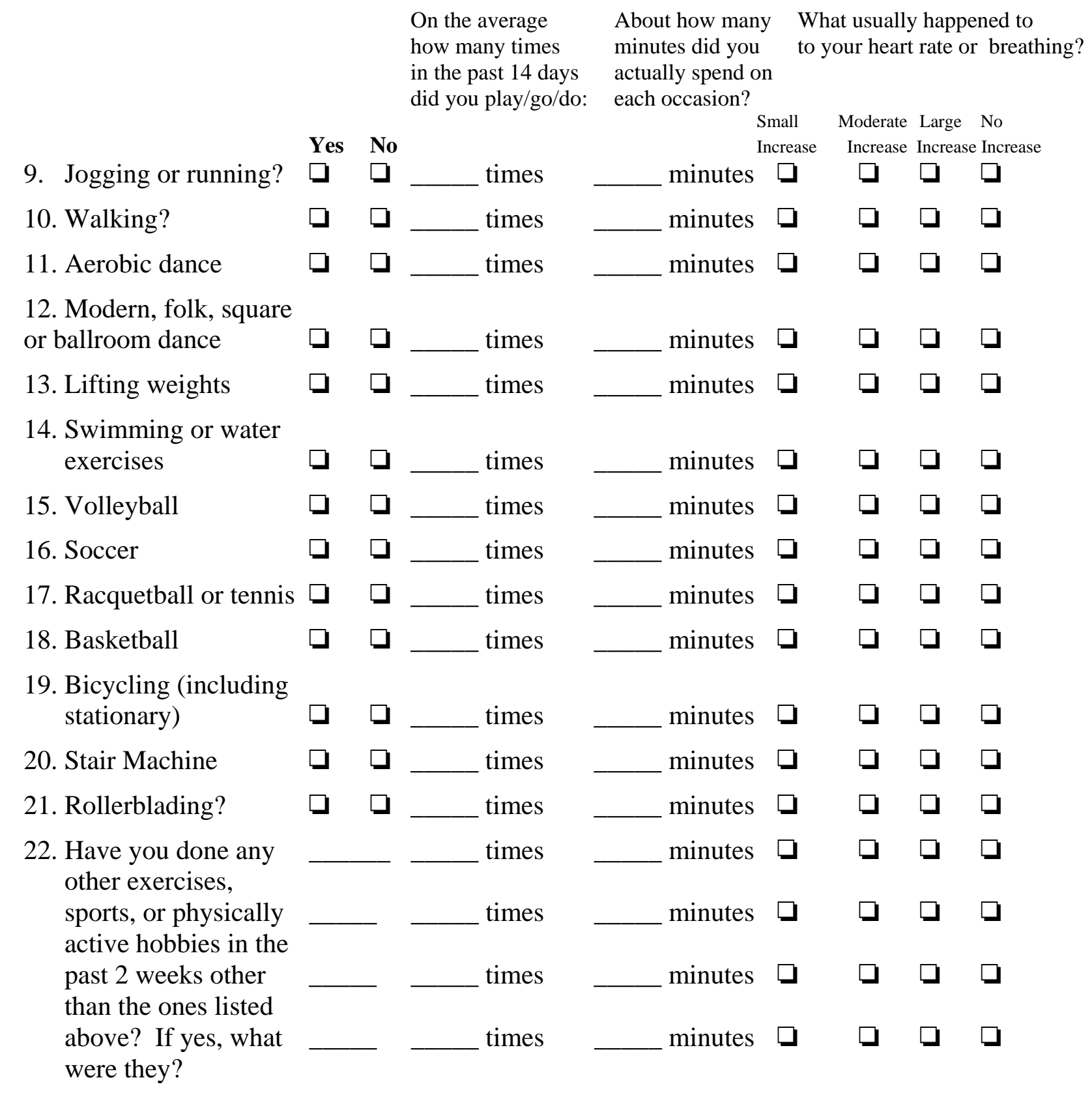


23. Would you say that the exercise, sports, or physically active hobbies that you have participated in over the past 2 weeks are less than, about the same or more than you usually have done in the past 12-months?

$\square$ Less than (why?

About the same

$\square$ More than (why?

24. Would you say that you are physically more active, less active, or about as active as another person your age?

More active

$\square$ Less active

$\square$ About as active

\section{Vitamins and Calcium Supplements}

The next series of questions has to do with specific vitamins and supplements that you may be currently taking or have taken in the past.

25. During the past year, have you taken a multiple vitamin?

$\square$ No, (skip to question 26).

$\square$ Yes, fairly regularly (go to question 25a)

$\square$ Yes, but not regularly (go to question 25a)

25a. Please list the brand of multiple vitamin you usually take:

26. During the past year, have you taken any calcium pills?

$\square$ No

$\square$ Yes, fairly regularly (go to question 26a)

$\square$ Yes, but not regularly (go to question 26a)

26a. How many and how often do you take calcium pills?

times per: $\square$ day $\square$ week $\square$ month

(quantity)

26b. What is the dosage of the calcium pill? milligrams unsure / don't know

\section{Hormonal Contraceptives}


The next series of questions have to do with hormonal contraceptives or birth control pills.

38. Have you ever taken birth control pills?

$\square$ yes (go to question 38a)

$\square$ no (skip to question 39)

38a. How old were you when you first started taking birth control pills? years old

38b. Of the entire time you took birth control pills how many MONTHS have you taken them? months

38c. Do you take birth control pills now?

$\square$ Yes (skip to question 39)

$\square$ No

38d. How old were you when you stopped taking birth control pills? years old. 


\section{Menstrual History}

The next series of questions have to do with your menstruation (period). Please keep in mind that when we talk about your period we mean at least 2-days of bleeding that moderately to heavily fill either a tampon or sanitary napkin.

39. At what age did you begin to have a period? years old

40. In the PAST 6-MONTHS have you had a period?

$\square$ Yes

$\square$ No

41. In the PAST 12-MONTHS have you had period?

$\square$ Yes

$\square$ No

42. In the PAST 12-MONTHS how many times have you had a period? times

43. On the average, HOW MANY DAYS between your period? days

44. Since you had your first period have you EVER had LESS THAN TWO periods with a 12-MONTH time span?

$\square$ Yes

$\square$ No

45. How many times has your period ceased for longer than 6-months? times

46. About how many months before you begin to menstruate again? times 


\section{Smoking}

47. Have you smoked at least 100 cigarettes in your life?

$\square$ No (skip to question 48)

Yes (got to question 47b)

47b. Do you smoke cigarettes now?

$\square$ No (skip to question 47b)

$\square$ Yes (go to question 47d)

\section{EXERCISE and CALCIUM}

Yes No

48. Are you physically active?

49. Is you diet low in dairy products and other sources of calcium?

\section{Family History}

50. Below is a list of medical conditions. Has your mother or father ever had or been told that they had any of these conditions?
a. Osteoarthritis or inflammation of the joints
Yes
Don't
b. Osteoporosis or brittle bones
c. Fracture of the spine
d. Fracture of the hip
e. Fracture of the wrist
f. A dowager's hump or collapsed vertebrae? 


\section{INFORMATION SOURCES}

51. There are many different places or sources of where you could learn about the health condition called OSTEOPOROSIS or brittle bones. What PLACES or SOURCES would YOU most likely use to learn more about the health condition called OSTEOPOROSIS?

Please put the number in the appropriate box on the left.

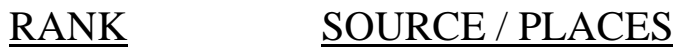

MOST LIKELY

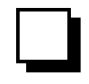

SECOND MOST

LIKELY

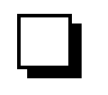

THIRD MOST

\section{LIKELY}

\section{Medical Visits}

1. Handout or brochure

2. Posters

3. Article in a school newspaper

4. Article in a magazine

5. 15-30 minute lecture held at the University Union, dormitory or sorority house

6. Computer program or information on the Internet or World Wide Web

7. 5-minute talk with a physician, nurse, or health educator during an office visit

8. 15-minute video that you could view while waiting in a clinic, doctor's office or health service

9. 15-minute video that you could view at home

10. Other (please explain)

52. During the past 12-months, have you visited a clinic, doctor's office or health service for a medical checkup, treatment of an illness or a gynecological examination?

$\square$ Yes

$\square$ No (skip to question 54)

53. During the past 12-months, ABOUT how many times did you go to a clinic, doctor's office or health service for a gynecological examination? times

\section{Other Information}


54. When were you born?

month day year

55. Which range best describes your age? Please circle:

18-20

21-23

24-26

27-29

$30-31$

56. What year are you in school?

$\square$ Freshman

$\square$ Sophomore

$\square$ Junior

$\square$ Senior

57. What is your major?

58. Do you live on campus in a dormitory room?

$\square$ Yes

$\square$ No

59. How tall are you without shoes? feet and __ inches

60. How much do you weigh without shoes? lbs.

61. Are you a collegiate athlete at West Virginia University?

o Yes

o No

62. What is your racial or ethnic background?

White, not of Hispanic origin

$\square$ Black, not of Hispanic origin

$\square$ Hispanic

$\square$ American Indian / Alaskan native

$\square$ Asian

$\square$ Pacific Islander

$\square$ Other (please specify) 
APPENDIX C 


\section{DIETARY ANALYSIS INTAKE FORM}

Directions: Please record your food and beverage intake as accurately as possible. List $A L L$ foods and beverages consumed.

\begin{tabular}{|c|c|c|c|c|c|}
\hline Time & $\begin{array}{l}\text { Meal } \\
\text { Code }\end{array}$ & Activity/Location & $\begin{array}{l}\text { Detailed Description of } \\
\text { Foods \& Beverages }\end{array}$ & Amount & \multirow{3}{*}{ Name: $1319 \mathrm{~s}$} \\
\hline & 47019 & & Brownie-2"w/nuts & 2 & \\
\hline & 20150 & & Diet Coke-can & $12 f 10 z$ & \\
\hline & 3046 & & $\begin{array}{l}\text { Pure Premium oJ } \\
\text { w/ Calcium }\end{array}$ & $10 f 10 z$ & \multirow{2}{*}{$\begin{array}{l}\text { Date: } 2 / 21 / 03 \\
\text { Day of Week: SUN }\end{array}$} \\
\hline & 20012 & & Coffee & 3 cups & \\
\hline & 54244 & & Creamer & 3Tbsp. & \multirow{3}{*}{$\begin{array}{l}\text { RDA Profile } \\
\text { Information: }\end{array}$} \\
\hline & 7557 & & Vegetarian Chili: & 3 cups & \\
\hline & & & w/meat substitute & & \\
\hline & $\frac{1008}{5549}$ & & Cheddar Cheese-shred. & $1 / 4$ cup & \multirow{3}{*}{$\begin{array}{l}\text { Age: } 19 \\
\text { Gender: Male } \\
\text { Female - }\end{array}$} \\
\hline & 53004 & & $\begin{array}{l}\text { Frozen Mixed Veg. } \\
\text { TeriuaKi Sauce. }\end{array}$ & $\frac{1202}{4 f 107}$ & \\
\hline & $460 / 2$ & & Yellow cake wl & $\frac{4+L O z}{2 p c}$ & \\
\hline & & & Choc lcing $21 / 2 " s g$. & & \multirow{2}{*}{$\begin{array}{l}\text { Pregnant } \\
\text { Nursina }\end{array}$} \\
\hline & $\frac{20041}{1880}$ & & Water J & $44 f L O z$ & \\
\hline & & & Long graint wild rice & $30 z-w t$ & \multirow{3}{*}{$\begin{array}{l}\text { Neight: } 5^{\prime} 7^{\prime \prime} \\
\text { Weight: } 128 \\
\text { Activity Level* }\end{array}$} \\
\hline & & & & & \\
\hline & & & & & \\
\hline & & & & & \\
\hline & & & & & \multirow{18}{*}{$\begin{array}{l}\text { *Note: Estimate the } \\
\text { appropriate activity } \\
\text { level based on your } \\
\text { activity record. If } \\
\text { most of your activity } \\
\text { was spent in } \\
\text { categories } A, B \text {, and } \\
C, \text { your activity is } \\
\text { light. If a significant } \\
\text { portion of your time } \\
\text { was spent on category } \\
E \text {, your activity is } \\
\text { heavy. }\end{array}$} \\
\hline & & & & & \\
\hline & & & & & \\
\hline & & & & & \\
\hline & & & & & \\
\hline & & & & & \\
\hline & & & & & \\
\hline & & & & & \\
\hline & & & & & \\
\hline & & & & & \\
\hline & & & & & \\
\hline & & & & & \\
\hline & & & & & \\
\hline & $-\ldots$ & $\cdots \cdots$ & & & \\
\hline & & & & & \\
\hline & & & & & \\
\hline & & & & & \\
\hline & & & & & \\
\hline
\end{tabular}




\section{DIETARY ANALYSIS INTAKE FORM}

Directions: Please record your food and beverage intake as accurately as possible. List $A L L$ foods and beverages consumed.

\begin{tabular}{|c|c|c|c|c|c|}
\hline Time & $\begin{array}{l}\text { Meal } \\
\text { Code }\end{array}$ & Activity/Location & $\begin{array}{l}\text { Detailed Description of } \\
\text { Foods \& Beverages }\end{array}$ & Amount & \multirow{3}{*}{ Name: 13195} \\
\hline & 47019 & & Brownie - 2 "w/nuts & 2 & \\
\hline & 20150 & & Diet Coke-can & $12 f 10 z$ & \\
\hline & 3046 & & Pure Premium OJ? & $10 f 10 z$ & \multirow{2}{*}{$\begin{array}{l}\text { Date: } 2 / 21 / 03 \\
\text { Day of Week: SUN }\end{array}$} \\
\hline & 20012 & & $\begin{array}{l}\text { w/ Calcium } \\
\text { Coffee }\end{array}$ & 3 cuas & \\
\hline & 54244 & & Creamer & 3 Tbsp. & \multirow{3}{*}{$\begin{array}{l}\text { RDA Profile } \\
\text { Information: }\end{array}$} \\
\hline & 7557 & & vegetarian Chili: & 3 cups & \\
\hline & & & W/meat substitute & & \\
\hline & $\frac{1008}{5549}$ & & Cheddar Cheese-shred. & $1 / 4 \mathrm{cup}$ & \multirow{3}{*}{$\begin{array}{l}\text { Age: } \frac{19}{\text { Gender: Male }} \\
\text { Female }\end{array}$} \\
\hline & 53004 & & $\begin{array}{l}\text { Frozen Mixed Veg. } \\
\text { TeriuaKi Sauce }\end{array}$ & $\frac{120 z}{4 \mathrm{floz}}$ & \\
\hline & $460 / 2$ & & $\begin{array}{l}\text { MenyakI sauce } \\
\text { Yellow cake w/ }\end{array}$ & $2 p c$ & \\
\hline & & & Choc Icing $21 / 2 " s g$. & & \multirow{2}{*}{$\begin{array}{l}\text { Pregnant } \\
\text { Nursing }\end{array}$} \\
\hline & 20041 & & Water & $44 f l 0 z$ & \\
\hline & 1880 & & Long graint wildrice & $30 z-\omega t$ & \multirow{4}{*}{$\begin{array}{l}\text { Height: } 55^{\prime \prime} 7^{\prime \prime} \\
\text { Weight: } 128 \\
\text { Activity Level* }\end{array}$} \\
\hline & & & Blend-Drymix & & \\
\hline & & & & & \\
\hline & & & & & \\
\hline & & & & & \multirow{13}{*}{$\begin{array}{l}\text { *Note: Estimate the } \\
\text { appropriate activity } \\
\text { level based on your } \\
\text { activity record. If } \\
\text { most of your activity } \\
\text { was spent in } \\
\text { categories } A, B \text {, and } \\
C, \text { your activity is } \\
\text { light. If a significant } \\
\text { portion of your time } \\
\text { was spent on category } \\
E, \text { your activity is } \\
\text { heavy. }\end{array}$} \\
\hline & & & & & \\
\hline & & & & & \\
\hline & & & & & \\
\hline & & & & & \\
\hline & & & & & \\
\hline & & & & & \\
\hline & & & & & \\
\hline & & & & & \\
\hline & & & & & \\
\hline & & & & & \\
\hline & & & & & \\
\hline & & & & & \\
\hline & ....... & 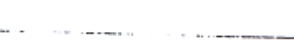 & & & \\
\hline & & & & & \\
\hline & & & & & \\
\hline & & & & & \\
\hline & & & & & \\
\hline
\end{tabular}




\section{DIETARY ANALYSIS INTAKE FORM}

Directions: Please record your food and beverage intake as accurately as possible. List $A L L$ foods and beverages consumed.

\begin{tabular}{|c|c|c|c|c|c|}
\hline Time & $\begin{array}{l}\text { Meal } \\
\text { Code }\end{array}$ & Activity/Location & $\begin{array}{l}\text { Detailed Description of } \\
\text { Foods \& Beverages }\end{array}$ & Amount & \multirow{3}{*}{ Name: 13195} \\
\hline & 47019 & & Brownie-2"w/nuts & 2 & \\
\hline & 20150 & & Diet coke-can & $12 f 10 z$ & \\
\hline & 3046 & & Pure Premium OJ? & $10 f 10 z$ & \multirow{3}{*}{$\begin{array}{l}\text { Date: } 2 / 21 / 03 \\
\text { Day of Week: SUN }\end{array}$} \\
\hline & 20012 & & w/ Calcium & & \\
\hline & $\frac{200 / 2}{54244}$ & & Coffee & 3 cups & \\
\hline & 7557 & & $\begin{array}{l}\text { Creamer } \\
\text { Vegetarian Chili: }\end{array}$ & 3Tbsp. & \multirow{2}{*}{$\begin{array}{l}\text { RDA Profile } \\
\text { Information: }\end{array}$} \\
\hline & & & w/meat substitute & cups & \\
\hline & 1008 & & Cheddar Cheese-shred. & $1 / 4$ cup & \multirow{3}{*}{$\begin{array}{l}\text { Age: } \frac{19}{\text { Gender: Male }} \\
\text { Female }\end{array}$} \\
\hline & $\frac{5549}{53004}$ & & Frozen Mixed Veg. & 1202. & \\
\hline & $\frac{35004}{46012}$ & & $\begin{array}{l}\text { lenyaki Sauce } \\
\text { Yetlow cake wl }\end{array}$ & 4 floz & \\
\hline & & & $\begin{array}{l}\text { Yellow cake w/ } \\
\text { Choc lcing } 21 / 2 " s q \text {. }\end{array}$ & $2 p c$ & \multirow{3}{*}{$\begin{array}{l}\text { Pregnant } \\
\text { Nursing }\end{array}$} \\
\hline & 20041 & & Water sq. & $44 f l o z$ & \\
\hline & 1880 & & Long graint wildrice & $30 z-\omega t$ & \\
\hline & & & Blend-Dry Mix & & \multirow{3}{*}{$\begin{array}{l}\text { Height: } \frac{5^{\prime} 7^{\prime \prime}}{128^{\prime}} \\
\text { Weight: } 128 \\
\text { Activity Level* }\end{array}$} \\
\hline & & & & & \\
\hline & & & & & \\
\hline & & & & & \multirow{18}{*}{$\begin{array}{l}\text { *Note: Estimate the } \\
\text { appropriate activity } \\
\text { level based on your } \\
\text { activity record. If } \\
\text { most of your activity } \\
\text { was spent in } \\
\text { categories } A, B \text {, and } \\
C, \text { your activity is } \\
\text { light. If a significant } \\
\text { portion of your time } \\
\text { was spent on category } \\
E, \text { your activity is } \\
\text { heavy. }\end{array}$} \\
\hline & & & & & \\
\hline & & & & & \\
\hline & & & & & \\
\hline & & & & & \\
\hline & & & & & \\
\hline & & & & & \\
\hline & & & & & \\
\hline & & & & & \\
\hline & & & & & \\
\hline & & & & & \\
\hline & & & & & \\
\hline & & & & & \\
\hline 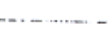 & $\cdots-$ & $\cdots$ & & & \\
\hline & & & & & \\
\hline & & & & & \\
\hline & & & & & \\
\hline & & & & & \\
\hline
\end{tabular}


Total Weight: $12415.73 \mathrm{~g}$ (437.94 oz-wt.)

Serving Size: 12415.73 g (437.94 oz-wt.)

Serves: $\quad 1.00$

\begin{tabular}{|c|c|c|}
\hline Amount for & & ESHA \\
\hline 1 serving & Food Item & Code \\
\hline 2 each & Brownies w/Walnuts-Recipe-prep 2"square & 47019 \\
\hline $12 \mathrm{fl} \mathrm{oz}$ & Diet Coke Soda Pop-Can/Bottle CCO & 20150 \\
\hline $10 \mathrm{fl} \mathrm{oz}$ & Pure Prem Orange Juice + Calc-RTD TRO & 3046 \\
\hline 3 cup & Brewed Coffee & 20012 \\
\hline 3 tbs & Carnation Coffee Mate Non-Dairy Creamer & 539 \\
\hline 3 cup & Vegetarian Chili (Meat Substitute Used) & 7557 \\
\hline 0.25 cup & Cheddar Cheese-Shredded & 1008 \\
\hline $0.75 \mathrm{lb}$ & Mixed Vegetables-Frozen $(100 z \mathrm{Pkg})$ & 5549 \\
\hline $4 \mathrm{fl} \mathrm{oz}$ & Teriyaki Sauce-RTS & 53004 \\
\hline 2 piece & Yellow Cake w/Chocolate Icing & 46012 \\
\hline $44 \mathrm{fl} \mathrm{oz}$ & Water & 20041 \\
\hline 3 oz-wt & Long Grain \& Wild Rice Blend-Dry UBI & 1880 \\
\hline $10 \mathrm{fl} \mathrm{oz}$ & Orange Juice-Chilled (incl.f/Conc)-Cup & 3092 \\
\hline 2 cup & Brewed Coffee & 20012 \\
\hline $3 \mathrm{tbs}$ & Carnation Coffee Mate Non-Dairy Creamer & 539 \\
\hline 1 each & Banana-Medium-Each & 3020 \\
\hline $3 \mathrm{tbs}$ & LoCal Caesar Salad Dressing & 8138 \\
\hline 2 cup & Romaine (Cos) Lettuce-Chopped-Cup & 5088 \\
\hline 0.25 cup & Seasoned Croutons & 42148 \\
\hline 1.5 cup & Scalloped Potatoes-Homemade w/Margarine & 5270 \\
\hline 1 cup & Broccoli Pieces-Steamed & 5653 \\
\hline 1 cup & Ben\&Jerrys Ice CreamChocChipCookieDough & 2216 \\
\hline $60 \mathrm{fl} \mathrm{oz}$ & Water & 20041 \\
\hline 1 cup & Hot Natural Whole/Rolled Wheat-Ckd & 40002 \\
\hline 0.25 cup & Cheddar Cheese-Shredded & 1008 \\
\hline 2 cup & Brewed Coffee & 20012 \\
\hline 3 tbs & Carnation Coffee Mate Non-Dairy Creamer & 539 \\
\hline 1 cup & Whole Wheat Spaghetti Noodles-Ckd & 38060 \\
\hline 1 cup & Spaghetti Noodles-Enr-Ckd & 38118 \\
\hline $1 \mathrm{tbs}$ & Hard Margarine-Soybean(Hydro\&Reg) & 8179 \\
\hline 0.75 cup & Mozzarella Cheese-WhlMilk-LoMoist-Shred & 1057 \\
\hline 3 tbs & All Purpose Flour-Unbleached-Enr PLB & 38170 \\
\hline 2 cup & $2 \%$ Fat Milk-Vitamin A Added & 2 \\
\hline 1 cup & Broccoli Flowerets-Raw-Cup & 6757 \\
\hline 1.5 cup & HDShops Choc Peanut Butter Ice Cream PLB & 2394 \\
\hline 2 piece & Bernardi's Supreme Vegetable Lasagna WIN & 57403 \\
\hline $75 \mathrm{fl} \mathrm{oz}$ & Water & 20041 \\
\hline
\end{tabular}

\section{Nutrients per Serving}

$\begin{array}{lrlr}\text { Calories } & 7191.76 & \text { Fat - Total } & 288.86 \mathrm{~g} \\ \text { Protein } & 323.90 \mathrm{~g} & \text { Saturated Fat } & 141.13 \mathrm{~g} \\ \text { Carbohydrates } & 869.44 \mathrm{~g} & \text { Vitamin A RE } & 4425.62 \mathrm{RE} \\ \text { Dietary Fiber } & 96.85 \mathrm{~g} & \text { Vitamin C } & 576.86 \mathrm{mg} \\ \text { \% Calories from fat } & 35 \% & \% \text { Calories from carbs } & 47 \%\end{array}$


Total Weight: $12415.73 \mathrm{~g}$ (437.94 oz-wt.)

Serving Size: 12415.73 g (437.94 oz-wt.)

Serves: $\quad 1.00$

Sources \& Amounts for Calcium

\begin{tabular}{cl} 
Amount & \multicolumn{1}{c}{ Food Item } \\
2 piece & Bernardi's Supreme Vegetable Lasagna WIN \\
2 cup & 2\% Fat Milk-Vitamin A Added \\
0.75 cup & Mozzarella Cheese-WhlMilk-LoMoist-Shred \\
$10 \mathrm{fl} \mathrm{oz}$ & Pure Prem Orange Juice + Calc-RTD TRO \\
$3 \mathrm{cup}$ & Vegetarian Chili (Meat Substitute Used) \\
$1.5 \mathrm{cup}$ & HDShops Choc Peanut Butter Ice Cream PLB \\
$1.5 \mathrm{cup}$ & Scalloped Potatoes-Homemade w/Margarine \\
$0.25 \mathrm{cup}$ & Cheddar Cheese-Shredded \\
$0.25 \mathrm{cup}$ & Cheddar Cheese-Shredded \\
$1 \mathrm{cup}$ & Ben\&Jerrys Ice CreamChocChipCookieDough \\
$0.75 \mathrm{lb}$ & Mixed Vegetables-Frozen (10oz Pkg) \\
$1 \mathrm{cup}$ & Broccoli Pieces-Steamed \\
$2 \mathrm{piece}$ & Yellow Cake w/Chocolate Icing \\
$75 \mathrm{fl} \mathrm{oz}$ & Water \\
$3 \mathrm{oz}-\mathrm{wt}$ & Long Grain \& Wild Rice Blend-Dry UBI \\
$2 \mathrm{cup}$ & Romaine (Cos) Lettuce-Chopped-Cup \\
$4 \mathrm{fl} \mathrm{oz}$ & Teriyaki Sauce-RTS \\
$60 \mathrm{fl} \mathrm{oz}$ & Water \\
$1 \mathrm{cup}$ & Broccoli Flowerets-Raw-Cup \\
$10 \mathrm{fl} \mathrm{oz}$ & Orange Juice-Chilled (incl.f/Conc)-Cup \\
$2 \mathrm{each}$ & Brownies w/Walnuts-Recipe-prep 2"square \\
$44 \mathrm{fl} \mathrm{oz}$ & Water \\
$1 \mathrm{cup}$ & Whole Wheat Spaghetti Noodles-Ckd \\
$1 \mathrm{cup}$ & Hot Natural Whole/Rolled Wheat-Ckd \\
$12 \mathrm{fl} \mathrm{oz}$ & Diet Coke Soda Pop-Can/Bottle CCO \\
$3 \mathrm{cup}$ & Brewed Coffee \\
$3 \mathrm{tbs}$ & LoCal Caesar Salad Dressing \\
$1 \mathrm{cup}$ & Spaghetti Noodles-Enr-Ckd \\
$0.25 \mathrm{cup}$ & Seasoned Croutons \\
$2 \mathrm{cup}$ & Brewed Coffee \\
$2 \mathrm{cup}$ & Brewed Coffee \\
$1 \mathrm{each}$ & Banana-Medium-Each \\
$1 \mathrm{tbs}$ & Hard Margarine-Soybean(Hydro\&Reg) \\
$3 \mathrm{tbs}$ & Carnation Coffee Mate Non-Dairy Creamer \\
$3 \mathrm{tbs}$ & Carnation Coffee Mate Non-Dairy Creamer \\
$3 \mathrm{tbs}$ & Carnation Coffee Mate Non-Dairy Creamer \\
$3 \mathrm{tbs}$ & All Purpose Flour-Unbleached-Enr PLB \\
& \\
& \\
&
\end{tabular}

\section{Calcium}

(mg)

1098.62

593.41

487.23

437.50

322.49

300.00

209.48

203.77

203.77

200.00

85.05

74.72

47.36

44.44

42.82

40.32

36.00

35.55

34.08

31.13

27.36

26.07

21.00

16.80

14.37

14.22

10.80

9.80

9.60

9.48

9.48

7.08

4.22

0

0

0

0

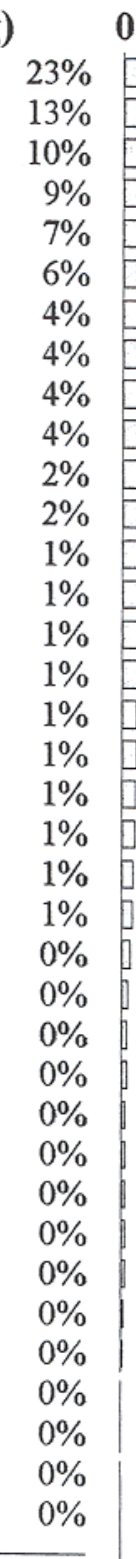

0

\begin{tabular}{llll}
0 & 8 & 15 & 23 \\
\hline
\end{tabular}

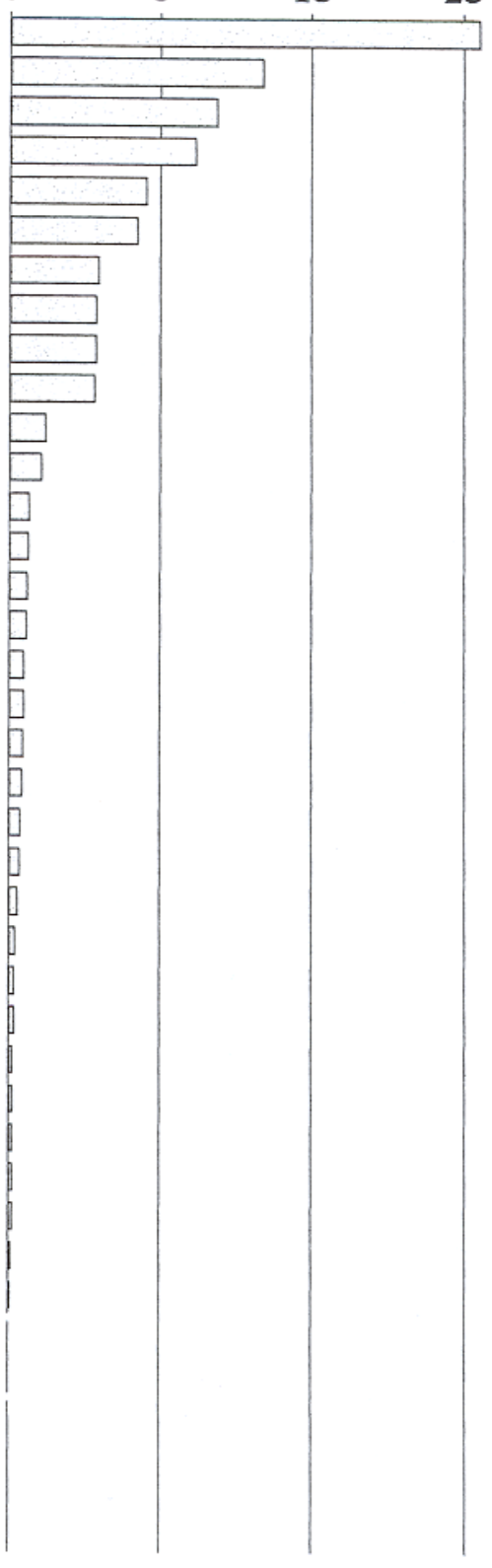

30

Total

$4708.00 \quad 100 \%$ 
Total Weight: $12415.73 \mathrm{~g}$ (437.94 oz-wt.)

Serving Size: $4138.58 \mathrm{~g}$ (145.98 oz-wt.)

Serves: 3.00

Food Pyramid

Meat, Poultry, Fish, Dry Beans, Eggs, \& Nuts Group (2 - 3 svgs)

Milk, Yogurt, \& Cheese Group (2 - 3 svgs)

Bread, Cereal, Rice, \& Pasta Group (6 - 11 svgs)

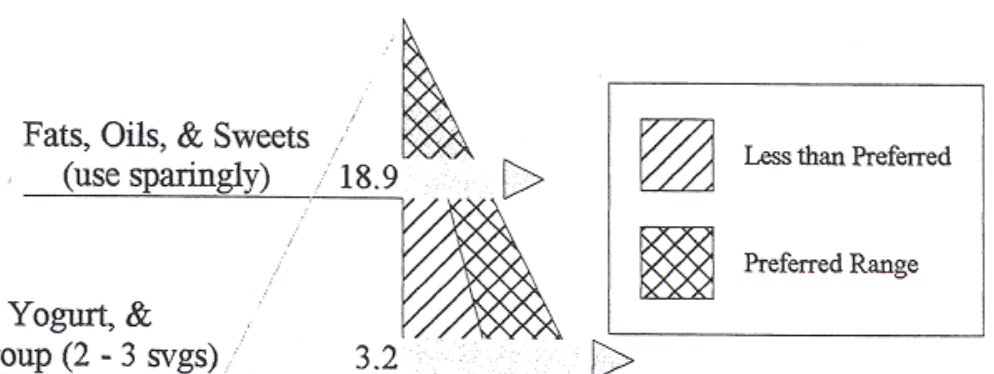

Vegetable Group (3 - 5 svgs)

3.7

1.5

(2 - 4 svgs)

0.7
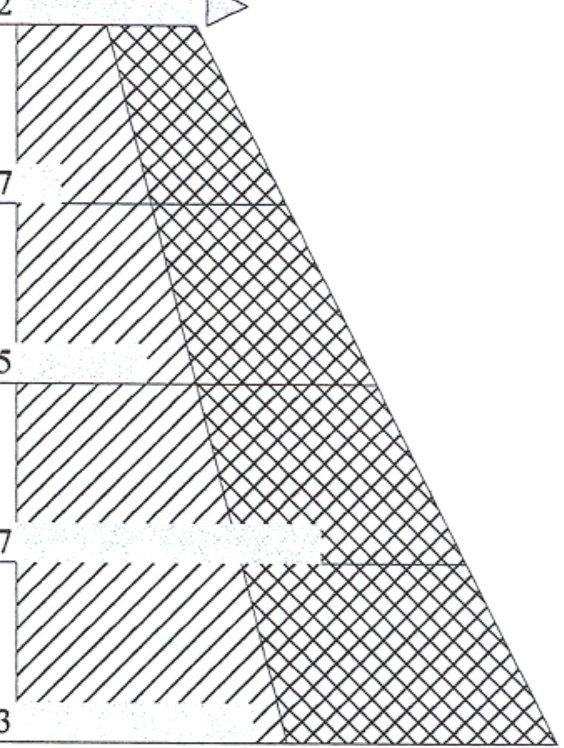
Total Weight: $12415.73 \mathrm{~g}$ (437.94 oz-wt.)

Serving Size: $4138.58 \mathrm{~g}(145.98 \mathrm{oz}$-wt.)

Serves: $\quad 3.00$

$\%$ comparison to: US Female (19-30 years)

Nutrient

Basic Components- 2397.25
Calories

Calories from Fat $\quad 866.58$

Calories from Saturated Fat $\quad 423.39$

Protein

Carbohydrates

Dietary Fiber

Soluble Fiber

Sugar - Total

Monosaccharides

Disaccharides

Other Carbs

Fat - Total

Saturated Fat

Mono Fat

Poly Fat

Trans Fatty Acids

Cholesterol

Water

Vitamins

Vitamin A RE

A - Carotenoid

A - Retinol

A - Beta Caroten

Thiamin-B1

Riboflavin-B2

Niacin-B3

Niacin Equiv.

Vitamin-B6

Vitamin-B12

Vitamin C

Vitamin D mcg

Vit E-Alpha Equiv.

Folate

Pantotheric Acid

423.39
107.97
289.81

$289.81 \mathrm{~g}$

$32.28 \mathrm{~g}$

$2.90 \mathrm{~g}$

$104.72 \mathrm{~g}$

$4.56 \mathrm{~g}$

$12.95 \mathrm{~g}$

$99.57 \mathrm{~g}$

$96.29 \mathrm{~g}$

$47.04 \mathrm{~g}$

$15.92 \mathrm{~g}$

$3.22 \mathrm{~g}$

$266.67 \mathrm{mg}$

$3613.28 \mathrm{~g}$

1475.21 RE

983.36 RE

268.24 RE

$4241.89 \mathrm{mcg}$

$1.18 \mathrm{mg}$

$1.25 \mathrm{mg}$

$11.72 \mathrm{mg}$

$18.94 \mathrm{mg}$

$1.38 \mathrm{mg}$

$1.07 \mathrm{mcg}$

$192.29 \mathrm{mg}$

$2.43 \mathrm{mcg}$

$7.14 \mathrm{mg}$

$456.16 \mathrm{mcg}$
$3.30 \mathrm{mg}$

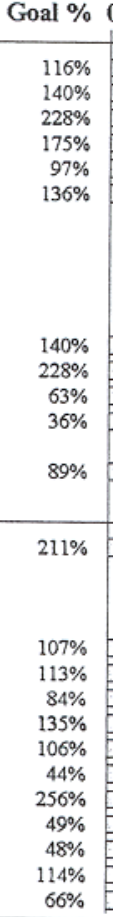

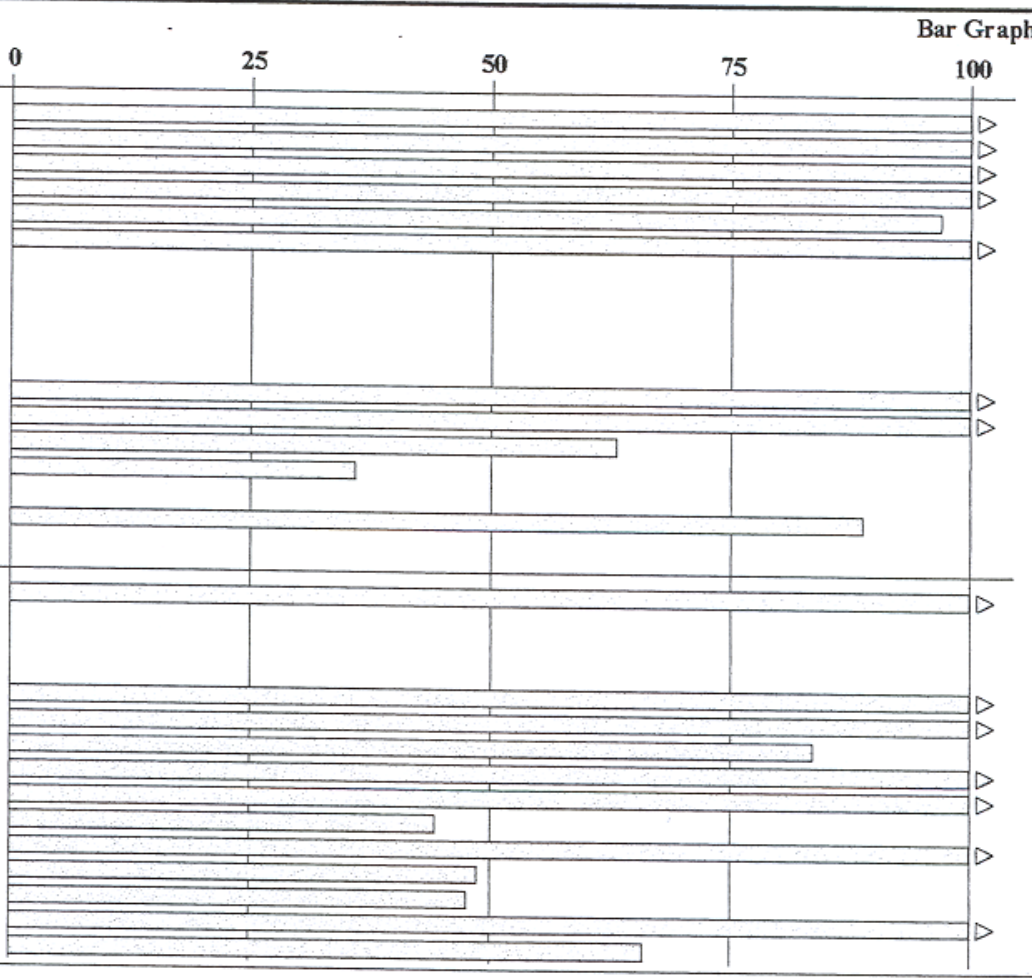

2001

1319S

Total Weight: $12415.73 \mathrm{~g}$ (437.94 oz-wt.)

Serving Size: $4138.58 \mathrm{~g}$ (145.98 oz-wt.)

Serves: $\quad 3.00$

$\%$ comparison to: US Female (19-30 years)

Nutrient

Minerals

Value Goal \% 0

Calcium

Copper

Iron

Magnesium

Manganese

Phosphorus

Potassium

Selenium

Sodium

Zinc

Other Fats

Omega 3 Fatty Acids

Omega 6 Fatty Acids

Other

Alcohol

Caffeine

$156933 \mathrm{mg}$

$157 \%$

\begin{tabular}{|l}
\hline- \\
\hline- \\
\hline- \\
\hline-
\end{tabular}

25

50

Bar Graph

$1.92 \mathrm{mg} \quad 213 \%$

$114 \%$

$337.93 \mathrm{mg}$

$3.68 \mathrm{mg}$

$1341.16 \mathrm{mg}$

$3239.64 \mathrm{mg}$

$50.72 \mathrm{mcg}$

.

$8.21 \mathrm{mg}$

$0.79 \mathrm{~g}$

$5.29 \mathrm{~g}$

$0 \mathrm{~g}$

$339.89 \mathrm{mg}$

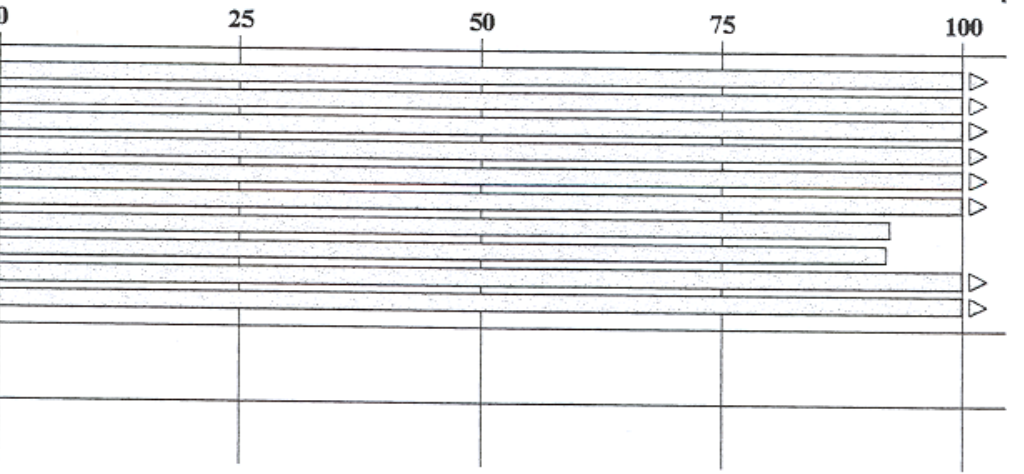




\begin{tabular}{|c|c|c|c|c|c|c|c|}
\hline & & & & & & & Spreadsheet \\
\hline & & $\begin{array}{c}\text { Weight } \\
\text { (g) }\end{array}$ & Cals & Fat Cals & $\begin{array}{c}\text { Sat Fat } \\
\text { Cals }\end{array}$ & $\begin{array}{l}\text { Prot } \\
\text { (g) }\end{array}$ & $\begin{array}{c}\text { Carb } \\
(\mathrm{g})\end{array}$ \\
\hline $\begin{array}{l}\text { Amount } \\
0.66667 \text { each }\end{array}$ & $\begin{array}{c}\text { Food Item } \\
\text { Brownies w/Walnuts-Recipe-prep 2"square }\end{array}$ & 16.00 & 74.56 & 41.90 & 10.54 & 0.99 & 8.03 \\
\hline $\begin{array}{r}0.66667 \text { each } \\
4 \mathrm{fl} \mathrm{oz}\end{array}$ & $\begin{array}{l}\text { Brownies w/Walnuts-Recipe-prep 2"square } \\
\text { Diet Coke Soda Pop-Can/Bottle CCO }\end{array}$ & 119.75 & 0.50 & 0 & 0 & 0 & 0.04 \\
\hline & $\begin{array}{l}\text { Diet Coke Soda Pop-Can/Bottle CCO } \\
\text { Pure Prem Orange Juice + Calc-RTD TRO }\end{array}$ & 103.00 & 45.83 & 0 & 0 & 0.83 & 10.83 \\
\hline $\begin{array}{c}3.3333 \mathrm{fl} \mathrm{oz} \\
1 \text { cup }\end{array}$ & $\begin{array}{l}\text { Pure Prem Orange Juice + Calc-RTD TRO } \\
\text { Brewed Coffee }\end{array}$ & 237.00 & 4.74 & 0.06 & 0.02 & 0.24 & 0.95 \\
\hline $\begin{array}{l}1 \text { cup } \\
1 \text { tbs }\end{array}$ & Carnation Coffee Mate Non-Deiry Creamer & 6.00 & 30.00 & 13.50 & 13.50 & 0 & 3.00 \\
\hline $\begin{array}{l}1 \text { tbs } \\
1 \text { cup }\end{array}$ & Vegetarian Chili (Meat Substitute Used) & 213.64 & 282.51 & 37.86 & 5.38 & 37.93 & 29.86 \\
\hline $\begin{array}{r}1 \text { cup } \\
0.08333 \text { cup }\end{array}$ & Cheddar Cheese-Shredded & 9.42 & 37.91 & 28.09 & 17.88 & 2.34 & 0.12 \\
\hline $\begin{array}{l}0.08333 \text { cup } \\
0.25 \mathrm{lb}\end{array}$ & Mixed Vegetables-Frozen (10oz Pkg) & 113.40 & 72.58 & 5.31 & 1.00 & 3.78 & 15.26 \\
\hline $\begin{array}{c}0.25 \mathrm{lb} \\
1.33333 \mathrm{fl} \mathrm{oz}\end{array}$ & Teriyaki Sauce-RTS & 48.00 & 40.32 & 0 & 0 & 2.85 & 7.66 \\
\hline $\begin{array}{l}1.33333 \mathrm{fl} \mathrm{oz} \\
0.66667 \text { piece }\end{array}$ & Yellow Cake w/Chocolate Icing & 42.67 & 161.71 & 66.82 & 17.88 & 1.62 & 23.64 \\
\hline $\begin{array}{l}0.66667 \text { piece } \\
14.6667 \text { fl oz }\end{array}$ & Water & 434.50 & 0 & 0 & 0 & 0 & 0 \\
\hline $\begin{array}{r}14.6667 \mathrm{fl} \mathrm{oz} \\
1 \mathrm{oz}-\mathrm{wt}\end{array}$ & Long Grain \& Wild Rice Blend-Dry UBI & 28.35 & 94.50 & 2.24 & 0 & 2.98 & 20.39 \\
\hline $\begin{array}{l}1 \text { oz-wt } \\
3.33333 \mathrm{fl} \mathrm{oz}\end{array}$ & Orange Juice-Chilled (incl.f/Conc)-Cup & 103.75 & 45.65 & 2.52 & 0.27 & 0.83 & 10.44 \\
\hline $\begin{array}{l}3.33333 \mathrm{fl} \mathrm{oz} \\
0.66667 \mathrm{cup}\end{array}$ & Brewed Coffee & 158.00 & 3.16 & 0.04 & 0.01 & 0.16 & 0.63 \\
\hline $\begin{array}{r}0.66667 \text { cup } \\
1 \text { tbs }\end{array}$ & Carnation Coffee Mate Non-Dairy Creamer & 6.00 & 30.00 & 13.50 & 13.50 & 0 & 3.00 \\
\hline $\begin{array}{c}1 \text { tbs } \\
0.33333 \text { each }\end{array}$ & Banana-Medium-Each & 39.33 & 36.19 & 1.70 & 0.65 & 0.41 & 9.22 \\
\hline $\begin{array}{c}0.33333 \text { each } \\
1 \text { tbs }\end{array}$ & LoCal Caesar Salad Dressing & 15.00 & 16.50 & 5.94 & 0.95 & 0.04 & 2.79 \\
\hline $\begin{array}{l}1 \text { ths } \\
0.66667 \text { cup }\end{array}$ & Romaine (Cos) Lettuce-Chopped-Cup & 37.33 & 5.23 & 0.67 & 0.09 & 0.60 & 0.88 \\
\hline 0.08333 cup & Seasoned Croutons & 3.33 & 15.50 & 5.49 & 1.57 & 0.36 & 2.12 \\
\hline 0.5 cup & Scalloped Potatoes-Homemade w/Margarine & 122.50 & 105.35 & 40.57 & 15.18 & 3.52 & 13.21 \\
\hline 0.33333 cup & Broccoli Pieces-Steamed & 52.00 & 14.56 & 1.64 & 0.25 & 1.55 & 2.73 \\
\hline 0.33333 cup & Ben\& Jerrys Ice CreamChooChipCookieDough & 70.00 & 200.00 & 96.00 & 60.00 & 3.33 & 22.67 \\
\hline $20 \mathrm{fl} \mathrm{oz}$ & Water & 592.50 & 0 & 0 & 0 & 0 & 0 \\
\hline 0.33333 cup & Hot Natural Whole/Rolled Wheat-Ckd & 80.00 & 49.60 & 2.88 & 0.43 & 1.60 & 10.96 \\
\hline 0.08333 cup & Cheddar Cheese-Shredded & 9.42 & 37.91 & 28.09 & 17.88 & 2.34 & 0.12 \\
\hline 0.66667 cup & Brewed Coffee & 158.00 & 3.16 & 0.04 & 0.01 & 0.16 & 0.63 \\
\hline 1 tbs & Camation Coffee Mate Non-Dairy Creamer & 6.00 & 30.00 & 13.50 & 13.50 & 0 & 3.00 \\
\hline 0.33333 cup & Whole Wheat Spaghetti Noodles-Ckd & 46.67 & 57.87 & 2.27 & 0.42 & 2.49 & 12.39 \\
\hline 0.33333 cup & Spaghetti Noodles-Enr-Ckd & 46.67 & 65.80 & 2.81 & 0.40 & 2.23 & 13.23 \\
\hline 0.33333 tbs & Hard Margarine-Soybean(Hydro\&Reg) & 4.70 & 33.78 & 34.05 & 5.54 & 0.04 & 0.04 \\
\hline 0.25 cup & Mozzarella Cheese-WhiMilk-LoMoist-Shred & 28.25 & 89.94 & 62.65 & 39.56 & 6.10 & 0.70 \\
\hline 1 tbs & All Purpose Flour-Unbleached-Enr PLB & 7.25 & 25.00 & 0 & 0 & 0.75 & 5.25 \\
\hline 0.66667 cup & $2 \%$ Fat Milk-Vitamin A Added & 162.67 & 80.80 & 28.11 & 17.49 & 5.42 & 7.81 \\
\hline
\end{tabular}

Total Weight: $12415.73 \mathrm{~g}$ (437.94 oz-wt)

Serving Size: $4138.58 \mathrm{~g}$ (145.98 oz-wt.)

Serves: 3.00

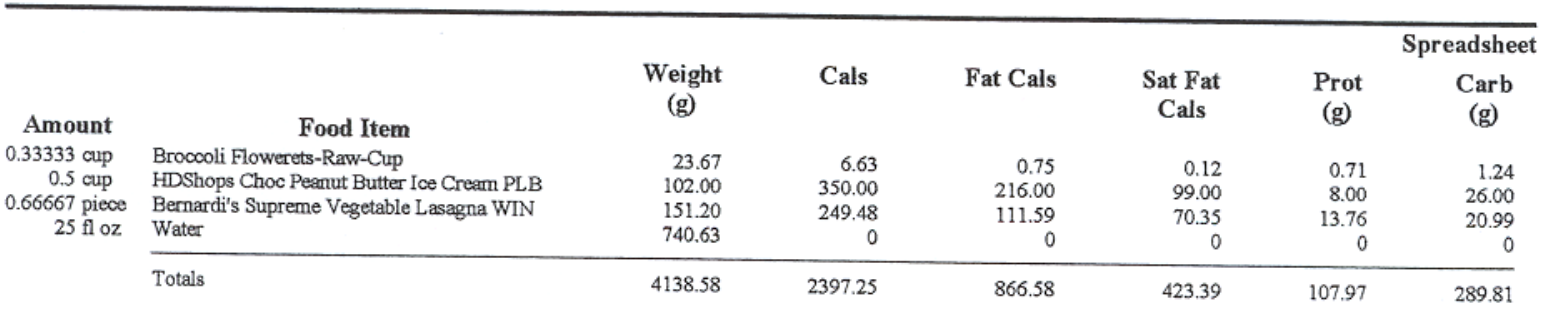


Total Weight: $12415.73 \mathrm{~g}$ (437.94 oz-wt.)

Serving Size: $4138.58 \mathrm{~g}$ (145.98 oz-wt.)

Serves:

3.00

\begin{tabular}{cl} 
Amount & \multicolumn{1}{c}{ Food Item } \\
0.66667 each & Brownies w/Walnuts-Recipe-prep 2"square \\
$4 \mathrm{fl}$ oz & Diet Coke Soda Pop-Can/Bottle CCO \\
3.33333 fl oz & Pure Prem Orange Juice + Calc-RTD TRO \\
1 cup & Brewed Coffee \\
1 tbs & Carnation Coffee Mate Non-Dairy Creamer \\
1 cup & Vegetarian Chili (Meat Substitute Used) \\
0.08333 cup & Cheddar Cheese-Shredded \\
$0.25 \mathrm{lb}$ & Mixed Vegetables-Frozen (10oz Pkg) \\
$1.33333 \mathrm{fl} \mathrm{oz}$ & Teriyaki Sauce-RTS \\
0.66667 piece & Yellow Cake w/Chocolate Icing \\
$14.6667 \mathrm{fl}$ oz & Water \\
1 oz-wt & Long Grain \& Wild Rice Blend-Dry UBI \\
$3.33333 \mathrm{fl}$ oz & Orange Juice-Chilled (incl.f/Conc)-Cup \\
0.66667 cup & Brewed Coffee \\
1 tbs & Carnation Coffee Mate Non-Dairy Creamer \\
0.33333 each & Banana-Medium-Each \\
1 tbs & LoCal Caesar Salad Dressing \\
0.66667 cup & Romaine (Cos) Lettuce-Chopped-Cup \\
0.08333 cup & Seasoned Croutons \\
0.5 cup & Scalloped Potatoes-Homemade w/Margarine \\
0.33333 cup & Brocooli Pieces-Steamed \\
0.33333 cup & Ben\&Jerrys Ice CreanChocChipCookieDough \\
$20 \mathrm{fl}$ oz & Water \\
0.33333 cup & Hot Natural Whole/Rolled Wheat-Ckd \\
0.08333 cup & Cheddar Cheese-Shredded \\
0.66667 cup & Brewed Coffee \\
1 tbs & Carnation Coffee Mate Non-Dairy Creamer \\
0.33333 cup & Whole Wheat Spaghetti Noodles-Ckd \\
0.33333 cup & Spaghetti Noodles-Enr-Ckd \\
0.33333 tbs & Hard Margarine-Soybean(Hydro\&Reg) \\
0.25 cup & Mozzarella Cheese-WhlMilk-LoMoist-Shred \\
1 tbs & All Purpose Flour-Unbleached-Enr PLB \\
0.66667 cup & 2\% Fat Milk-Vitamin A Added \\
0.33333 cup & Brocooli Flowerets-Raw-Cup \\
&
\end{tabular}

\begin{tabular}{rrr}
$\begin{array}{c}\text { Fiber } \\
(\mathrm{g})\end{array}$ & $\begin{array}{r}\text { Fib-S } \\
\text { (g) }\end{array}$ & $\begin{array}{c}\text { Sugar } \\
(\mathrm{g})\end{array}$ \\
0.35 & -- & \multicolumn{1}{c}{5.60} \\
0 & 0 & - \\
0 & 0 & 9.17 \\
0 & 0 & 0 \\
0 & 0 & 0 \\
9.94 & -- & - \\
0 & 0 & 0.12 \\
4.54 & - & - \\
0.05 & -- & 3.98 \\
0.77 & 0.16 & 16.13 \\
0 & 0 & 0 \\
0.50 & -- & 0.50 \\
0.21 & 0.07 & 10.23 \\
0 & 0 & 0 \\
0 & 0 & 0 \\
0.94 & 0.30 & 7.27 \\
0.01 & -- & - \\
0.63 & 0.30 & 0.18 \\
0.17 & -- & 0 \\
2.33 & 0.47 & 0.74 \\
1.56 & 0.68 & 1.04 \\
0 & 0 & 17.33 \\
0 & 0 & 0 \\
1.28 & - & 0.32 \\
0 & 0 & 0.12 \\
0 & 0 & 0 \\
0 & 0 & 0 \\
2.10 & 0.28 & 0.37 \\
0.79 & 0.58 & 0.61 \\
0 & 0 & 0.04 \\
0 & 0 & 0.70 \\
0.19 & -- & 0 \\
0 & 0 & 7.81 \\
0.71 & 0.07 & 0.47
\end{tabular}

Total Weight: $12415.73 \mathrm{~g}$ (437.94 oz-wt.)

Serving Size: $4138.58 \mathrm{~g}$ (145.98 oz-wt.)

Serves: 3.00

\begin{tabular}{|c|c|c|c|c|c|c|c|}
\hline Amount & Food Item & $\begin{array}{l}\text { Fiber } \\
\text { (g) }\end{array}$ & $\begin{array}{c}\text { Fib-S } \\
\text { (g) }\end{array}$ & $\begin{array}{l}\text { Sugar } \\
(\mathrm{g})\end{array}$ & $\begin{array}{c}\text { MoSac } \\
\text { (g) }\end{array}$ & $\begin{array}{l}\text { DiSac } \\
(\mathrm{g})\end{array}$ & $\begin{array}{c}\text { OCarb } \\
\text { (g) }\end{array}$ \\
\hline 0.5 cup & HDShops Choc Peanut Butter Ice Cream PLB & 4.00 & - & 22.00 & - & - & 0 \\
\hline 0.66667 piece & Bernardi's Supreme Vegetable Lasagna WIN & 1.21 & - & - & - & - & - \\
\hline \multirow[t]{2}{*}{$25 \mathrm{fl} \mathrm{oz}$} & Water & 0 & 0 & 0 & 0 & 0 & 0 \\
\hline & Totals & 32.28 & 2.90 & 104.72 & 4.56 & 12.95 & 99.57 \\
\hline
\end{tabular}


Total Weight: $12415.73 \mathrm{~g}$ (437.94 oz-wt.)

Serving Size: $4138.58 \mathrm{~g}$ (145.98 oz-wt.)

Serves:

3.00

\begin{tabular}{|c|c|c|c|c|c|c|c|}
\hline & & & & & & & $\overline{\text { Spreadsheet }}$ \\
\hline & & Fat & Sat & Mono & Poly & TFA & Chol \\
\hline Amount & Food Item & & (g) & (g) & (g) & (g) & $(\mathrm{mg})$ \\
\hline 0.66667 each & Brownies w/Walnuts-Recipe-prep 2"square & 4.66 & 1.17 & 1.73 & 1.51 & - & 11.68 \\
\hline $4 \mathrm{fl} \mathrm{oz}$ & Diet Coke Soda Pop-Can/Bottlo CCO & 0 & 0 & 0 & 0 & 0 & 0 \\
\hline $3.33333 \mathrm{fl} \mathrm{oz}$ & Pure Prem Orange Juice + Calc-RTD TRO & 0 & 0 & 0 & 0 & 0 & 0 \\
\hline 1 cup & Brewed Coffee & 0.01 & 0.00 & 0 & 0.00 & 0 & 0 \\
\hline 1 tbs & Carnation Coffee Mate Non-Dairy Creamer & 1.50 & 1.50 & 0 & 0 & - & 0 \\
\hline 1 cup & Vegetarian Chili (Meat Substitute Used) & 4.21 & 0.60 & 1.29 & 1.80 & - & 0 \\
\hline 0.08333 cup & Cheddar Cheese-Shredded & 3.12 & 1.99 & 0.88 & 0.09 & 0.08 & 9.88 \\
\hline $0.25 \mathrm{lb}$ & Mixed Vegetables-Frozen (10oz Pkg) & 0.59 & 0.11 & 0.04 & 0.27 & 0 & 0 \\
\hline $1.33333 \mathrm{fl} \mathrm{oz}$ & Teriyaki Sauce-RTS & 0 & 0 & 0 & 0 & 0 & 0 \\
\hline 0.66667 piece & Yellow Cake w/Chocolate Icing & 7.42 & 1.99 & 4.09 & 0.90 & 1.28 & 23.47 \\
\hline $14.6667 \mathrm{fl} \mathrm{oz}$ & Water & 0 & 0 & 0 & 0 & 0 & 0 \\
\hline $1 \mathrm{oz}$-wt & Long Grain \& Wild Rice Blend-Dry UBI & 0.25 & 0 & - & - & - & 0 \\
\hline $3.33333 \mathrm{fl} \mathrm{oz}$ & Orange Juica-Chilled (incl.f/Conc)-Cup & 0.28 & 0.03 & 0.05 & 0.07 & 0 & 0 \\
\hline 0.66667 cup & Brewed Coffee & 0.00 & 0.00 & 0 & 0.00 & 0 & 0 \\
\hline $1 \mathrm{tbs}$ & Carnation Coffee Mate Non-Dairy Creamer & 1.50 & 1.50 & 0 & 0 & - & 0 \\
\hline 0.33333 each & Benana-Medium-Each & 0.19 & 0.07 & 0.02 & 0.04 & 0 & 0 \\
\hline 1 tbs & LoCal Caesar Salad Dressing & 0.66 & 0.11 & 0.17 & 0.36 & - & 0.30 \\
\hline 0.66667 cup & Romaine (Cos) Lettuce-Chopped-Cup & 0.07 & 0.01 & 0.00 & 0.04 & 0 & 0 \\
\hline 0.08333 cup & Seasoned Croutons & 0.61 & 0.17 & 0.32 & 0.08 & - & 0.23 \\
\hline 0.5 cup & Scalloped Potatoes-Homemade w/Margarine & 4.51 & 1.69 & 1.66 & 0.91 & 0 & 7.35 \\
\hline 0.33333 cup & Brocooli Pieces-Steamed & 0.18 & 0.03 & 0.01 & 0.09 & 0 & 0 \\
\hline 0.33333 cup & Ben\&Jerrys Ice CreamChocChipCookieDough & 10.67 & 6.67 & - & - & - & 43.33 \\
\hline $20 \mathrm{fl} \mathrm{oz}$ & Water & 0 & 0 & 0 & 0 & 0 & 0 \\
\hline 0.33333 cup & Hot Natural Whole/Rolled Wheat-Ckd & 0.32 & 0.05 & 0.05 & 0.16 & - & 0 \\
\hline 0.08333 cup & Cheddar Cheese-Shredded & 3.12 & 1.99 & 0.88 & 0.09 & 0.08 & 9.88 \\
\hline 0.66667 cup & Brewed Coffee & 0.00 & 0.00 & 0 & 0.00 & 0 & 0 \\
\hline 1 tbs & Camnation Coffee Mate Non-Dairy Creamer & 1.50 & 1.50 & 0 & 0 & - & 0 \\
\hline 0.33333 cup & Whole Wheat Spaghetti Noodles-Ckd & 0.25 & 0.05 & 0.03 & 0.10 & -- & 0 \\
\hline 0.33333 cup & Spaghetti Noodles-Enr-Ckd & 0.31 & 0.04 & 0.04 & 0.13 & - & 0 \\
\hline 0.33333 tbs & Hard Margarine-Soybean(Hydro\&Reg) & 3.78 & 0.62 & 1.77 & 1.23 & 1.69 & 0 \\
\hline 0.25 cup & Mozzarella Cheese-WhilMilk-LoMoist-Shred & 6.96 & 4.40 & 1.99 & 0.22 & - & 25.26 \\
\hline 1 tbs & All Purpose Flour-Unbleached-Enr PLB & 0 & 0 & 0 & 0 & 0 & 0 \\
\hline 0.66667 cup & $2 \%$ Fat Milk-Vitamin A Added & 3.12 & 1.94 & 0.90 & 0.12 & 0.08 & 12.20 \\
\hline 0.33333 cup & Broccoli Flowerets-Raw-Cup & 0.08 & 0.01 & 0.01 & 0.04 & 0 & 0 \\
\hline
\end{tabular}

Total Weight: $12415.73 \mathrm{~g}$ (437.94 oz-wt.)

Serving Size: $4138.58 \mathrm{~g}$ (145.98 oz-wt.)

Serves: $\quad 3.00$

\begin{tabular}{|c|c|c|c|c|c|c|c|}
\hline Amount & $\begin{array}{c}\text { Food Item } \\
\end{array}$ & $\begin{array}{l}\text { Fat } \\
\text { (g) }\end{array}$ & $\begin{array}{l}\text { Sat } \\
\text { (g) }\end{array}$ & $\begin{array}{l}\text { Mono } \\
\text { (g) }\end{array}$ & $\begin{array}{l}\text { Poly } \\
\text { (g) }\end{array}$ & $\begin{array}{l}\text { TFA } \\
\text { (g) }\end{array}$ & $\begin{array}{l}\text { Chol } \\
\text { (mg) }\end{array}$ \\
\hline 0.5 cup & HDShops Choc Peanut Butter Ice Cream PLB & 24.00 & 11.00 & - & - & - & 80.00 \\
\hline \multirow[t]{3}{*}{$\begin{array}{l}0.0006 \mathrm{fplecos} \\
25 \mathrm{floz}\end{array}$} & $\begin{array}{l}\text { Bernardi's Supreme Vegetable Lasagna WIN } \\
\text { Water }\end{array}$ & $\begin{array}{r}12.40 \\
0\end{array}$ & $\begin{array}{r}7.82 \\
0\end{array}$ & $\overline{0}$ & $\overline{0}$ & $\overline{0}$ & 43.09 \\
\hline & & 0 & 0 & 0 & 0 & & 0 \\
\hline & Totals & 96.29 & 47.04 & 15.92 & 8.23 & 3.22 & 266.67 \\
\hline
\end{tabular}


Total Weight: $12415.73 \mathrm{~g}(437.94 \mathrm{oz}-\mathrm{wt}$ )

Serving Size: $4138.58 \mathrm{~g}$ (145.98 oz-wt.)

Serves:

3.00

\begin{tabular}{|c|c|c|c|c|c|c|c|}
\hline & & & & & & & Spreadsheet \\
\hline Amount & Food Item & $\begin{array}{l}\mathrm{H} 2 \mathrm{O} \\
(\mathrm{g})\end{array}$ & $\begin{array}{l}\text { A-RE } \\
\text { (RE) }\end{array}$ & $\begin{array}{c}\text { A-Car } \\
\text { (RE) }\end{array}$ & $\begin{array}{c}\text { A-Pre } \\
\text { (RE) }\end{array}$ & $\begin{array}{l}\text { A-Bet } \\
\text { (mcg) }\end{array}$ & $\begin{array}{c}\mathrm{B} 1 \\
(\mathrm{mg})\end{array}$ \\
\hline 0.66667 each & Brownies w/Walnuts-Recipe-prep 2"square & 2.02 & 31.84 & 2.40 & 29.44 & - & 0.02 \\
\hline $4 \mathrm{fl} \mathrm{oz}$ & Diet Coke Soda Pop-Can/Bottle CCO & 119.69 & 0 & 0 & 0 & 0 & 0.01 \\
\hline $3.33333 \mathrm{fl} \mathrm{oz}$ & Pure Prem Orange Juice + Calc-RTD TRO & 91.17 & 0 & 0 & 0 & 0 & 0.06 \\
\hline 1 cup & Brewed Coffee & 235.34 & 0 & 0 & 0 & 0 & 0 \\
\hline 1 tos & Camation Coffee Mate Non-Dairy Creamer & - & 0 & 0 & 0 & 0 & -- \\
\hline 1 cup & Vegetarian Chili (Meat Substitute Used) & 138.41 & 148.29 & 148.29 & 0 & - & 0.24 \\
\hline 0.08333 cup & Cheddar Cheese-Shredded & 3.46 & 26.18 & 2.64 & 23.54 & -- & 0.00 \\
\hline $0.25 \mathrm{lb}$ & Mixed Vegetables-Frozen (10oz Pkg) & 93.08 & 576.07 & 576.07 & 0 & 2955.20 & 0.14 \\
\hline $1.33333 \mathrm{fl} \mathrm{oz}$ & Teriyaki Sauce-RTS & 32.49 & 0 & 0 & 0 & 0 & 0.01 \\
\hline 0.66667 piece & Yellow Cake w/Chocolate Icing & 9.34 & 14.08 & 0 & 14.08 & 0 & 0.05 \\
\hline $14.6667 \mathrm{fl} \mathrm{oz}$ & Water & 434.07 & 0 & 0 & 0 & 0 & 0 \\
\hline 1 oz-wt & Long Grain \& Wild Rice Blend-Dry UBI & 3.52 & - & - & - & -- & - \\
\hline $3.33333 \mathrm{fl} \mathrm{oz}$ & Orange Juica-Chilled (incl.f/Conc)-Cup & 91.72 & 8.30 & 8.30 & 0 & 15.46 & 0.12 \\
\hline 0.66667 cup & Brewed Coffee & 156.89 & 0 & 0 & 0 & 0 & 0 \\
\hline 1 tbs & Camation Coffee Mate Non-Dairy Creamer & - & 0 & 0 & 0 & 0 & - \\
\hline 0.33333 each & Banana-Medium-Each & 29.21 & 3.15 & 3.15 & 0 & 18.88 & 0.02 \\
\hline $1 \mathrm{tbs}$ & LoCal Caesar Salad Dressing & 10.98 & 0.30 & 0.30 & 0 & - & 0.00 \\
\hline 0.66667 cup & Romaine (Cos) Lettuce-Chopped-Cup & 35.43 & 97.07 & 97.07 & 0 & 582.40 & 0.04 \\
\hline 0.08333 cup & Seasoned Croutons & 0.12 & 0.33 & - & - & -. & 0.02 \\
\hline 0.5 cup & Scalloped Potatoes-Homemade w/Margarine & 99.15 & 23.28 & - & - & - & 0.08 \\
\hline 0.33333 cup & Brocooli Pieces-Steamed & 47,16 & 76.02 & 76.02 & 0 & 452.92 & 0.03 \\
\hline 0.33333 cup & Ben\& Jerrys Ice CreamChocChipCookieDough & 32.73 & 100.00 & -- & - & - & -- \\
\hline $20 \mathrm{fl} \mathrm{oz}$ & Water & 591.91 & 0 & 0 & 0 & 0 & 0 \\
\hline 0.33333 cup & Hot Natural Whole/Rolled Wheat-Ckd & 66.88 & 0 & 0 & 0 & 0 & 0.06 \\
\hline 0.08333 cup & Cheddar Cheese-Shredded & 3.46 & 26.18 & 2.64 & 23.54 & - & 0.00 \\
\hline 0.66667 cup & Brewed Coffee & 156.89 & 0 & 0 & 0 & 0 & 0 \\
\hline 1 tbs & Carnation Coffee Mate Non-Dairy Creamer & -. & 0 & 0 & 0 & 0 & - \\
\hline 0.33333 cup & Whole Wheat Spaghetti Noodles-Ckd & 31.34 & 0 & 0 & 0 & 0 & 0.05 \\
\hline 0.33333 cup & Spaghetti Noodles-Enr-Ckd & 30.80 & 0 & 0 & 0 & 0 & 0.10 \\
\hline 0.33333 tbs & Hard Margarine-Soybean(Hydro\&Reg) & 0.74 & 37.55 & 6.02 & 31.54 & - & 0.00 \\
\hline 0.25 cup & Mozzarella Cheese-WhlMilk-LoMoist-Shred & 13.67 & 77.41 & 17.52 & 59.89 & - & 0.00 \\
\hline $1 \mathrm{tbs}$ & All Purpose Flour-Unbleached-Enr PLB & 1.21 & 0 & 0 & 0 & 0 & 0.04 \\
\hline 0.66667 cup & $2 \%$ Fat Milk-Vitamin A Added & 145.11 & 92.72 & 6.51 & 86.21 & - & 0.06 \\
\hline 0.33333 cup & Broccoli Flowerets-Raw-Cup & 21.46 & 36.45 & 36.45 & 0 & 217.02 & 0.02 \\
\hline
\end{tabular}

Total Weight: $12415.73 \mathrm{~g}$ (437.94 oz-wt.)

Serving Size: $4138.58 \mathrm{~g}(145.98 \mathrm{oz}-\mathrm{wt}$.)

Serves: 3.00

\begin{tabular}{|c|c|c|c|c|c|c|c|}
\hline Amount & Food Item & $\begin{array}{c}\mathrm{H} 2 \mathrm{O} \\
\text { (g) }\end{array}$ & $\begin{array}{c}\text { A-RE } \\
\text { (RE) }\end{array}$ & $\begin{array}{l}\text { A-Car } \\
\text { (RE) }\end{array}$ & $\begin{array}{l}\text { A-Pre } \\
\text { (RE) }\end{array}$ & $\begin{array}{l}\text { A-Bet } \\
\text { (mcg) }\end{array}$ & $\begin{array}{c}\mathrm{B} 1 \\
(\mathrm{mg})\end{array}$ \\
\hline $\begin{array}{c}0.5 \text { cup } \\
0.66667 \text { piece }\end{array}$ & $\begin{array}{l}\text { HDShops Choc Peanut Butter Ice Cream PLB } \\
\text { Bernardi's Supreme Vegetele }\end{array}$ & 42.47 & 100.00 & - & - & - & - \\
\hline \multirow{3}{*}{$25 \mathrm{fl} \mathrm{oz}$} & $\begin{array}{l}\text { Bemardi's Supreme Vegetable Lasagna WIN } \\
\text { Water }\end{array}$ & $\begin{array}{l}101.47 \\
73988\end{array}$ & $\overline{0}$ & $\overline{0}$ & - & - & $\overline{-}$ \\
\hline & & 739.88 & 0 & 0 & 0 & 0 & 0 \\
\hline & Totals & 3613.28 & 1475.21 & 983.36 & 268.24 & 4241.89 & 1.18 \\
\hline
\end{tabular}


Serves:

\begin{tabular}{|c|c|c|c|c|c|c|c|}
\hline & & & & & & & Spreadsheet \\
\hline Amount & Food Item & $\begin{array}{c}\mathrm{B} 2 \\
(\mathrm{mg})\end{array}$ & $\begin{array}{c}\mathrm{B} 3 \\
(\mathrm{mg})\end{array}$ & $\begin{array}{c}\text { B3-NE } \\
(\mathrm{mg})\end{array}$ & $\begin{array}{c}\text { B6 } \\
(\mathrm{mg})\end{array}$ & $\begin{array}{c}\mathrm{B} 12 \\
\text { (mcg) }\end{array}$ & $\begin{array}{l}\text { Vit C } \\
(\mathrm{mg})\end{array}$ \\
\hline 0.66667 each & Brownies w/Walnuts-Recipe-prep 2"square & 0.03 & 0.16 & 0.37 & 0.02 & 0.03 & 0.05 \\
\hline $4 \mathrm{fl} \mathrm{oz}$ & Diet Coke Soda Pop-Can/Bottle CCO & 0.02 & 0 & 0 & 0 & 0 & 0 \\
\hline $3.33333 \mathrm{fl} \mathrm{oz}$ & Pure Prem Orange Juice + Calc-RTD TRO & - & 0.33 & 0.33 & 0.05 & - & 45.00 \\
\hline 1 cup & Brewed Coffee & 0 & 0.53 & 0.53 & 0 & 0 & 0 \\
\hline 1 ths & Carnation Coffee Mate Non-Dairy Creamer & - & - & - & - & -- & 0 \\
\hline 1 cup & Vegetarian Chili (Meat Substitute Used) & 0.13 & 2.43 & 2.43 & 0.30 & 0 & 11.04 \\
\hline 0.08333 cup & Cheddar Cheese-Shredded & 0.04 & 0.01 & 0.43 & 0.01 & 0.08 & 0 \\
\hline $0.25 \mathrm{lb}$ & Mixed Vegetables-Frozen (10oz Pkg) & 0.10 & 1.42 & 2.06 & 0.11 & 0 & 11.79 \\
\hline $1.33333 \mathrm{fl} \mathrm{oz}$ & Teriyaki Sauce-RTS & 0.03 & 0.61 & 0.61 & 0.05 & 0 & 0 \\
\hline 0.66667 piece & Yellow Cake w/Chocolate Icing & 0.07 & 0.53 & 0.89 & 0.01 & 0.07 & 0 \\
\hline $14.6667 \mathrm{fl} \mathrm{oz}$ & Water & 0 & 0 & 0 & 0 & 0 & 0 \\
\hline $1 \mathrm{oz}$-wt & Long Grain \& Wild Rice Blend-Dry UBI & - & - & - & - & - & - \\
\hline $3.33333 \mathrm{fl} \mathrm{oz}$ & Orange Juice-Chilled (incl.f/Conc)-Cup & 0.02 & 0.29 & 0.31 & 0.06 & 0 & 34.13 \\
\hline 0.66667 cup & Brewed Coffee & 0 & 0.35 & 0.35 & 0 & 0 & 0 \\
\hline 1 tbs & Carnation Coffee Mate Non-Dairy Creamer & - & - & - & - & - & 0 \\
\hline 0.33333 each & Banana-Medium-Each & 0.04 & 0.21 & 0.29 & 0.23 & 0 & 3.58 \\
\hline 1 tbs & LoCal Caesar Salad Dressing & 0.00 & 0.01 & 0.01 & 0 & 0.00 & 0 \\
\hline 0.66667 cup & Romaine (Cos) Lettuce-Chopped-Cup & 0.04 & 0.19 & 0.26 & 0.02 & 0 & 8.96 \\
\hline 0.08333 cup & Seasoned Croutons & 0.01 & 0.15 & 0.22 & 0.00 & 0.00 & 0 \\
\hline 0.5 cup & Scalloped Potatoes-Homemade w/Margarine & 0.11 & 1.29 & 2.09 & 0.22 & 0 & 12.99 \\
\hline 0.33333 cup & Brocooli Pieces-Steamed & 0.06 & 0.31 & 0.57 & 0.07 & 0 & 41.13 \\
\hline 0.33333 cup & Ben\&Jerrys Ice CreamChocChipCookieDough & - & - & - & - & -. & 0 \\
\hline $20 \mathrm{fl} \mathrm{oz}$ & Water & 0 & 0 & 0 & 0 & 0 & 0 \\
\hline 0.33333 cup & Hot Natural Whole/Rolled Wheat-Ckd & 0.04 & 0.71 & 1.12 & 0.06 & 0 & 0 \\
\hline 0.08333 cup & Cheddar Cheese-Shredded & 0.04 & 0.01 & 0.43 & 0.01 & 0.08 & 0 \\
\hline 0.66667 cup & Brewed Coffee & 0 & 0.35 & 0.35 & 0 & 0 & 0 \\
\hline 1 tbs & Carnation Coffee Mate Non-Dairy Creamer & - & -. & - & - & - & 0 \\
\hline 0.33333 cup & Whole Wheat Spaghetti Noodles-Ckd & 0.02 & 0.33 & 0.87 & 0.04 & 0 & 0 \\
\hline 0.33333 cup & Spaghetti Noodles-Enr-Ckd & 0.05 & 0.78 & 1.25 & 0.02 & 0 & 0 \\
\hline 0.33333 tbs & Hard Margarine-Soybean(Hydro\&Reg) & 0.00 & 0.00 & 0.01 & 0.00 & 0.00 & 0.01 \\
\hline 0.25 cup & Mozzarella Cheese-WhilMilk-LoMoist-Shred & 0.08 & 0.03 & 1.20 & 0.02 & 0.21 & 0 \\
\hline 1 ths & All Purpose Flour-Unbleached-Enr PLB & 0.03 & 0.40 & 0.40 & - & -_. & 0 \\
\hline 0.66667 cup & $2 \%$ Fat Milk-Vitamin A Added & 0.27 & 0.14 & 1.29 & 0.07 & 0.59 & 1.55 \\
\hline 0.33333 cup & Broccoli Flowerets-Raw-Cup & 0.03 & 0.15 & 0.27 & 0.04 & 0 & 22.06 \\
\hline
\end{tabular}

Total Weight: $12415.73 \mathrm{~g}(437.94 \mathrm{oz}$-wt.)

Serving Size: $4138.58 \mathrm{~g}(145.98 \mathrm{oz}$-wt.)

Serves: 3.00

\begin{tabular}{|c|c|c|c|c|c|c|c|}
\hline Amount & Food Item & $\begin{array}{c}\mathrm{B} 2 \\
(\mathrm{mg})\end{array}$ & $\begin{array}{c}\mathrm{B} 3 \\
(\mathrm{mg})\end{array}$ & $\begin{array}{c}\text { B3-NE } \\
\text { (mg) }\end{array}$ & $\begin{array}{c}\mathrm{B} 6 \\
(\mathrm{mg})\end{array}$ & $\begin{array}{c}\mathrm{B} 12 \\
(\mathrm{mcg})\end{array}$ & $\begin{array}{l}\text { Vit C } \\
\text { (mg) }\end{array}$ \\
\hline $\begin{array}{c}0.5 \text { cup } \\
0.66667 \text { piece }\end{array}$ & HDShops Choc Peanut Butter Ice Cream PLB & - & - & - & - & - & 0 \\
\hline $\begin{array}{r}0.66667 \text { piece } \\
25 \mathrm{fl} \mathrm{oz}\end{array}$ & $\begin{array}{l}\text { Bernardi's Supreme Vegetable Lasagna WIN } \\
\text { Water }\end{array}$ & $\overline{0}$ & $\ddot{n}$ & $\overline{-}$ & - & - & - \\
\hline \multirow{2}{*}{$25 \mathrm{fl} \mathrm{oz}$} & Water & 0 & 0 & 0 & 0 & 0 & 0 \\
\hline & Totals & 1.25 & 11.72 & 18.94 & 1.38 & 1.07 & 192.29 \\
\hline
\end{tabular}


Total Weight: $12415.73 \mathrm{~g}$ (437.94 oz-wt.)

Serving Size: $4138.58 \mathrm{~g}$ (145.98 oz-wt.)

Serves: 3.00

\begin{tabular}{|c|c|c|c|c|c|c|c|}
\hline & & & & & & & Spreadsheet \\
\hline Amount & Food Item & $\begin{array}{c}\text { D-mcg } \\
\text { (mcg) }\end{array}$ & $\begin{array}{c}\text { E-aTE } \\
(\mathrm{mg})\end{array}$ & $\begin{array}{c}\text { Fola } \\
\text { (mcg) }\end{array}$ & $\begin{array}{l}\text { Panto } \\
\text { (mg) }\end{array}$ & $\begin{array}{l}\text { Calc } \\
(\mathrm{mg})\end{array}$ & $\begin{array}{l}\text { Copp } \\
\text { (mg) }\end{array}$ \\
\hline 0.66667 each & Brownies w/Walnuts-Recipe-prep 2"square & 0.03 & 0.46 & 4.64 & 0.05 & 9.12 & 0.06 \\
\hline $4 \mathrm{fl} \mathrm{oz}$ & Diet Coke Soda Pop-Can/Bottle CCO & 0 & 0 & 0 & - & 4.79 & 0.01 \\
\hline $3.33333 \mathrm{fl} \mathrm{oz}$ & Pure Prem Orange Juice + Calc-RTD TRO & - & 0 & 25.00 & - & 145.83 & - \\
\hline 1 cup & Brewed Coffee & 0 & 0 & 0.24 & 0.00 & 4.74 & 0.02 \\
\hline 1 tbs & Carnation Coffee Mate Non-Dairy Creamer & - & - & - & - & 0 & - \\
\hline 1 cup & Vegetarian Chili (Meat Substitute Used) & 0 & 2.55 & 164.54 & 0.43 & 107.50 & 0.92 \\
\hline 0.08333 cup & Cheddar Cheese-Shredded & 0.03 & 0.03 & 1.71 & 0.04 & 67.92 & 0.00 \\
\hline $0.25 \mathrm{lb}$ & Mixed Vegetables-Frozen (10oz Pkg) & 0 & 0.34 & 32.89 & 0.18 & 28.35 & 0.11 \\
\hline $1.33333 \mathrm{fl} \mathrm{oz}$ & Teriyaki Sauce-RTS & 0 & 0 & 9.60 & 0.10 & 12.00 & 0.05 \\
\hline 0.66667 piece & Yellow Cake w/Chocolate Icing & 0.17 & 0.97 & 9.39 & 0.12 & 15.79 & 0.08 \\
\hline $14.6667 \mathrm{fl} \mathrm{oz}$ & Water & 0 & 0 & 0 & 0 & 8.69 & 0.03 \\
\hline $10 z$-wt & Long Grain \& Wild Rice Blend-Dry UBI & - & - & - & -- & 14.27 & - \\
\hline $3.33333 \mathrm{fl} \mathrm{oz}$ & Orange Juice-Chilled (incl.f/Conc)-Cup & 0 & 0.20 & 18.78 & 0.20 & 10.38 & 0.04 \\
\hline 0.66667 cup & Brewed Coffee & 0 & 0 & 0.16 & 0.00 & 3.16 & 0.01 \\
\hline 1 tbs & Carnation Coffee Mate Non-Dairy Creamer & - & -- & - & - & 0 & - \\
\hline 0.33333 each & Banana-Medium-Each & 0 & 0.11 & 7.51 & 0.10 & 2.36 & 0.04 \\
\hline 1 ths & LoCal Caesar Salad Dressing & 0 & 0.06 & 0.30 & - & 3.60 & 0.00 \\
\hline 0.66667 cup & Romaine (Cos) Lettuce-Chopped-Cup & 0 & 0.16 & 50.66 & 0.06 & 13.44 & 0.01 \\
\hline 0.08333 cup & Seasoned Croutons & 0 & 0.07 & 2.93 & 0.03 & 3.20 & 0.01 \\
\hline 0.5 cup & Scalloped Potatoes-Homemade w/Margarine & 0.50 & 0.40 & 13.48 & 0.63 & 69.83 & 0.20 \\
\hline 0.33333 cup & Brocooli Pieces-Steamed & 0 & 0.25 & 31.30 & 0.26 & 24.91 & 0.02 \\
\hline 0.33333 cup & Ben\&Jerrys Ice CreamChocChipCookieDough & - & - & - & - & 66.67 & - \\
\hline $20 \mathrm{fl} \mathrm{oz}$ & Water & 0 & 0 & 0 & 0 & 11.85 & 0.04 \\
\hline 0.33333 cup & Hot Natural Whole/Rolled Wheat-Ckd & 0 & 0.16 & 8.80 & 0.13 & 5.60 & 0.07 \\
\hline 0.08333 cup & Cheddar Cheese-Shredded & 0.03 & 0.03 & 1.71 & 0.04 & 67.92 & 0.00 \\
\hline 0.66667 cup & Brewed Coffee & 0 & 0 & 0.16 & 0.00 & 3.16 & 0.01 \\
\hline 1 tbs & Carnation Coffee Mate Non-Dairy Creamer & - & - & - & -- & 0 & - \\
\hline 0.33333 cup & Whole Wheat Spaghetti Noodles-Ckd & 0 & 0.02 & 2.33 & 0.20 & 7.00 & 0.08 \\
\hline 0.33333 cup & Spaghetti Noodles-Enr-Ckd & 0 & 0.03 & 32.67 & 0.05 & 3.27 & 0.05 \\
\hline $0.33333 \mathrm{tbs}$ & Hard Margarine-Soybean(Hydro\& Reg) & - & 0.60 & 0.06 & 0.00 & 1.41 & 0 \\
\hline 0.25 cup & Mozzarella Cheese-WhlMilk-LoMoist-Shred & 0.05 & 0.19 & 2.20 & 0.02 & 162.41 & 0.01 \\
\hline 1 tbs & All Purpose Flour-Unbleached-Enr PLB & - & $-\overline{-}$ & 10.00 & - & 0 & - \\
\hline 0.66667 cup & $2 \%$ Fat Milk-Vitamin A Added & 1.63 & 0.11 & 8.30 & 0.52 & 197.80 & 0.01 \\
\hline 0.33333 cup & Broccoli Flowerets-Raw-Cup & 0 & 0.39 & 16.80 & 0.13 & 11.36 & 0.01 \\
\hline
\end{tabular}

Total Weight: $12415.73 \mathrm{~g}$ (437.94 oz-wt.)

Serving Size: $4138.58 \mathrm{~g}$ (145.98 oz-wt.)

Serves: $\quad 3.00$

\begin{tabular}{|c|c|c|c|c|c|c|c|}
\hline Amount & Food Item & $\begin{array}{l}\text { D-mcg } \\
\text { (mcg) }\end{array}$ & $\begin{array}{c}\text { E-aTE } \\
(\mathrm{mg})\end{array}$ & $\begin{array}{c}\text { Fola } \\
(\mathrm{mcg})\end{array}$ & $\begin{array}{c}\text { Panto } \\
\text { (mg) }\end{array}$ & $\begin{array}{l}\text { Calc } \\
(\mathrm{mg})\end{array}$ & $\begin{array}{l}\text { Copp } \\
(\mathrm{mg})\end{array}$ \\
\hline $\begin{array}{c}0.5 \text { cup } \\
0.66667 \text { piece }\end{array}$ & $\begin{array}{l}\text { HDShops Choc Peanut Butter Ice Cream PLB } \\
\text { Bernardi's Supreme Vegetable Lasagna WIN }\end{array}$ & - & - & - & - & 100.00 & - \\
\hline \multirow[t]{2}{*}{25 fl oz } & Water & $\overline{0}$ & $\overline{0}$ & $\overline{0}$ & $\overline{0}$ & 366.21 & - \\
\hline & Totals & 2.43 & 7.14 & 45616 & & & \\
\hline
\end{tabular}


Total Weight: $12415.73 \mathrm{~g}$ (437.94 oz-wt.)

Serving Size: $4138.58 \mathrm{~g}(145.98 \mathrm{oz}-\mathrm{wt}$.)

Serves:

3.00

\begin{tabular}{|c|c|c|c|c|c|c|c|}
\hline & & & & & & & Spreadsheet \\
\hline Amount & Food Item & $\begin{array}{l}\text { Iron } \\
(\mathrm{mg})\end{array}$ & $\begin{array}{l}\text { Mag } \\
(\mathrm{mg})\end{array}$ & $\begin{array}{c}\text { Mang } \\
(\mathrm{mg})\end{array}$ & $\begin{array}{l}\text { Phos } \\
(\mathrm{mg})\end{array}$ & $\begin{array}{c}\text { Potas } \\
(\mathrm{mg})\end{array}$ & $\underset{(\mathrm{mcg})}{\mathrm{Sel}}$ \\
\hline 0.66667 each & Brownies w/Walnuts-Recipe-prep 2"square & 0.29 & 8.48 & 0.09 & 21.12 & 28.16 & 1.84 \\
\hline $4 \mathrm{fl} \mathrm{oz}$ & Diet Coke Soda Pop-Can/Bottle CCO & 0.04 & 1.19 & -- & 9.00 & 6.00 & - \\
\hline $3.33333 \mathrm{fl} \mathrm{oz}$ & Pure Prem Orange Juice + Calc-RTD TRO & 0 & - & - & - & 187.50 & - \\
\hline 1 cup & Brewed Coffee & 0.12 & 11.85 & 0.06 & 2.37 & 127.98 & 0.24 \\
\hline $1 \mathrm{tbs}$ & Camation Coffee Mate Non-Dairy Creamer & 0 & - & - & - & - & - \\
\hline 1 cup & Vegetarian Chili (Meat Substitute Used) & 8.75 & 71.25 & 1.07 & 434.71 & 730.47 & - \\
\hline 0.08333 cup & Cheddar Cheese-Shredded & 0.06 & 2.62 & 0.00 & 48.22 & 9.27 & 1.31 \\
\hline $0.25 \mathrm{lb}$ & Mixed Vegetables-Frozen (10oz Pkg) & 1.08 & 27.22 & 0.28 & 66.91 & 240.41 & 0.45 \\
\hline $1.33333 \mathrm{fl} \mathrm{oz}$ & Teriyaki Sauce-RTS & 0.82 & 29.28 & 0 & 73.92 & 108.00 & 0.53 \\
\hline 0.66667 piece & Yellow Cake w/Chocolate Icing & 0.89 & 12,80 & 0.11 & 68.69 & 75.95 & 1.45 \\
\hline $14.6667 \mathrm{fl} \mathrm{oz}$ & Water & 0.04 & 4.35 & 0.00 & 0 & 0 & 0 \\
\hline 1 oz-wt & Long Grain \& Wild Rice Blend-Dry UBI & 0.81 & - & -- & - & - & - \\
\hline $3.33333 \mathrm{fl} \mathrm{oz}$ & Orange Juice-Chilled (inct.f/Conc)-Cup & 0.18 & 11.41 & 0.02 & 11.41 & 197.13 & 0.10 \\
\hline 0.66667 cup & Brewed Coffee & 0.08 & 7.90 & 0.04 & 1.58 & 85.32 & 0.16 \\
\hline $1 \mathrm{tbs}$ & Carnation Coffee Mate Non-Dairy Creamer & 0 & -- & -- & -- & -- & - \\
\hline 0.33333 each & Banana-Medium-Each & 0.12 & 11.41 & 0.06 & 7.87 & 155.76 & 0.43 \\
\hline $1 \mathrm{tbs}$ & LoCal Caesar Salad Dressing & 0.03 & 0.30 & 0.00 & 2.85 & 4.35 & - \\
\hline 0.66667 cup & Romaine (Cos) Lettuce-Chopped-Cup & 0.41 & 2.24 & 0.24 & 16.80 & 108.27 & 0.07 \\
\hline 0.08333 cup & Seasoned Croutons & 0.09 & 1.40 & 0.02 & 4.67 & 6.03 & 0.96 \\
\hline 0.5 cup & Scalloped Potatoes-Homemade w/Margarine & 0.70 & 23.28 & 0.20 & 77.18 & 463.05 & 1.96 \\
\hline 0.33333 cup & Broccoli Pieces-Steamed & 0.46 & 13.00 & 0.11 & 34.27 & 168.48 & - \\
\hline 0.33333 cup & Ben\&Jerrys Ice CreamChooChipCookieDough & 0.72 & - & - & - & - & - \\
\hline $20 \mathrm{fl} \mathrm{oz}$ & Water & 0.06 & 5.93 & 0.01 & 0 & 0 & 0 \\
\hline 0.33333 cup & Hot Natural Whole/Rolled Wheat-Ckd & 0.50 & 17.60 & 0.47 & 55.20 & 56.80 & 8.88 \\
\hline 0.08333 cup & Cheddar Cheese-Shredded & 0.06 & 2.62 & 0.00 & 48.22 & 9.27 & 1.31 \\
\hline 0.66667 cup & Brewed Coffee & 0.08 & 7.90 & 0.04 & 1.58 & 85.32 & 0.16 \\
\hline 1 tbs & Carnation Coffee Mate Non-Dairy Creamer & 0 & - & -- & -- & - & - \\
\hline 0.33333 cup & Whole Wheat Spaghetti Noodles-Ckd & 0.49 & 14.00 & 0.64 & 41.53 & 20.53 & 12.09 \\
\hline 0.33333 cup & Spaghetti Noodles-Enr-Ckd & 0.65 & 8.40 & 0.13 & 25.20 & 14.47 & 9.94 \\
\hline 0.33333 tbs & Hard Margarine-Soybean(Hydro\&Reg) & 0 & 0.12 & 0.00 & 1.08 & 1.99 & 0 \\
\hline 0.25 cup & Mozzarella Cheese-WhilMilk-LoMoist-Shred & 0.06 & 5.84 & 0.00 & 116.47 & 21.07 & 4.55 \\
\hline 1 tbs & All Purpose Flour-Unbleached-Enr PLB & 0.36 & -- & - & -- & - & -- \\
\hline 0.66667 cup & $2 \%$ Fat Milk-Vitamin A Added & 0.08 & 22.24 & 0.00 & 154.70 & 251.16 & 3.58 \\
\hline 0.33333 cup & Brocooli Flowerets-Raw-Cup & 0.21 & 5.92 & 0.05 & 15.62 & 76.92 & 0.71 \\
\hline
\end{tabular}

Total Weight: $12415.73 \mathrm{~g}$ (437.94 oz-wt.)

Serving Size: $4138.58 \mathrm{~g}$ (145.98 oz-wt.)

Serves: $\quad 3.00$

\begin{tabular}{|c|c|c|c|c|c|c|c|}
\hline Amount & $\begin{array}{c}\text { Food Item } \\
\end{array}$ & $\begin{array}{l}\text { Iron } \\
\text { (mg) }\end{array}$ & $\begin{array}{l}\text { Mag } \\
(\mathrm{mg})\end{array}$ & $\begin{array}{c}\text { Mang } \\
\text { (mg) }\end{array}$ & $\begin{array}{l}\text { Phos } \\
\text { (mg) }\end{array}$ & $\begin{array}{l}\text { Potas } \\
\text { (mg) }\end{array}$ & $\begin{array}{c}\text { Sel } \\
(\mathrm{mcg})\end{array}$ \\
\hline $\begin{array}{c}0.5 \text { cup } \\
0.66667 \text { piece }\end{array}$ & $\begin{array}{l}\text { HDShops Choc Peanut Butter Ice Crean PLB } \\
\text { Bernardi's Supreme Vegetable Lasagna }\end{array}$ & 1.44 & - & - & - & - & - \\
\hline $25 \mathrm{fl} \mathrm{oz}$ & $\begin{array}{l}\text { Bernardh's Supreme Vegetable Lasagna WIN } \\
\text { Water }\end{array}$ & $\begin{array}{l}0.82 \\
0.07\end{array}$ & $7 . \overline{41}$ & $0 . \overline{01}$ & $\overline{0}$ & $\overline{0}$ & $\overline{0}$ \\
\hline & Totals & 20.56 & 337.93 & 3.68 & 1341.16 & 3239.64 & 50.72 \\
\hline
\end{tabular}


Total Weight: $12415.73 \mathrm{~g}$ (437.94 oz-wt.)

Serving Size: $4138.58 \mathrm{~g}$ (145.98 oz-wt.)

Serves:

3.00

\begin{tabular}{|c|c|c|c|c|c|c|c|}
\hline & & & & & & & Spreadsheet \\
\hline Amount & Food Item & $\begin{array}{l}\text { Sod } \\
(\mathrm{mg})\end{array}$ & $\begin{array}{l}\text { Zinc } \\
\text { (mg) }\end{array}$ & $\begin{array}{l}\text { Omeg3 } \\
\text { (g) }\end{array}$ & $\begin{array}{c}\text { Omeg6 } \\
\text { (g) }\end{array}$ & $\begin{array}{l}\text { Alco } \\
(g)\end{array}$ & $\begin{array}{l}\text { Caff } \\
(\mathrm{mg})\end{array}$ \\
\hline 0.66667 each & Brownies w/Walnuts-Recipe-prep 2"square & 54.88 & 0.16 & 0.15 & 1.36 & 0 & (mg) \\
\hline $4 \mathrm{fl} \mathrm{oz}$ & Diet Coke Soda Pop-Can/Bottle CCO & 2.00 & 0.10 & 0 & 0 & 0 & 15.50 \\
\hline $3.33333 \mathrm{fl} \mathrm{oz}$ & Pure Prem Orange Juice + Calc-RTD TRO & 0 & - & 0 & 0 & 0 & 0 \\
\hline 1 cup & Brewed Coffee & 4.74 & 0.05 & 0 & 0.00 & 0 & 137.46 \\
\hline $1 \mathrm{tbs}$ & Carnation Coffee Mate Non-Dairy Creamer & 0 & - & 0 & 0 & 0 & 0 \\
\hline 1 cup & Vegetarian Chili (Meat Substitute Used) & 709.42 & 2.53 & - & - & 0 & 0 \\
\hline 0.08333 cup & Cheddar Cheese-Shredded & 58.43 & 0.29 & 0.03 & 0.05 & 0 & 0 \\
\hline $0.25 \mathrm{lb}$ & Mixed Vegetables-Frozen (10oz Pkg) & 53.30 & 0.51 & 0.07 & 0.20 & 0 & 0 \\
\hline $1.33333 \mathrm{floz}$ & Teriyaki Sauce-RTS & 1839.84 & 0.05 & 0 & 0 & 0 & 0 \\
\hline 0.66667 piece & Yellow Cake w/Chocolate Icing & 143.79 & 0.26 & 0.05 & 0.86 & 0 & 3.65 \\
\hline $14.6667 \mathrm{fl} \mathrm{oz}$ & Water & 13.04 & 0.13 & 0 & 0 & 0 & 0 \\
\hline $10 z-w t$ & Long Grain \& Wild Rice Blend-Dry UBI & 378.00 & - & - & -- & 0 & 0 \\
\hline $3.33333 \mathrm{fl} \mathrm{oz}$ & Orange Juice-Chilled (incl.f/Conc)-Cup & 1.04 & 0.04 & 0.01 & 0.05 & 0 & 0 \\
\hline 0.66667 cup & Brewed Coffee & 3.16 & 0.03 & 0 & 0.00 & 0 & 91.64 \\
\hline $1 \mathrm{tbs}$ & Camation Coffee Mate Non-Dairy Creamer & 0 & - & 0 & 0 & 0 & 0 \\
\hline 0.33333 each & Banana-Medium-Each & 0.39 & 0.06 & 0.01 & 0.02 & 0 & 0 \\
\hline 1 tbs & LoCal Caesar Salad Dressing & 161.70 & 0.02 & - & - & 0 & 0 \\
\hline 0.66667 cup & Romaine (Cos) Lettuce-Chopped-Cup & 2.99 & 0.09 & 0.03 & 0.01 & 0 & 0 \\
\hline 0.08333 cup & Seasoned Croutons & 41.27 & 0.03 & 0.00 & 0.07 & 0 & 0 \\
\hline 0.5 cup & Scalloped Potatoes-Homemade w/Margarine & 410.38 & 0.49 & 0.07 & 0.84 & 0 & 0 \\
\hline 0.33333 cup & Brocooli Pieces-Steamed & 14.04 & 0.21 & 0.07 & 0.02 & 0 & 0 \\
\hline 0.33333 cup & Ben\&Jerrys Ice CreamChocChipCookieDough & 63.33 & - & - & -- & 0 & - \\
\hline $20 \mathrm{fl} \mathrm{oz}$ & Water & 17.77 & 0.18 & 0 & 0 & 0 & 0 \\
\hline 0.33333 cup & Hot Natural Whole/Rolled Wheat-Ckd & 0 & 0.38 & 0.01 & 0.15 & 0 & 0 \\
\hline 0.08333 cup & Cheddar Cheese-Shredded & 58.43 & 0.29 & 0.03 & 0.05 & 0 & 0 \\
\hline 0.66667 cup & Brewed Coffee & 3.16 & 0.03 & 0 & 0.00 & 0 & 91.64 \\
\hline 1 tbs & Carnation Coffee Mate Non-Dairy Creamer & 0 & - & 0 & 0 & 0 & 0 \\
\hline 0.33333 cup & Whole Wheat Spaghetti Noodles-Ckd & 1.40 & 0.38 & 0.00 & 0.09 & 0 & 0 \\
\hline 0.33333 cup & Spaghetti Noodles-Enr-Ckd & 0.47 & 0.25 & 0.01 & 0.12 & 0 & 0 \\
\hline 0.33333 tbs & Hard Margarine-Soybean(Hydro\&Reg) & 44.34 & - & 0.09 & 1.14 & 0 & 0 \\
\hline 0.25 cup & Mozzarella Cheese-WhlMilk-LoMoist-Shred & 117.24 & 0.69 & 0.06 & 0.16 & 0 & 0 \\
\hline 1 tbs & All Purpose Flour-Unbleached-Enr PLB & 0 & - & 0 & 0 & 0 & 0 \\
\hline 0.66667 cup & $2 \%$ Fat Milk-Vitamin A Added & 81.17 & 0.63 & 0.05 & 0.07 & 0 & 0 \\
\hline 0.33333 cup & Broccoli Flowerets-Raw-Cup & 6.39 & 0.09 & 0.03 & 0.01 & 0 & 0 \\
\hline
\end{tabular}

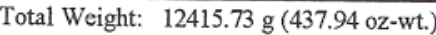

Serving Size: $4138.58 \mathrm{~g}$ (145.98 oz-wt.)

Serves: $\quad 3.00$

\begin{tabular}{|c|c|c|c|c|c|c|c|}
\hline Amount & Food Item & $\begin{array}{c}\text { Sod } \\
(\mathrm{mg})\end{array}$ & $\begin{array}{l}\text { Zinc } \\
(\mathrm{mg})\end{array}$ & $\begin{array}{l}\text { Omeg3 } \\
\text { (g) }\end{array}$ & $\begin{array}{c}\text { Omeg6 } \\
\text { (g) }\end{array}$ & $\begin{array}{c}\text { Alco } \\
\text { (g) }\end{array}$ & $\begin{array}{c}\text { Caff } \\
(\mathrm{mg})\end{array}$ \\
\hline $\begin{array}{l}0.5 \text { cup } \\
.66667 \text { piece }\end{array}$ & HDShops Choc Peanut Butter Ice Cream PLB & 100.00 & - & - & - & 0 & . \\
\hline \multirow[t]{2}{*}{$25 \mathrm{fl} \mathrm{oz}$} & $\begin{array}{l}\text { Bernardi's Supreme Vegetable Lasagna WIN } \\
\text { Water }\end{array}$ & $\begin{array}{r}483.08 \\
22.22\end{array}$ & $\overrightarrow{0}$ & $\overline{0}$ & $\overline{0}$ & 0 & 0 \\
\hline & Totals & & & & & & \\
\hline
\end{tabular}




\section{JAMIE SUTTON DEEM}

JamieSDeem@hotmail.com

\section{EDUCATION:}

West Virginia University- Morgantown, WV

Davis College of Agriculture, Forestry and Consumer Science

Master of Science Degree in Human Nutrition to be awarded, August 2003

West Virginia University- Morgantown, WV

Davis College of Agriculture, Forestry and Consumer Science

Bachelor of Science Degree in Human Nutrition and Foods, May 2001

\section{CLINICAL EDUCATION EXPERIENCE:}

Louis A. Johnson VA Medical Center- Clarksburg, WV

Dietetic Intern

Foodservice Rotation (May 2002-July 2002)

- Participated in foodservice management decisions, menu writing, kitchen renovations and administered veteran menu satisfaction surveys.

Clinical Rotation (July 2002-September 2002)

- Worked with inpatient veteran population in acute and critical care nutrition. Taught outpatient nutrition education courses in diabetic, cardiac and weight loss diet management.

West Virginia University- Morgantown, WV

Dietetic Intern

Community Nutrition Rotation (October 2002-March 2003)

- Gained clinical experience at regional WIC offices, dialysis unit, WVU Center for Excellence in Disabilities, congregate meal site and long-term care facility.

OTHER EXPERIENCE:

West Virginia University- Morgantown, WV

Teaching Assistant- Human Nutrition and Foods (Fall 2001-Spring 2003)

- Responsible for teaching foods laboratory courses, preparing experiments, writing student exams, and evaluating student grades. Also provided teaching relief to instructors for Introductory Nutrition courses.

Arkansas River Tours- Cotopaxi, CO Whitewater Rafting Guide (Summers 1999-2001)

- Assisted in preparation of $1 / 2$-day to multi-day river trips on the Arkansas River. Responsible for trip leading and safe navigation of class I-IV rivers with paddle and oar boats. 


\section{MEMBERSHIPS AND HONORS:}

- Awarded UMWA Scholarship (1996-1998)

- Awarded Student Leader Scholarship (1996-2000)

- President's List (Fall 1996, Fall \& Spring 2000, Spring 2001)

- Dean's List (Spring 1997, Spring 1999)

- Golden Key National Honors Society (1999-present)

- Student Dietetic Association (2000-2001)

- Phi Upsilon Omicron (2000-present)

\section{REFERENCES:}

Provided upon request. 